\title{
Inter-species horizontal toxicity: Experimental control of Argentine ants and their citrophilus mealybug mutualists in a viticultural system
}

by

\section{Catherine Hardiman}

\author{
A thesis submitted to \\ Victoria University of Wellington \\ in fulfilment of the requirements for the degree of \\ Master of Science in Ecology and Biodiversity
}

September 2018

School of Biological Sciences

Victoria University of Wellington 
This thesis was conducted under the supervision of

\section{Dr. Fabian Ludwig Westermann [primary supervisor]}

Victoria University of Wellington

Wellington, New Zealand

and

Professor Phil J. Lester [secondary supervisor]

Victoria University of Wellington

Wellington, New Zealand 



\section{ABSTRACT}

The invasive Argentine ant, Linepithema humile, is known to form a trophobiotic association with honeydew excreting homopterans Pseudococcus sp. providing protection from natural enemies in exchange for the honeydew they excrete. The vine mealybug Pseudococcus calceolariae, can transmit Grapevine leafrollassociated virus 3 (GLRaV-3) between vines as it travels and feeds with the ensuing leafroll disease negatively impacting on vine health and wine quality. Therefore, if an effective chemical control method targeting incursions of Argentine ants in vineyards contributes to the dissociation of this invasive ant species with its citrophilus mealybug mutualist, then in theory the spread of GLRaV-3 in vineyards by its mealybug vector can be stemmed. Three insecticidal treatments targeting Argentine ants in the canopy of potted Pinot Noir grapevines inoculated with citrophilus mealybugs were trialled at a field site established in Nelson during the summer of 2016/2017. Bifenthrin (1200ppm) was sprayed on vine trunks and the low- toxicity baits, thiamethoxam $(0.0006 \%)$ or boric acid $(0.5 \%)$ carried in polyacrylamide gel with $25 \%$ sucrose and $0.15 \%$ citric acid solution, were placed at the base of vines. A significant decline in ant activity $(p<0.001)$ and citrophilus mealybugs was observed for the bifenthrin treatment. A follow-on bioassay was conducted at Mt. Albert Plant and Food Research, in the absence of P. calceolariae's natural enemies to test the hypothesis that the decline in citrophilus mealybugs in response to vines treated with bifenthrin, could in fact be due to inter-species horizontal toxicity because of Argentine ants transferring the toxicant bifenthrin to citrophilus mealybugs while tending them or contaminating the substrate that they fed on. The significant decrease in average citrophilus mealybug activity rate $(p<0.001)$ for bifenthrin treatments compared with the controls provides evidence for inter-species horizontal toxicity. Bifenthrin sprayed on grapevine trunks may be suitable to control Argentine ants in the vine canopy and indirectly control P. calceolariae, a known vector of GLRaV-3 between grapevine hosts. The concept of inter-species horizontal toxicity could become a model for targeted pest management by exploiting different insect mutualisms in various horticultural cropping systems.

Keywords: Argentine ant, citrophilus mealybug, trophobiotic association, GLRaV-3, bifenthrin, inter-species horizontal toxicity, boric acid, thiamethoxam, polyacrylamide gel, 


\section{ACKNOWLEDGEMENTS}

I would like to acknowledge the following people with much gratitude and appreciation for their various contributions to the Nelson and Mt. Albert research projects, without whom neither projects would have been possible:

Fabian Westermann, for being a fabulous supervisor and going beyond the call of duty such as your mercy dash down here to Nelson to help me identify an alternative research site when it became apparent the original site could not be used; for always making yourself available whenever I was in Wellington and showing me stuff that I needed to know; for coming down to Nelson on another occasion to show me the ropes with regards to how to go about digging up ant nests and getting them into nest boxes and always providing such clear direction.

Phil Lester, for touching base with me whenever I was visiting with Fabian at VUW and for your very salient comments at times.

Vaughn Bell, for backing me in the first instance; for all the supportive phone calls, texts and emails; taking time out to meet with me in Blenheim and in Hawke's Bay and for arranging Plant and Food Research funding on my behalf.

Plant and Food Research, for providing me with a stipend to help keep body and soul together during this thesis journey and granting me access to the Riwaka and Mt. Albert Plant and Food Research campuses.

Jon and Vivienne Parkes, for agreeing to let me share Red and Blue's grazing area and set up my research site on your property, as well as allowing to use such things in your shed as waratahs and shade cloth.

Alex Johnson, for your truly amazing generosity with your time and resources to help establish the Nelson field site, together with your cheery encouragement to spur me on and Lynne Johnston for being so supportive of Alex helping with "the ant project". Mark Shepherd, of Treehab Arborists for weed-eating the plot areas at the Nelson site so Alex could spray them and then helping Alex with banging in wooden stakes in the plot areas and waratahs for the fencing around the plot enclosures.

My thanks to my nearby Nelson research site neighbours, Tania McBride as well as Rangi and Rachel Rogers, for allowing me to dig up Argentine ant nests on your properties and for the companionable chats over the fence when I was on site. 
Andrew Ford, for saving the day and providing some electric fencing to deter my fourfooted flatmates Red and Blue from visiting too closely after Red breached the farm fencing around the trial plots and was found languishing in one of the plots during the establishment phase....

Roger Wallis of Riwaka Plant and Food Research, for taking me under your wing and helping me to raise my own colony of citrophilus mealybugs. Thankyou Roger and Peter Shaw for allowing me to use the bi-ocular microscope in your lab for ant identification work and Dave Anderson from the chemistry lab for letting me have the run of your lab to make up treatment solutions.

Peter Visser of Key Industries, for supplying the Biff $\mathrm{Ant}^{\mathrm{TM}}$ product for the bifenthrin treatment and the spray gear to apply it.

Paul Hassan of Syngenta New Zealand, for arranging to supply me with Actara ${ }^{\circledR}$, the thiamethoxam treatment.

The Mt. Albert Plant and Food Research crew: Mano Sandanayaka, Gonzalo Avila, Vicky Davis and Frances MacDonald, for accommodating me in my own "ante chamber" at a time when you were in a state of flux yourselves with your lab relocation happening and for providing me with additional gear when required.

Brian Shields, biosecurity advisor with Auckland Regional Council, for guiding me to a great spot for digging up Argentine ant nests.

Auntie Joan (Hardiman), for looking after me so well during my stay in Auckland.

My children, Jeremy, Aaron, Jonathan, Anita, Natalie, Kevin and Melanie Hardiman who variously helped over the Christmas period at the Nelson site during the establishment phase and for generally being such good company while on site.

And finally, my dear husband Chris Hardiman, who has been with me every step of the way, rendering practical assistance at the site when required, putting up with many a late dinner and having to forego having a tramping buddy this last summer because she was too bound to the site ensuring the containment of the Argentinean population. 


\section{Table of Contents}

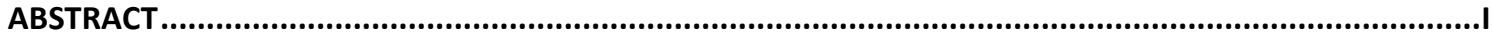

ACKNOWLEDGEMENTS................................................................................................................

TABLE OF CONTENTS ............................................................................................................... IV

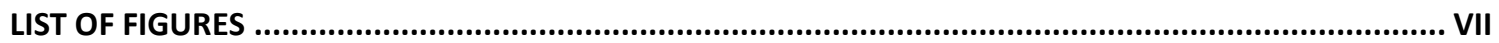

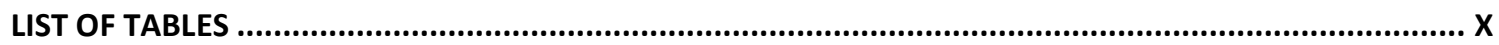

CHAPTER 1: GENERAL INTRODUCTION ..................................................................................................1

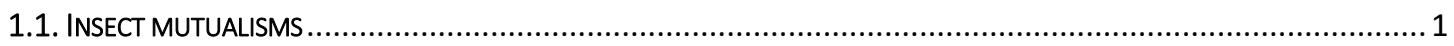

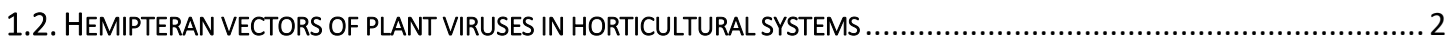

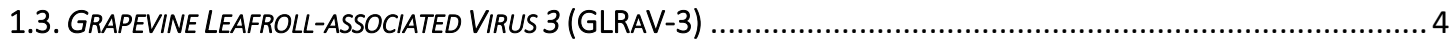

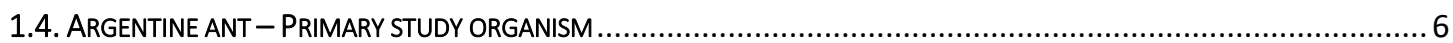

1.5. MEALYBUgS (PSEUDOCOCCUS CALCEOLARIAE) - SECONDARY STUdY ORGANISM ...........................................

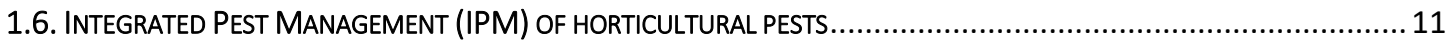

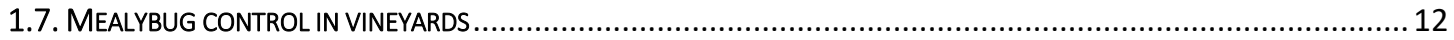

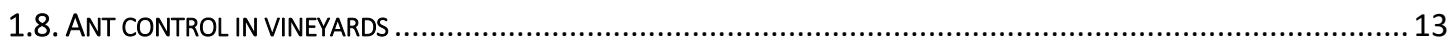

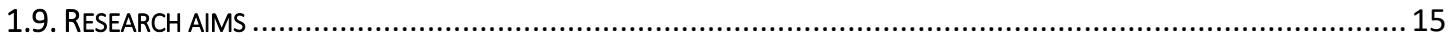

CHAPTER 2: EFFICACY OF ANT TOXIN TREATMENTS TARGETING LINEPITHEMA HUMILE: IS THERE A COEFFECT WITH VINE INOCULATED MEALYBUG PSEUDOCOCCUS CALCEOLARIAE? .........................................17

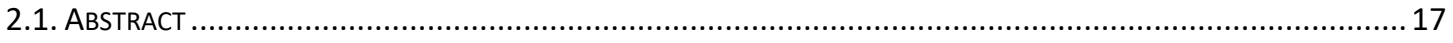

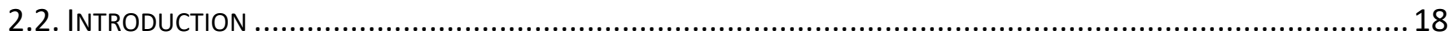

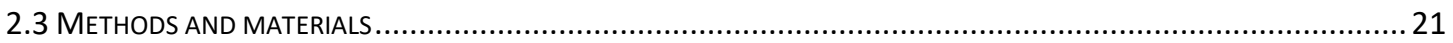

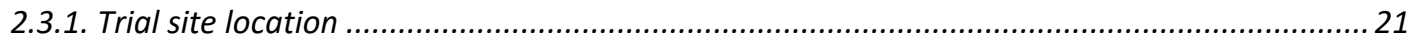

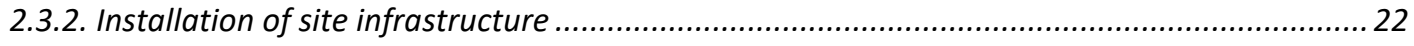

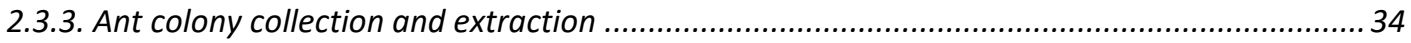

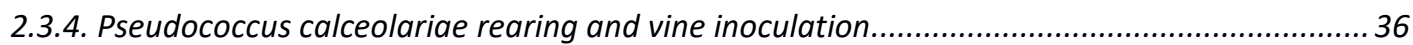

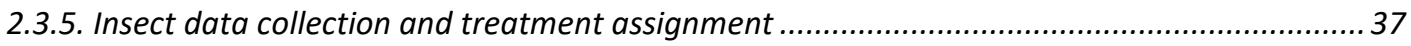




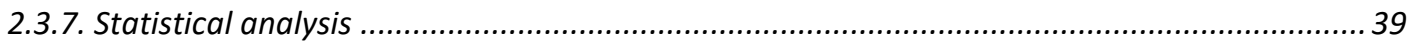

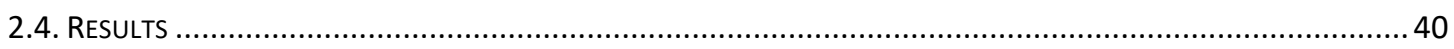

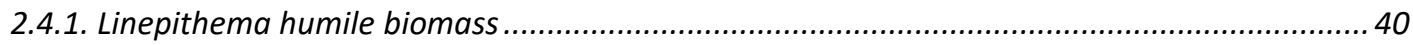

2.4.2. Linepithema humile response to ant toxin vine treatments ........................................... 41

2.4.3. Pseudococcus calceolariae reponse to ant toxin vine treatments ...................................... 44

2.4.4. L. humile and P. calceolariae response to vine treatments ............................................. 46

2.4.5. Effect on ant counts when irrigation days coincided with data collection days .................... 46

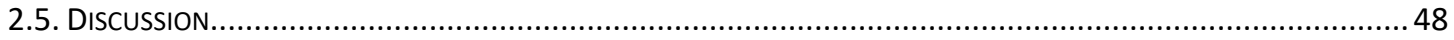

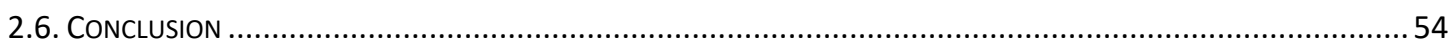

CHAPTER 3: TOXIC EFFECT OF BIFENTHRIN ON NON-TARGET PSEUDOCOCCUS CALCEOLARIAE: IS

BIFENTHRIN TRANSFERRED HORIZONTALLY FROM LINEPITHEMA HUMILE TO NON-TARGET SPECIES $P$.

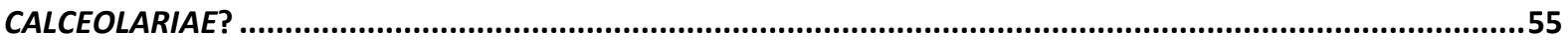

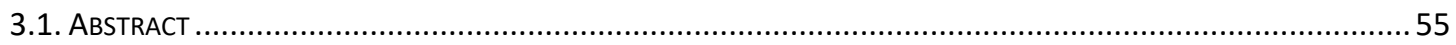

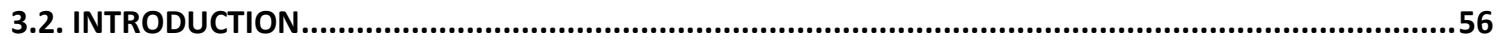

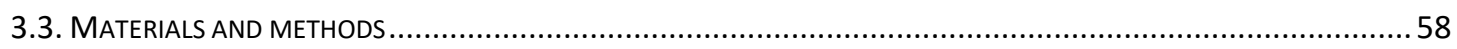

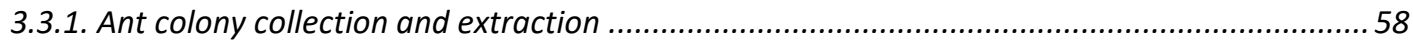

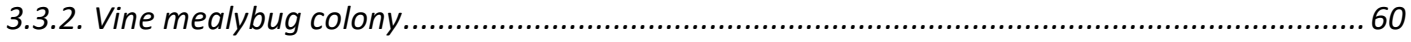

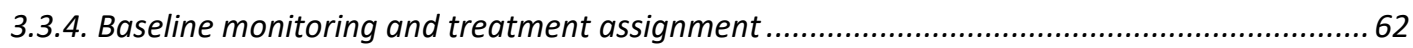

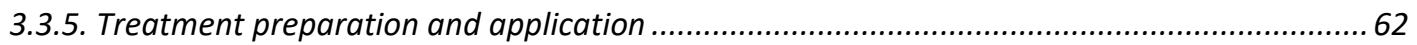

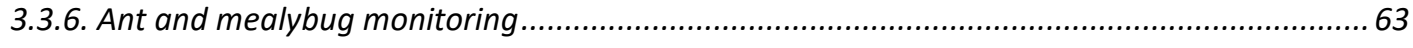

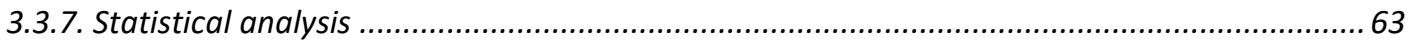

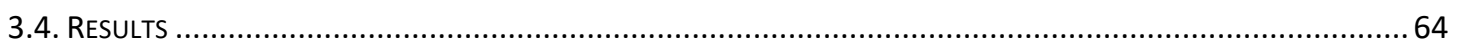

3.4.1. Effect of bifenthrin treatments on P. calceolariae ........................................................ 64

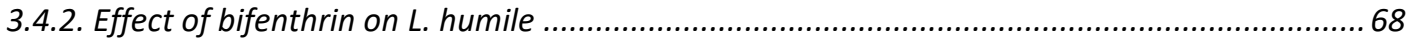

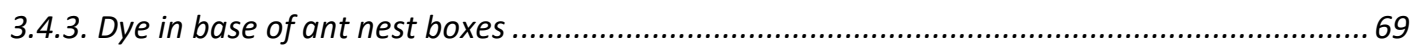

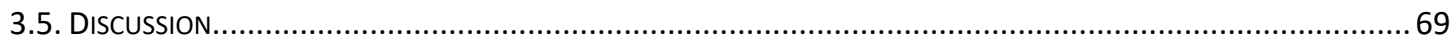

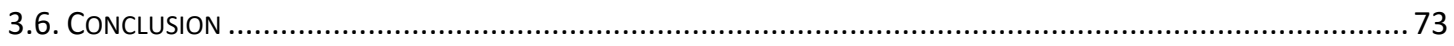




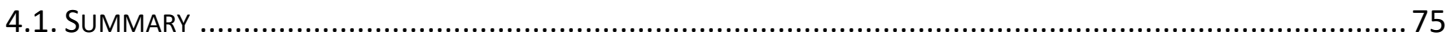

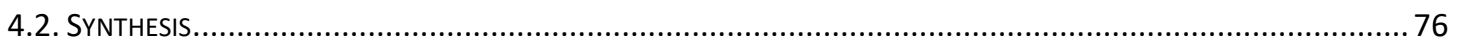

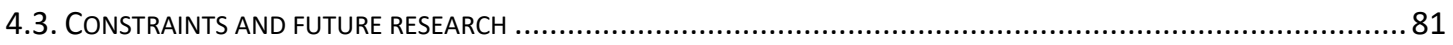

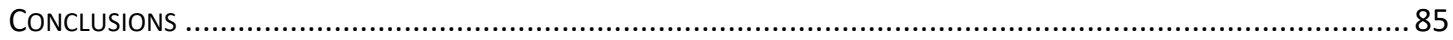

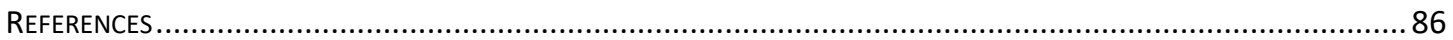

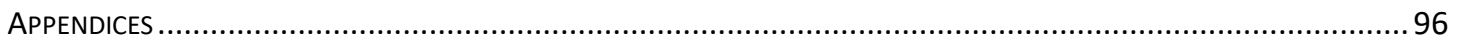




\section{List of Figures}

Figure 2.1: Dimensions (NOt to SCAle) AND SPATIAL ARRANGEMENT OF PLOTS AT NELSON ANT TOXIN TRIAL SITE ....................23

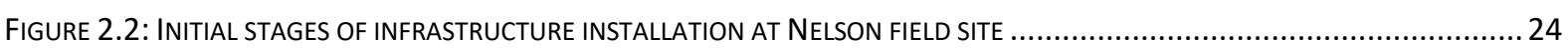

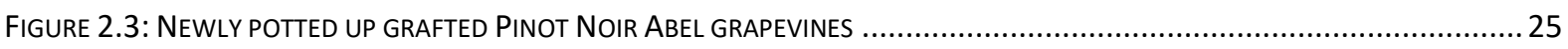

Figure 2.4: IRRIGATION INSTALLATION AT NelSON Site. A) IRRIGATION CONNECTIONS IN PLOT AND ON MAIN LINE .....................26

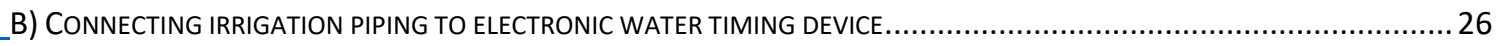

Figure 2.5: CONNECTING VINES to IRRIGATION SYSTEM AT NelSON FIELD SITE (A) CONNECTING IRRIGATION WhISKER BETWEen PLOT IRRIGATION LINE AND VINE CONTAINER (B) PLUGGING IRRIGATION WHISKER INTO POTTING MIX AT BASE OF VINE ................27

FIGURE 2.6: IRRIGATION CALIBRATION AT NELSON FIELD SITE A) WATER RESERVOIR IN CORNER OF PLOTS. B) INLINE VINE WATER

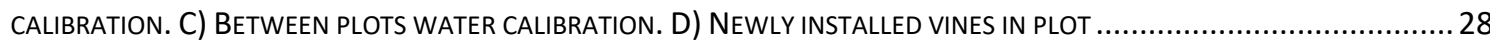

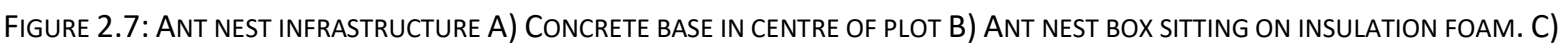

PVC TUBING SECURED TO NEST BOX WITH RUBBER ELASTRATOR RINGS D) REMOVABLE NEST BOX COVER ..........................30

E) INSULATIVE LAYER BETWEEN NEST BOX COVER AND CONCRETE PAVER. F) CONCRETE PAVER TO WEIGHT NEST BOX INFRASTRUCTURE TO GROUND.

FIGURE 2.8: ANT CONDUIT BETWEEN VINE AND NEST BOX

FIGURE 2.9: DIMENSIONS (NOT TO SCALE) AND SPATIAL ARRANGEMENT OF VINES ABOUT ANT NEST INFRASTRUCTURE IN PLOTS AT NELSON ANT TOXIN TRIAL SITE 32

FiguRE 2.10: VINE REINFORCEMENT AT NELSON FIELD SITE A) ROCKS AND BROKEN PAVERS IN BASE OF VINE 33

B) TWO LEVELS OF PLASTIC CLOTHESLINE CORD ATTACHED TO TOMATO STAKES IN PLOT CORNER 33

FIGURE 2.11: TANGLEFOOT ${ }^{\circledR}$ APPLICATION A) TOP OF TOMATO STAKE ABOVE CLOTHESLINE CORD AND PART WAY ALONG TOP OF GUY ROPES B) AROUND INSIDE RIM OF VINE CONTAINER, FIRST SECTION OF PVC TUBING ON OUTSIDE OF VINE CONTAINER AND WHERE IRRIGATION WHISKER CONNECTS TO VINE CONTAINER. 34

FIGURE 2.12: ARGENTINE ANT EXTRACTION PROCESS 35

Figure 2.13: ANT NEST INSTALLATION A) LEAF LITTER BRIDGES IN AN ANT NEST BOX B) NEWLY INSTALLED ANT NEST BOX IN THE CENTRE OF A PLOT

Figure 2.14: Citrophilus mealybug A) P. calceolariae rearing at Plant and Food Research Riwaka. B) Citrophilus MEALYBUG VINE INOCULATION.

FIGURE 2.15: TREATMENT APPLICATION A) BORIC ACID OR THIAMETHOXAM IN GEL MATRIX B) BIFENTHRIN SPRAY APPLICATION TO VINE TRUNKS. 39

FIGURE 2.16: MEAN PERCENTAGE OF BASELINE ACTIVITY ( \pm SEM) OF ARGENTINE ANTS (AA) ON VINE PARTS IN PLOTS TREATED WITH (A) BIFENTHRIN SPRAYED ON VINE TRUNKS (B) THIAMETHOXAM OR BORIC ACID IN GEL APPLIED AT THE BASE OF VINES. ONEMINUTE COUNTS OF ANTS IN VINE PARTS PER VINE IN EACH TREATMENT AND CONTROL PLOT FOR EACH MONITORING DAY WERE CONVERTED TO A PERCENTAGE OF BASELINE (TO) COUNTS. THERE WERE FIVE PRE-TREATMENT MONITORING DAYS BETWEEN 16TH - 25TH FEBRUARY 2017 WHERE N = 80 FOR EACH TREATMENT AND N = 40 FOR THE CONTROL OR CONTROL GEL PLOT. POST-TREATMENT ANT COUNTS WERE RECORDED ON TEN SEPARATE DAYS FROM FEBRUARY 27TH - 31ST MARCH 2017 WHERE N = 16 FOR EACH TREATMENT AND N = 8 FOR EACH CONTROL OR CONTROL GEL PLOT. ON 15TH MARCH (DAY 17), 
AFTER MONITORING FOR THAT DAY, A SECOND BORIC ACID AND THIAMETHOXAM TREATMENT WAS PLACED AT THE BASE OF EACH VINE

FigURE 2.17: MEAN PERCENTAGE OF BASELINE ACTIVITY ( \pm SEM) OF CITROPHILUS MEALYBUGS (CMB) ON VINE PARTS IN PLOTS TREATED WITH (A) BIFENTHRIN SPRAYED ON VINE TRUNKS (B) THIAMETHOXAM OR BORIC ACID IN GEL APPLIED AT THE BASE OF VINES. ONE-MINUTE COUNTS OF MEALYBUGS IN VINE PARTS PER VINE IN EACH TREATMENT AND CONTROL PLOT FOR EACH MONITORING DAY WERE CONVERTED TO A PERCENTAGE OF BASELINE (TO) COUNTS. THERE WERE FIVE PRE-TREATMENT MONITORING DAYS BETWEEN 16TH - 25TH FEBRUARY 2017 WHERE N = 80 FOR EACH TREATMENT AND N = 40 FOR THE CONTROL OR CONTROL GEL PLOT. POST-TREATMENT MEALYBUG COUNTS WERE RECORDED ON TEN SEPARATE DAYS FROM FEBRUARY 27TH - 31ST MARCH 2017 WHERE N = 16 FOR EACH TREATMENT AND N = 8 FOR EACH CONTROL OR CONTROL GEL PLOT. ON 15TH MARCH (DAY 17), AFTER MONITORING FOR THAT DAY, A SECOND BORIC ACID AND THIAMETHOXAM TREATMENT WAS PLACED AT THE BASE OF EACH VINE.

Figure 2.18: L. HUMILE AND P. CALCEOLARIAE RESPONSE TO VINE TREATMENTS (A) BIFENTHRIN (B) BoRIC ACID (C)

THIAMETHOXAM.

FIGURE 3.1: BIFENTHRIN MOLECULE

FIGURE 3.2: ANT EXTRACTION SET-UP 59

Figure 3.3: P. Calceolariae Rearing at Mt. Albert Plant and Food Research 60

FIGURE 3.4: EXPERIMENTAL SET-UP SHOWING ANT NEST BOX CONNECTED TO CONTAINER HOLDING POTATO SECTION SUPPORTING $P$.

CALCEOLARIAE 61

Figure 3.5: “NO ANTS” TREATMENT AND CONTROL CONTAINERS BEARING POTATO SECTION SUPPORTING P. CALCEOLARIAE. 61

FIGURE 3.6: COVERED CONTAINERS HOUSING CITROPHILUS MEALYBUGS 62

FIGURE 3.7: APPLICATION OF BLUE POWDERED DYE AND BIFENTHRIN TO BASE OF ANT NEST BOXES..... 63

FIGURE 3.8: MEAN PERCENTAGE OF BASELINE ACTIVITY ( \pm SEM) OF CITROPHILUS MEALYBUGS (CMB) ON POTATO SECTION SPRAYED DIRECTLY WITH (A) WATER AND (B) BIFENTHRIN. THERE WERE THREE PRE-TREATMENT MONITORING OCCASIONS ON 1ST MAY 2017 WHERE N = 6 FOR THE CONTROL AND N = 6 FOR THE TREATMENT. POST-TREATMENT MEALYBUG COUNTS WERE RECORDED ON NINE SEPARATE OCCASIONS ON 2ND, 3RD, 4TH, 5TH, 8TH AND 9TH MAY 2017 WHERE N = 18 FOR THE CONTROL AND N =18 FOR THE TREATMENT. ONE-MINUTE COUNTS OF LIVE MEALYBUGS ON THE POTATO SECTION OF THE "NO ANTS” CONTROLS AND “NO ANTS” TREATMENTS EACH MONITORING OCCASION WERE CONVERTED TO A PERCENTAGE OF BASELINE (TO) COUNTS. MISSING DATA POINTS BETWEEN DAY 4 AND DAY 6 CORRESPOND WITH THE WEEKEND.

Figure 3.9: MEAN PERCENTAGE OF BASELINE ACTIVITY ( \pm SEM) OF CITROPHILUS MEALYBUGS (CMB) ON POTATO SECTIONS WHERE (A) BIFENTHRIN WAS SPRAYED IN THE BASE OF THE ANT NEST BOXES (B) BIFENTHRIN WAS SPRAYED OVER THE TOP OF BLUE POWDERED DYE IN THE BASE OF THE ANT NEST BOXES. THERE WERE THREE PRE-TREATMENT MONITORING OCCASIONS ON 1ST MAY 2017 WHERE N = 6 FOR EACH THE CONTROLS AND N = 9 FOR EACH OF THE TREATMENTS. POST-TREATMENT MEALYBUG COUNTS WERE RECORDED ON NINE SEPARATE OCCASIONS ON 2ND, 3RD, 4TH, 5TH, 8TH AND 9TH MAY 2017 WHERE N = 18 FOR EACH OF THE CONTROLS AND N = 27 FOR EACH OF THE TREATMENTS. ONE-MINUTE COUNTS OF LIVE MEALYBUGS ON THE POTATO SECTIONS OF THE “WATER ONLY" AND “WATER/DYE” CONTROLS AND “BifENTHRIN ONLY" AND "BIFENTHRIN/DYE” TREATMENTS EACH MONITORING OCCASION WERE CONVERTED TO A PERCENTAGE OF BASELINE (TO) COUNTS. MISSING DATA POINTS BETWEEN DAY 4 AND DAY 6 CORRESPOND WITH THE WEEKEND. 
FigURE 3.10: MEAN PERCENTAGE OF BASELINE ACTIVITY ( \pm SEM) FoR CITROPHILUS MEALYBUgS (CMB) ON POTATO SECTIONS OF (A)

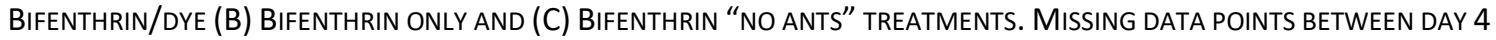

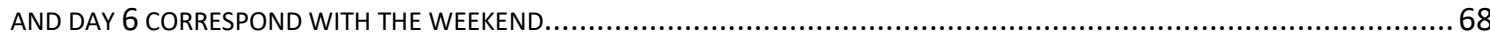




\section{List of Tables}

TABLE 2.1: SUMMARY OF GLMM STATISTICAL ANALYSIS FOR THE EFFECT ON L. HUMILE PERCENTAGE OF BASELINE ACTIVITY IN RESPONSE TO SPRAYING VINE TRUNKS WITH BIFENTHRIN COMPARED WITH APPLYING BORIC ACID OR THIAMETHOXAM IN GEL TO THE bASE OF POTted GRAPEVINES IN PLOTS AT THE NELSON FIELD SITE. THE PARAMETER EXP(B) IS THE EXPONENTIATED LOGRATE RATIO B AND COMPARES THE TREATMENT ANT ACTIVITY WITH THE CONTROL ANT ACTIVITY.

TABLE 2.2: SUMMARY OF GLMM STATISTICAL ANALYSIS FOR THE EFFECT ON P. CALCEOLARIAE PERCENTAGE OF BASELINE ACTIVITY IN RESPONSE TO SPRAYING VINE TRUNKS WITH BIFENTHRIN COMPARED WITH APPLYING BORIC ACID OR THIAMETHOXAM IN GEL TO THE BASE OF POTted GRAPEVINES IN PLOTS AT THE NelSON FIELD SITE. THE PARAMETER EXP(B) IS THE EXPONENTIATED LOGRATE RATIO B AND COMPARES THE TREATMENT MEALYBUG ACTIVITY WITH THE CONTROL MEALYBUG ACTIVITY

TABLE 3.1: SUMMARY OF GLMM STATISTICAL ANALYSIS FOR THE EFFECT ON P. CALCEOLARIAE PERCENTAGE OF BASELINE ACTIVITY IN RESPONSE TO DIRECTLY SPRAYING WATER OR BIFENTHRIN ON POTATO SECTIONS SUPPORTING CITROPHILUS MEALYBUGS (NO ANTS) AND SPRAYING WATER OR BIFENTHRIN IN THE BASE OF ANT NEST BOXES. THE PARAMETER EXP(B) IS THE EXPONENTIATED LOG-RATE RATIO B AND COMPARES THE TREATMENT MEALYBUG ACTIVITY WITH THE CONTROL MEALYBUG ACTIVITY .66

TABLE 3.2: SUMMARY OF GLMM STATISTICAL ANALYSIS FOR THE EFFECT ON L. HUMILE PERCENTAGE OF BASELINE ACTIVITY IN RESPONSE TO SPRAYING BIFENTHRIN OR WATER IN THE BASE OF THE ANT NEST BOXES. THE PARAMETER EXP(B) IS THE EXPONENTIATED LOG-RATE RATIO B AND COMPARES THE TREATMENT ANT ACTIVITY WITH THE CONTROL ANT ACTIVITY.

APPENDIX A: GoOgLE EARTH PRo IMAge SHOWING THE DISTRIBUtION OF LINEPITHEMA HUMILE AND OTHER ANT SPECIES THROUGHOUT THE HUNTER VINEYARD. 


\section{Chapter 1: General Introduction}

\subsection{Insect mutualisms}

Mutualism has been broadly defined by New (2017) as "an interaction between species in which the inclusive fitness of each party is increased by the action of its partner" (p. v) and by Price, Denno, Eubanks, Finke, \& Kaplan (2011) as "the association of two species, which is beneficial to both: a plus-plus relationship" (p. 224). A very close lifelong association of both species constitutes a symbiotic mutualism and when this association is vital for the survival and reproduction of the species then the mutualists are obligate (Price et al., 2011). An example of an obligate mutualist is the relationship between the intracellular microbe of the genus Buchnera found in aphids which according to Douglas (1998) provides aphids with necessary amino acids without which growth and fecundity is poor, while Buchnera are unable to be cultured outside of aphids. Mutualists may be facultative in that their association is beneficial but not essential for survival and reproduction (Price et al., 2011) as seen with many ant-Hemiptera interactions whereby phloemfeeding insects are tended and protected by visiting ants (New, 2017a).

Bronstein (2001) has outlined three categories of functional mutualisms being (1) transportation mutualisms whereby one partner is physically translocated (to safety) by its mutualist or the reproductive products (pollen or seeds) of one partner are dispersed by another and usually involves a food reward as with myrmecochorous seeds of Proteaceae dispersed by native ants (Bond \& Slingsby, 1984); (2) nutrition mutualisms in which an organism is provided with essential nutrients usually within a symbiotic relationship (as above); and (3) protection mutualisms involving plant protection by insects from insect herbivores or protection of other insects from their natural enemies. Classical food-for-protection mutualisms exist between ants (Hymenoptera: Formicidae) and honeydew-excreting insects of the hemipteran suborders Sternorrhyncha (including aphids, whiteflies, scale insects and mealybugs) and Auchenorrhyncha (specifically 
planthoppers and leafhoppers) (New, 2017a; Styrsky \& Eubanks, 2007). Ants are attracted to the honeydew produced by hemipterans and in exchange for this readily available food resource, they provide protection from predators and parasitoids, as well as removing any accumulation of honeydew from the host plant which would otherwise become a substrate for sooty mould growth leading to leaf death and abscission (Bach, 1991; Styrsky \& Eubanks, 2007; Way, 1963).

Honeydew, the sugary excretion produced by many hemipterans as a result of them feeding from the phloem of host plants, is a complex food composed of mono-, di- and trisaccharides, free amino acids, amides, proteins, minerals and B-vitamins (Styrsky \& Eubanks, 2007; Way, 1963). It has been shown that differences in the phloem chemistry of two host plant congeners produces different compositions of sugars, secondary metabolites and amino acids in honeydew produced by the aphid Aphis nerii, with implications for plant-ant-hemipteran interactions and plant performance in the field (Pringle, Novo, Ableson, Barbehenn, \& Vannette, 2014). The trisaccharides melezitose and raffinose and the disaccharide sucrose found in the honeydew of antattended aphids were preferred by Lasius niger Linnaeus worker ants and elicited trail-laying and recruitment of other workers by ant scouts (Detrain, Verheggen, Diez, Wathelet, \& Haubruge, 2010; Völkl, Woodring, Fischer, Lorenz, \& Hoffmann, 2010; Yao, 2014). Exploitation of hemipteran honeydew food resources by an incipient invasive ant species has ecological consequences for the species richness of several guilds of herbivores, predators and native ant species when invasive ants achieve numerical dominance through their aggression and omnivory (Fagundes, Dáttilo, Ribeiro, Rico-Gray, \& Del-Claro, 2016; Holway, 1999; Styrsky \& Eubanks, 2007). Way (1963) also points out that the honeydew-producing homopterans can be killed by the ants themselves as a source of solid protein or their carcasses collected by ants in the event of death by other causes.

\subsection{Hemipteran vectors of plant viruses in horticultural systems}


World-wide, insect-vectored plant viruses seriously affect yields of many economically important crops including wheat and potato (Bosque-Pérez \& Eigenbrode, 2011), cotton (Kaplan \& Eubanks, 2002), tomato (Moreno-Delafuente, Garzo, Moreno, \& Fereres, 2013) and grapes (Naidu, Rowhani, Fuchs, Golino, \& Martelli, 2014). More than 80\% of insect-transmitted viruses representing almost 400 virus species within 39 genera, are vectored by homopterans including aphids, whiteflies, leafhoppers and mealybugs (Fereres \& Moreno, 2009). For example, aphids vector both Barley yellow dwarf virus (BYDV) of the genus Luteovirus and Potato leafroll virus (PLRV) of the genus Polerovirus (Bosque-Pérez \& Eigenbrode, 2011; Ng \& Perry, 2004; Whitfield, Falk, \& Rotenberg, 2015). Tomato spotted wilt virus (TSWV) of the genus Tospovirus is vectored by thrips (Rotenberg, Jacobson, Schneweis, \& Whitfield, 2015; Whitfield et al., 2015). The genera Begomovirus and Crinivirus and their respective species Tomato yellow leaf curl virus (TYLCV) and Lettuce infectious yellow virus (LIYV) are each vectored by whiteflies (Martelli et al., 2002; Rubinstein \& Czosnek, 1997; Whitfield et al., 2015). Planthoppers vector Maize mosaic virus (MMV) of the genus Nucleorbabdovirus (Whitfield et al., 2015) and Rice dwarf virus (RDV) of the genus Phytorevirus is vectored by leafhoppers. The Ampelovirus species Grapevine leafroll-associated virus 3 (GLRaV-3) and Pineapple mealybug wilt-associated virus 2 (PMWaV-2) are each vectored by mealybugs (Jahn, Beardsley, \& González-Hernández, 2003; Maree et al., 2013; Martelli et al., 2012; Sether \& Hu, 2002).

Since plants are sessile, viruses hosted by plants must employ an efficient mechanism to move from one host plant to the next and so they utilise specific sap sucking insect vectors which transmit the virus as they feed on and travel between plants (Whitfield et al., 2015). However, these homopteran vectors must first be able to recognise host plants, which they do by pre-alighting behaviour, probing on superficial tissues, followed by settlement and stylet penetration to target feeding tissues, salivation, and continuous sap ingestion from preferred feeding tissue (Fereres \& Moreno, 2009; Mauck, Bosque-Pérez, Eigenbrode, De Moraes, \& Mescher, 2012). Compared with virus-free plants, virus-infected plants have been shown to be superior hosts for insect vectors in terms of their growth rates, fecundity and longevity (Bosque-Pérez \& Eigenbrode, 2011). 
Vector transmission plays a pivotal role in the infection cycle of most plant viruses (Whitfield et al., 2015). Transmission of viruses in plant fluids is either via a noncirculative or circulative route in the insect vector. The former involves the retention of viruses bound to specific protein receptors on the cuticular lining of the stylet or foregut which are released upon inoculation of plants during salivation. Circulative virus transmission entails their passage through the alimentary canal (where they may propagate) and across membrane barriers to the salivary gland where they are ejected with saliva (Blanc, Uzest, \& Drucker, 2011; Ng \& Perry, 2004; Uzest et al., 2007; Whitfield et al., 2015).

Ingwell, Eigenbrode, \& Bosque-Pérez (2012) have proposed the "Vector Manipulation Hypothesis" to account for strategies that plant pathogens employ to enhance their spread to new hosts via insect vectors. In host plants, Bosque-Pérez \& Eigenbrode (2011) have shown that virus infection modulates the concentration and relative composition of volatile organic compounds which elicit a response in aphid insect vectors whereby they prefer to settle on virus-infected plants. In addition to this, compared with non-viruliferous aphid vectors, viruliferous aphids are less responsive or unresponsive towards virus induced host plant volatiles. Plant pathogen spread is enhanced since non-viruliferous vectors prefer virus-infected plants leading to virus acquisition while viruliferous vectors prefer non-virus infected plants leading to transmission (Ingwell et al., 2012).

\subsection{Grapevine Leafroll-associated Virus 3 (GLRaV-3)}

GLRaV-3 belongs to one of the four genera of the recently revised family Closteroviridae (Martelli et al., 2012). The genus Ampelovirus (from ampelos, Greek for grapevine) was established to accommodate viruses transmitted semi-persistently by Coccidae (scale insects) or Psendococcidae (mealybug) to dicotyledonous hosts (like grapevines) (Martelli et al., 2002). One of the most important grapevine viral diseases affecting grapevines worldwide is grapevine leafroll disease 
(GLRD) and the Ampelovirus, GLRaV-3 is regarded as the most important disease causative agent (Maree et al., 2013).

GLRaV-3 is spread via infected grapevine propagation material and by insect vectors, notably mealybugs and soft scale insects which carry and transmit the virus between adjacent plants (Douglas \& Krüger, 2008). Although mealybugs are the main vector of GLRaV-3 in vineyards worldwide, the species are likely to differ in each country (Bonfiglioli \& Hoskins, 2006) and provided there is virus inoculum and mealybugs present, then GLRaV-3 spread from vine to vine is rapid (Cabaleiro et al., 2008). Charles et al. (2009) propose three means of virus spread in vineyards via mealybugs (i) natural crawling dispersal of infected mealybugs leading to within-row, vine-to-vine transmission (ii) aerial dispersal (wind) of infectious mealybugs resulting in between blocks or between vineyards scale (iii) human assisted via vineyard machinery leading to random but localised infection on a within- or between- block scale.

Upon colonisation of the grapevine, the virus becomes a permanent resident and the ensuing leafroll disease is incurable (Keller, 2010). Virus particles, according to Lough and Lucas (2006 cited in Keller, 2010), can spread symplastically in infected tissues and organs, facilitated by movement proteins that enable them to travel via plasmodesmata from cell to cell as well as via the phloem to other organs. According to Espinoza et al., (2007 cited in Keller, 2010) it is thought that in order to limit viral spread via the phloem, the vine responds by depositing calloses which block the phloem so that sugar export is restricted from the leaves and accumulation of sugar in the leaves induces a feedback inhibition of photosynthesis. In fact, (Charles et al., 2006a) report that GLRaV-3 can diminish photosynthesis by as much as $25-65 \%$, depending on cultivar and environment.

Visual symptoms of GLRaV-3 infected grapevines are more evident from veraision onwards, particularly on basal leaves of red varieties. Red spots parallel with leaf veins increase in size and eventually join so that the leaf is completely red apart from green coloration of the major veins. 
Leaf edges roll under (hence the name Grapevine Leafroll disease) and leaves assume a typical straight-edge shape as rolling becomes more pronounced. Worldwide studies support evidence that grapevines of both red and white varieties infected with GLRaV-3 have poor fruit set; reduced bunch and berry size; reduced yields; delayed maturity; lower fruit sugar levels; higher titratable acidity and lower $\mathrm{pH}$; reduced flavours and lower berry anthocyanin levels, when compared with healthy vines and generally they produce lower quality wine (Charles et al., 2006b, 2006a; Maree et al., 2013; Naidu et al., 2014).

Grapevine leafroll disease (GLRD) is a devasting viral disease and its economic impact is felt worldwide across many winegrowing regions. In Californian winegrowing counties alone, the cost per hectare for vineyards producing Cabernet Sauvignon affected by GLRD has been estimated to range from $\$$ US29,902-\$US226,405 over a 25 -year lifespan for a vineyard. This estimated range takes into account yield losses, price penalties and strategies to minimize virus spread such as replacement of virused vines or total vineyard replanting and applications of insecticides targeting mealybugs, the insect vector (Atallah, Gómez, Fuchs, \& Martinson, 2012; Ricketts et al., 2015). The economic impact of GLRaV-3 on the New Zealand wine industry is a sobering prospect also. A 2005 report by the consultancy form Nimmo-Bell \& Company, commissioned by New Zealand Winegrowers, revealed that the difference in income and expenditure between a Merlot vineyard in Hawke's Bay that became completely virused and one where infected vines and neighbouring vines were removed annually was $\$ 12,580$ per hectare. It was also estimated that total lost income plus the cost of total vine replacement when the vineyard reached $100 \%$ infection rate was $\$ 57,618$ per hectare (New Zealand Winegrowers, 2015; Nimmo-Bell \& Company Ltd, 2006).

\subsection{Argentine ant - Primary study organism}

Linepithema bumile (Mayr), 1868, is the correct taxonomic name for the Argentine ant (Wild, 2004). Formerly known as Iridomyrmex humilis (Mayr) (Markin, 1970), L. bumile is native to the lowland area of the Parana River drainage in Argentina (Wild, 2004). The invasive L. bumile has 
become established in many Mediterranean-type ecosystems worldwide and by comparing nuclear microsatellite allele frequencies, it has been shown that most of these introduced populations are genetically similar to the native populations of the southern Parana River, particularly the native population from Rosario, Argentina (Tsutsui, Suarez, Holway, \& Case, 2001). In Southern Europe, two introduced Argentine ant super colonies have been identified, namely the Catalonian and the largest ever recorded, main European super colony, spanning over $6,000 \mathrm{~km}$ from coastal Italy to the Spanish Atlantic coast (Blight, Renucci, Tirard, Orgeas, \& Provost, 2010; Giraud, Pedersen, \& Keller, 2002). In light of global climate change, not only is the potential geographical and ecological distribution of $L$. humile predicted to spread to tropical coastal Africa and southeast Asia, but ecological niche modelling projections from 2050 forecast that L. bumile will retreat in tropical regions but extend its range at higher altitudes as climates warm (Roura-Pascual et al., 2004).

According to Suarez et al. (2001), the spread of the invasive L. bumile is by two distinct modes, namely, budding reproduction and human-mediated jump-dispersal. Since nests tend to be connected within a $3-4 \mathrm{~m}$ radius, it is assumed that new nests bud from older ones (Heller, Ingram, \& Gordon, 2008), whereby a queen and a contingent of worker ants will simply walk a short distance from the mother nest to establish a new one (Hölldobler \& Wilson, 1977). A single Argentine ant colony can be described as a biological entity consisting of a group of nests interconnected by worker food sharing activity and passage, or a subset of the super colony characterised by lack of aggression (Heller et al., 2008). In a year, the maximum Argentine ant invasion front advances by about $150 \mathrm{~m}$ for colonies undergoing reproductive budding (Suarez et al., 2001). In riparian woodlands of northern California, Holway (1998b) found that for independent $L$. bumile populations, colonies spread an average of $16 \mathrm{~m}$ a year where there was constant stream flow, but where stream flow was intermittent, colonies retreated by an average of $6 \mathrm{~m}$ a year overall. 
The highly socially organised structure that unicoloniality accords, has facilitated invasions of L. bumile in its introduced range and the outcompeting of native species for resources (Chen \& Nonacs, 2000) when densities of $L$. bumile worker ants exceed native ants, enabling them to discover food resources and recruit to them more quickly (Holway, 1998a). For some time, it was thought that (Z)-9-hexadecenal was the main constituent of L. bumile trail pheromone used to recruit workers to food sources, but Choe, Villafuerte and Tsutsui (2012) have shown that the two iridoids, dolichodial and iridomyrmecin are the primary chemical components of L. humile pheromone trails and that (Z)-9-hexadecenal may instead act as an additive with the two iridoids. Instead of travelling to distant nests, foraging workers recruit other ants to new food sources from nearby trails by walking back and forth, sometimes sharing food with nestmates by trophyllaxis along the way (Flanagan, Pinter-Wollman, Moses, \& Gordon, 2013). Using labelled food, Heller et al. (2008) showed that L. humile workers shared food between nests linked by foraging trails up to $50 \mathrm{~m}$ in length.

The success of $L$. bumile's displacement of native ant species has been attributed to their rapid recruitment, shear numerical dominance and fighting aggression (Blight, Provost, Renucci, Tirard, \& Orgeas, 2010). In several studies L. humile had the ascendancy over the native ant species they displaced with regard to exploitative and interference competition (Blight et al., 2010; Holway, 1999; Human \& Gordon, 1999; Human \& Gordon, 1996). Not only was L. humile consistently more superior than native ant species at locating and recruiting to baited food sources (Holway, 1999; Human \& Gordon, 1996), but they initiated more fights (Blight et al., 2010), deployed chemical defensive compounds (Holway, 1999), interfered with native ant foraging activity and curtailed the establishment of new native ant colonies by preying on winged queens (Human \& Gordon, 1996).

Abiotic conditions are of importance in determining the rate of colony growth and activity for the invasive Argentine ant species (Holway, 1998b; Holway, Suarez, \& Case, 2002). Variation 
in temperature and soil moisture can influence the rate of $L$. bumile foraging activity and invasion spread (Holway et al., 2002; Krushelnycky, Joe, Medeiros, Daehler, \& Loope, 2005). Compared with six native ant species, L. bumile was least tolerant of temperatures higher than $34.0^{\circ} \mathrm{C}$ and completely abandoned foraging at baits when temperatures exceeded $41.6^{\circ} \mathrm{C}$ (Holway, Suarez, et al., 2002). Seasonal climatic changes dictated Argentine ant nest site selection so that in warmer months $L$. bumile nested at the base of trees but during cooler rainy months they relocated under rocks (Enríquez, Abril, Díaz, \& Gómez, 2013). Optimum abiotic conditions for L. bumile worker survival and activity appears to be high levels of soil moisture and warm temperatures as opposed to hot dry conditions (Holway, Suarez, et al., 2002; Krushelnycky et al., 2005).

The invasive Argentine ant is now established on six continents and many oceanic islands (Suarez, Holway, \& Case, 2001). L. humile has extended its range to the island nation of New Zealand where it was first recorded in 1990 at Mt. Smart in Auckland (Green, 1990). Since then Argentine ant colonies have become well established around Auckland and Northland, parts of the central North Island, East Coast and Wellington (Harris, 2002; Ward et al., 2010; Ward \& Toft, 2011) with potential for spread around all inland coastal areas of the North Island based on the mean July temperature in those regions ranging between $7^{\circ} \mathrm{C}$ and $14^{\circ} \mathrm{C}$ (Ward et al., 2010). The estimated median distances of human-mediated dispersal of Argentine ants in New Zealand is 9.97 - 71.99km (Ward, Harris, \& Stanley, 2005) given that L. bumile readily hitches rides between urban areas in vehicles, pot plant containers, rubbish and freight (Ward \& Toft, 2011). In 2000, Argentine ants arrived in Christchurch (Ward et al., 2010) and in 2001, they were discovered at Port Nelson in the South Island (Ward \& Toft, 2011). In 2006, Argentine ants were found widely distributed throughout the property bordering the rear section of the property where the previous summer's research site was established (Ward \& Toft, 2011).

\subsection{Mealybugs (Pseudococcus calceolariae) - Secondary study organism}


Mealybugs, with their piercing and sucking mouthparts, are classified in the order Hemiptera and family Pseudococcidae (McMaugh, 1985). The order Hemiptera includes most insect vectors of plant disease and within this order the family Pseudococcidae (mealybugs) and Coccidae (scale insects) represent the known vectors of leafroll disease (Nault, 1997). Twenty-six species of mealybugs from sixteen genera have been associated with grapes and many of them have also been found to be polyphagous pests, with the most important of these pest species globally being Planococcus ficus, Planococcus citri, Pseudococcus calceolariae, Pseudococcus longispinus and Pseudococcus viburni. All five of the above mentioned mealybug species are known vectors of Grapevine Leafroll-associated Virus 3 (GLRaV-3) (Charles et al., 2006) and the three species which feed on the leaves, shoots, fruit and sometimes the roots of grapevines in New Zealand, are the long-tailed mealybug $P$. longispinus, the citrophilus mealybug P. calceolariae, and the obscure mealybug P. viburni (Charles et al., 2006b).

Mealybugs feed via sucking mouth parts to extract phloem sap from phloem tissue and using their thread-like proboscis, which is often longer than their body, mealybugs can skilfully guide their proboscis between plant cells towards the phloem, where once in place they remain feeding for some time before moving onto another feeding site (Charles et al., 2006a). Phloem sap is rich in carbohydrate but lacks high nitrogen levels, so to acquire sufficient nitrogen, the mealybugs must imbibe copious quantities of it (Clearwater, 2003). Since mealybugs have a continuous gut, they eliminate vast quantities of honeydew from their anus. Honeydew is an important food source for ants foraging on grapevines, so they actively "farm" mealybugs, corralling them to protect them from attack by their natural enemies and in so doing, ensure an ongoing food source for themselves (Charles et al., 2006a).

In New Zealand, common natural enemies of vineyard mealybugs are the wasp parasites Coccophagus gurneyi, Tetracnemoidea sydneyensis, and Ophelosia charlesi; the ladybirds Cryptolaemus montrourieri and Midas pygmaeus; the dusky lacewing Cryptoscenea australiensis and the predatory fly 
Diadiplosis koebelei (Furness \& Charles, 1994). From 1993 to 2009, surveys of mealybug natural enemies conducted in North Island vineyards and the top of the South Island found that in addition to those mentioned above, the parasitic wasps Anagyrus fusciventris, Gyranusoidea advena, $T$. brevicornis and T. peregrina could be found. Not surprisingly the host-specific T. sydneyensis and T. peregrine was found in association with $P$. longispinis while the essentially host-specific T. brevicornis was found in vineyards with P. calceolariae (Charles, Bell, Lo, Cole, \& Chhagan, 2010). By their association with mealybugs, ants cause disruption to biological control of mealybugs in vineyards, preventing parasitic wasps from effectively parasitizing their mealybug hosts (Addison, Mgocheki, Nyamukondiwa, \& Wohlfarter, 2011). This has been seen to occur for example, in the vine canopy, with the predominant Hawke's Bay ant, Ochetellus glaber, which actively seeks and kills the parasitoid wasp A. fusciventris (Reid, 2010).

\subsection{Integrated Pest Management (IPM) of horticultural pests}

Integrated pest management (IPM) has been defined as "a decision-based process involving coordinated use of multiple tactics for optimizing the control of all classes of pests (insects, pathogens, weeds, vertebrates) in an economically sound manner" (Ehler, 2006, p. 787). Sitespecific management decisions around the control of pest species is informed by establishing economic action thresholds for intervention and real-time monitoring of pest abundance, as well as their natural enemies and antagonists (Castle \& Naranjo, 2009; Ehler, 2006; Sandler, 2010). In fact the term "integrated" infers that these natural enemy/antagonist levels are taken into account as part of the decision-making process to ensure that compatible, non-disruptive tactics are employed to preserve these biologicals (Ehler, 2006).

The inception of the IPM movement was born out of concern that the indiscriminate use of synthetic organic insecticides developed after World War 2 to combat agricultural pests was having negative repercussions as evidenced by the evolution of resistance by the target pest insects, mites and ticks, pest resurgence, secondary pest outbreaks and contamination of the environment 
(Bottrell \& Smith, 1982; Castle \& Naranjo, 2009; Chandler et al., 2011; Ehler, 2006). In an IPM system, cultural, biological and chemical control methods are employed to manage pest and disease pressure (Sandler, 2010). The underlying philosophy of IPM is to combine cultural, biological and chemical control methods to mitigate the shortcomings of each of them in isolation while not totally eradicating target pests but rather managing them below levels that would cause economic harm (Chandler et al., 2011). Some IPM tactics include (1) cultural practises such as crop rotation, canopy management, intercropping and under-sowing (to attract beneficials), as well as genetically modified crop cultivars bred to resist pests; (2) biological control with natural enemies, including predatory insects and mites, parasitoids, parasites, microbial pathogens and microbial antagonists of plant pathogens; (3) chemical controls such as synthetic pesticides with high selectivity, semiochemicals and biocidal plant extracts (Bottrell \& Smith, 1982; Chandler et al., 2011).

\subsection{Mealybug control in vineyards}

Beneficial insects play a part in IPM and the ecology of the vineyard (Charles et al., 2010), but when mealybug populations exceed the $2 \%$ infestation level, biological control mediated by the augmentative release of commercially available natural enemies alone cannot control mealybug populations and insecticidal control must be employed (Charles et al., 2006a). Since the waxy secretion covering adult mealybugs resists wetting by insecticidal sprays, newly hatched crawlers should be targeted in the new growing season as they migrate onto young shoots and settle on the underside of leaves (Furness \& Charles, 1994). Thorough coverage of vine trunks, cordons and breaking buds with the broad spectrum organophosphate prothiofos (Tokuthion ${ }^{\circledR}$ ) and buprofezin (Applaud ${ }^{\mathrm{TM}}$ ), both contact insecticides, is required to render pest toxicity (Lo, Bell, \& Walker, 2009; Lo \& Walker, 2011).

In more recent years, winegrowers in New Zealand have had at their disposal, the systemic foliar spray Movento ${ }^{\circledR}$ 100SC which has been registered for use on grapevines between budburst and flowering and is in the ketoenol class of chemicals (Bayer Crop Science, 2013). Foliar 
applications of Movento ${ }^{\circledR}$ (active ingredient spirotetramat) has translaminar activity so that spirotetramat-enol is translocated via the vine's vascular system to growing shoots and roots, where sucking insect pests at juvenile stages are affected by inhibition of their lipid biosynthesis and fecundity in female adults is affected also. Movento ${ }^{\circledR}$ can be used with IPM as there are low adverse effects on beneficial insects (Bruck et al., 2009) and insect pollinators (bees) (Mansour et al., 2018). The neonicotinoid imidacloprid (Confidor ${ }^{\circledR}$ or Nuprid $\left.{ }^{\circledR}\right)$, which has systemic activity, can be used as a soil drench targeting mealybug on the roots of rogued vines destined for removal (Lo et al., 2009; Lo \& Walker, 2011; New Zealand Winegrowers, 2011).

\subsection{Ant control in vineyards}

According to Charles et al., (2006) early season monitoring of ants should continue until they are seen moving into the vine canopy and when $25 \%$ of vines are infested, insecticidal control is warranted. However, in South African vineyards, this action threshold has been revised down to $20 \%$, a level at which $95 \%$ of the time growers would not be under reacting to ant infestations of their vines, necessitating chemical control (Addison \& Mgocheki, 2010; Mgocheki \& Addison, 2009).

In South African vineyards, various stem barrier treatments have been trialled including the organophosphates chlorpyrifos and terbufos, either as an impregnated band or a slow release band of granulated chemical respectively and each fastened around the vine stem just above the irrigation conduit. The pyrethroid $\alpha$ - cypermethrin sprayed on vine trunks as a $10 \mathrm{~cm}$ wide band just above the irrigation conduit using a knapsack spray unit with a ring sprayer attachment was found to be effective against $L$. humile and subsequently $\alpha$-cypermethrin SC has been registered as a chemical stem barrier on vines at a concentration of $10 \mathrm{~mL} \mathrm{~L}^{-1}$. However, even though the organophosphate band treatments were found to be the most effective at controlling all ant species (including $L$. humile) in the trial, at a vine density of \pm 2000 vines $\mathrm{Ha}^{-1}$, this method would not be economically sustainable in a commercial vineyard (Addison, 2002). 
In South African and Californian coastal vineyards, low-toxicity liquid baits variously containing either boric acid, fipronil, fenoxycarb, spinosad, thiamethoxam or imidacloprid, have been trialled for the control of ants (Boser et al., 2014; Daane et al., 2006; Nelson \& Daane, 2007; Nyamukondiwa \& Addison, 2011). To be economically comparable with insecticidal spray-based ant control, Nelson \& Daane (2007), recommend a bait station density of less than 85 baits $\mathrm{Ha}^{-1}$ targeting Argentine ants in Californian coastal vineyards, but, in South African vineyards, Nyamukondiwa \& Addison (2014) found that at a density of 81 baits $\mathrm{Ha}^{-1}$ (equivalent to placing baits $54 \mathrm{~m}$ apart along each vine row), $\pm 80 \%$ of the Argentine ant population would be reached.

The trial of a novel IPM compatible method deploying dispensers of the Argentine ant trail pheromone (Z)-9-hexadecenal at the base of vines in a Hawke's Bay commercial vineyard has been trialled and was effective at suppressing ant foraging activity in the vine canopy as a consequence of disruption of worker trail following, but, as an ant management practice on a vineyard scale, this would be economically unviable when compared to the cost of insecticidal control of vine mealybug infestations (Westermann, Bell, Suckling, \& Lester, 2016; Westermann, Bell, Suckling, \& Lester, 2016).

For ant control in New Zealand vineyards, baiting with low-toxicity $0.5 \%$ boric acid in $25 \%$ sucrose solution deployed in $50 \mathrm{~mL}$ containers and replenished monthly until harvest is recommended (Reid, 2010). However, there are no chemical insecticidal sprays targeting ants featured in the New Zealand Winegrowers Export Wine Grape Spray Schedule (Fantail Viticulture Consultants, 2012).

Honeydew-producing homopterans Pseudococcus sp. being tended by Argentine ants have increased their populations in Californian coastal vineyards (Daane, Sime, Fallon, \& Cooper, 2007). Such mutualisms also increase the risk of the spread of GLRaV-3 infection when viruliferous mealybug are involved (Douglas \& Krüger, 2008). Therefore if L. bumile can be eradicated in 
vineyards, then it follows that growth in mealybug populations can be stemmed and GLRaV-3 infection rates diminish.

\subsection{Research aims}

In recent years, incursions of the invasive Argentine ant, Linepithema bumile, have been reported in commercial vineyards in Gisborne and the Gimblett Gravels winegrowing appellation of Hawke's Bay and now in Nelson (Charles, Bell, Lo, Cole, \& Chhagan, 2010; Westermann, Bell, Suckling, \& Lester, 2016; Westermann, Bell, Suckling, \& Lester, 2016). Since there are no registered chemical spray controls against Argentine ants for commercial winegrowers to avail themselves of, the idea behind this study was to identify a chemical control method that targeted Argentine ants in a viticultural system and that would contribute to the disassociation of this invasive ant species with its citrophilus mealybug mutualist. In theory, such a dissociation could stem the spread of GLRaV-3 in vineyards by its mealybug vector. To this end, at the Nelson field site, bifenthrin was sprayed on vine trunks and two low-toxicity baits, thiamethoxam and boric acid each carried separately in a polyacrylamide gel matrix were applied to the base of potted grapevines which had each been inoculated with citrophilus mealybugs. A BACI experimental design (Smith, 2002) was used to assess the performance of each of the treatments trialled so that Argentine ant and citrophilus mealybug activity was monitored for a period prior to and after the administration of the treatments. Each of the insecticidal treatments trialled represented relatively low chemical inputs consistent with the tenets of IPM. The polyacrylamide gel medium used for two of the treatments is a novel format previously reported to carry thiamethoxam targeting incursions of Argentine ants in a conservation area and in a commercial plum orchard (Boser et al., 2014; Buczkowski, Roper, Chin, Mothapo, \& Wossler, 2014). Two of the ant toxin treatments trialled, thiamethoxam and bifenthrin, could be suitable for use in conventionally managed vineyards, while the other, boric acid, can be used in organic or biodynamically certified vineyards. 
In Chapter 2, I assess the efficacy of each of the three treatments for controlling Argentine ants in plots of potted vines at the research field site established in Nelson during the previous summer (December 2016 - March 2017). The effect of each ant toxin treatment on citrophilus mealybug inoculated onto each vine is studied. The performance in the field of the polyacrylamide gel matrix carrying two of the treatments is also assessed.

Chapter 3 reports on a laboratory-based study conducted at the Mt. Albert Plant and Food Research campus in Auckland over April and May 2017 in response to recording plummeting mealybug numbers on vines in bifenthrin-treated plots at the Nelson field site. I investigate whether there is a case for inter-species horizontal toxicity occurring between Argentine ants exposed to the bifenthrin treatment and citrophilus mealybug as a direct result of the Argentine ants either transferring the toxin directly to the mealybugs while tending them or by contaminating the leafy substrate that they feed on. In this bioassay, which is performed using a BACI design, Argentine ants are exposed to bifenthrin in a citrophilus mealybug excluded zone then given access to citrophilus mealybugs in a separate compartment and live activity of each insect species is monitored.

In Chapter 4, I discuss the findings of each of these studies; address any constraints which could have impacted on the outcomes of the research; recommend enhancements and discuss future research options. 


\section{Chapter 2: Efficacy of ant toxin treatments targeting Linepithema humile: Is there a co-effect with vine inoculated mealybug Pseudococcus calceolariae?}

\subsection{Abstract}

In South African and coastal Californian vineyards, the invasive Argentine ant L. bumile is known to form a trophobiotic association with honeydew excreting homopterans Pseudococcus sp., enhancing their populations in the vine canopy and the spread between vines of Grapevine Leafroll associated Virus 3 (GLRaV3) which the mealybugs vector, resulting in a deleterious effect on vine health and ultimately wine quality. Incursions of Argentine ants have now been reported in New Zealand vineyards but unlike in South Africa, there are no registered chemical control treatments in New Zealand targeting ants in vineyards. The objective of this study was to assess the efficacy of three ant toxin treatments targeting Argentine ants foraging on potted Pinot Noir vines which had also been inoculated with $P$. calceolariae and to see whether there was a concomitant effect on mealybug populations within treatment plots. A research site was established in Nelson during the summer of 2016/2017 and in duplicate plots, two low-toxicity baits, boric acid $(0.5 \%)$ or thiamethoxam $(0.0006 \%)$ carried in polyacrylamide gel with $25 \%$ sucrose and $0.15 \%$ citric acid solution, were applied to the base of the vines, while bifenthrin (1200ppm) was sprayed on vine trunks. In a BACI experimental design format, pre- and post-treatment rates of insect activity on each vine of each treatment or control plot was enumerated in a one- minute time interval. Count data was expressed as a percentage of baseline activity and analysed for statistical significance using GLMM. Of the three ant toxin treatments, there was a significant decline in average ant activity on vines treated with bifenthrin $(p<0.001)$ compared control vines. Average $P$. calceolariae activity also plummeted in plots where vine trunks had been treated with bifenthrin. The study concluded that of the three treatments trialled, bifenthrin, sprayed in a band on vine trunks, was the most effective treatment to control the target insect species L. humile and that bifenthrin could also indirectly control P. calceolariae.

Keywords: Argentine ant, Linepithema humile, citrophilus mealybug, Pseudococcus calceolariae, trophobiotic association, GLRaV-3, bifenthrin, low-toxicity baits, boric acid, thiamethoxam, polyacrylamide gel 


\subsection{Introduction}

Honeydew-excreting insects of the hemipteran suborders Sternorrhyncha (including aphids, whiteflies, scale insects and mealybugs) and Auchenorrhyncha (specifically planthoppers and leafhoppers) form classical food-for-protection mutualisms with ants (Hymenoptera: Formicidae) (New, 2017a; Styrsky \& Eubanks, 2007). Ants are attracted to the honeydew produced by hemipterans and in exchange for this readily available food resource, they provide protection from predators and parasitoids (Styrsky \& Eubanks, 2007; Way, 1963). The order Hemiptera includes most insect vectors of plant disease and within this order the family Pseudococcidae (mealybugs) and Coccidae (scale insects) represent the known vectors of leafroll disease (Nault, 1997).

Worldwide, Argentine ants are a significant agricultural pest known to enhance populations of phloem-feeding hemipteran insects with which they form mutualisms (Buczkowski, Roper, Chin, et al., 2014; Daane et al., 2007; Nelson \& Daane, 2007). The invasive Argentine ant is one of 30 exotic ant species to have been introduced to New Zealand shores and of them all, L. bumile (Mayr) is likely to be a significant economic pest for a number of horticultural crops, having been found on 15 of the 18 crops surveyed including pipfruit, citrus and grapes (Lester, Baring, Longson, \& Hartley, 2003). In recent years, Argentine ants have been found foraging in commercial vineyards in Gisborne and in the Gimblett Gravels winegrowing appellation of Hawke’s Bay (Charles, Bell, Lo, Cole, \& Chhagan, 2010; Westermann, Bell, Suckling, \& Lester, 2016; Westermann, Bell, Suckling, \& Lester, 2016). In vineyards, Argentine ants are among several ant species known to form a trophobiotic relationship with vine mealybugs and enhance their population in the vine canopy (Mgocheki \& Addison, 2009b). Viruliferous mealybugs transmit the leafroll virus GLRaV-3 from grapevine to grapevine as they travel and feed on green parts of the vine canopy (Charles et al., 2006b; N. Douglas \& Krüger, 2008)

Different formats of chemical control targeting ants (including Argentine ants) in vineyards have been trialled in South Africa and California. In South African vineyards, various stem barrier 
treatments have been trialled to break the association between vine mealybugs and ants in the vine canopy while at the same time having minimal impact on beneficial insects and have included the organophosphates chlorpyrifos and terbufos and the pyrethroid $\alpha$-cypermethrin SC (Addison, 2002). An alternative approach to the application of broad spectrum insecticides, is the combination of a slow acting target specific insecticide with a $25 \%$ sucrose feeding attractant to create a low-toxicity liquid bait (Nelson \& Daane, 2007; Nyamukondiwa \& Addison, 2014; Nyamukondiwa \& Addison, 2011). Delayed toxicity of the toxicant in the bait gives ample time for workers to return to the colony numerous times, mass recruit other workers to the bait and transfer the toxicant to nestmates by trophyllaxis before they themselves succumb to the toxic effects of the bait (Rust, Reierson, \& Klotz, 2004).

Low-toxicity liquid baits, variously containing either boric acid, fipronil, fenoxycarb, spinosad, thiamethoxam or imidacloprid, have been trialled in South African and Californian coastal vineyards for the control of ants (Daane et al., 2006; Nelson \& Daane, 2007; Nyamukondiwa \& Addison, 2011). Nelson \& Daane (2007) found that bait stations deployed at densities ranging from 54-225 per hectare provided some reduction in ant activity and mealybug hot spots in the vineyard, but that to be economically comparable with alternative insecticidal spray treatments for ants, bait station density needed to be less than $85 \mathrm{Ha}^{-1}$. Nyamukondiwa \& Addison (2014) found that since L. humile's foraging distance was 32m, then by deploying 81 low toxicity baits per hectare, $\pm 80 \%$ of the Argentine ant population was reached.

The use of hydrogels is a novel format to carry low-toxicity liquid baits. For example, the neonicotinoid, thiamethoxam in a polyacrylamide gel matrix has also been successfully trialled as a low-toxicity bait in a coastal Southern Californian conservation area and in a commercial plum orchard in the Western Cape of South Africa (Boser et al., 2014; Buczkowski, Roper, Chin, et al., 2014; Rust et al., 2015). Incorporation of low-toxicity bait in a polyacrylamide gel matrix could be a more cost-effective alternative than deploying liquid baits in bait station dispensers (Rust et al., 
2015). Some disadvantages of bait station dispensers are the cost of the dispensers; the time and labour involved in cleaning and refilling them every few weeks; the need to remove them before vineyard operations such as mechanical harvesting; loss of bait attractiveness through the effects of evaporation and fermentation of the sugar carrier by indigenous yeasts (Buczkowski, Roper, \& Chin, 2014; Daane et al., 2006; Nelson \& Daane, 2007; Rust et al., 2015). The advantages of polyacrylamide crystals as a bait carrier for low-toxicity baits are that they are able to absorb approximately 300 times their weight in water and once hydrated the gel matrix provides greater surface area for feeding since ants are able to stand on the gel; less labour intensive since no cleaning of a dispenser is required; inexpensive compared with bait dispensers and scoops of bait can be placed out in the field (Buczkowski, Roper, \& Chin, 2014; Buczkowski, Roper, Chin, Mothapo, \& Wossler, 2014; Silverman \& Roulston, 2001).

In New Zealand there are no chemical controls registered for use in vineyards targeting ants. By controlling ants (notably Argentine ants) in vineyards, the food-for-protection mutualism between ants and mealybugs could be broken since in the absence of ants, mealybugs would become predated upon by their natural enemies. The indirect flow-on effect of this is that GLRaV3 infection rates of their grapevine hosts would diminish with the control of its' mealybug vector. Here, chemical control trials targeting Argentine ants in a viticultural system conducted in Nelson during the previous summer $(2016 / 2017)$ are reported.

Two different formats of insecticide administration are used in the trials, namely the deployment of low-toxicity liquid baits in a polyacrylamide gel matrix and a spray format. In treatment plots at the Nelson field site, Biff Ant ${ }^{\circledR}$ is sprayed on vine trunks and Actara ${ }^{\circledR}$ or Boric Acid in polyacrylamide gel are placed at the base of potted grapevines (inoculated with citrophilus mealybugs). The two low-toxicity ant baits are each carried in polyacrylamide crystals hydrated in $25 \%$ sucrose solution with $0.15 \%$ citric acid. to retard mould growth and fermentation in accordance with Nelson \& Daane (2007). Field performance of the polyacrylamide gel matrix is 
also assessed. Syngenta's Actara ${ }^{\circledR}$ (A.I. thiamethoxam $250 \mathrm{~g} / \mathrm{kg}$ ) is currently registered for control of scales and passion vine hopper on kiwifruit, scales and Froggatt's apple leafhopper on pipfruit and aphids on potatoes (Syngenta, 2016). Thiamethoxam, a neonicotinoid, at a concentration of $0.0006 \%$, is chosen to mitigate against the dilution effect resulting from trophyllaxis (Rust et al., 2015). Currently, boric acid $0.5 \%$, in a liquid bait format, is recommended for control of ants in New Zealand vineyards according to Reid (2010), but the polyacrylamide gel matrix could be a more convenient format. Biff Ant ${ }^{\circledR}$, (A. I. bifenthrin $80 \mathrm{gL}^{-1}$ ) is a pyrethroid preparation which has been developed by Key Industries for the control of all ant species (including Argentine ants) in urban and industrial areas and is applied at the recommended field rate for L. bumile of $15 \mathrm{~mL} \mathrm{~L}$ ${ }^{1}$ (1200ppm bifenthrin) (Toft, 2011).

The primary objective of this study therefore is to identify which of the treatment methods is most effective for the control of Argentine ants in the vine canopy. It is predicted that for the ant toxicant treatment which is most effective at suppressing ant activity on the potted vines, there will also be a concomitant reduction in citrophilus mealybug populations due to predation related to the dissociation between Argentine ants in the vine canopy and citrophilus mealybug inhabiting the green vine parts. The secondary objective of the study is to assess the field performance of the hydrogel bait delivery system which would be more convenient and cost effective than deploying liquid baits.

\subsection{Methods and materials}

\subsubsection{Trial site location}

The trial site was established in the front paddock of a rural property in Hope, Nelson ($41.35588^{\circ}, 173.1610^{\circ}$ ) from 28 November 2016 after ant specimens collected from the property and neighbouring properties confirmed the presence of $L$. bumile. An ant survey conducted at a commercial vineyard $400 \mathrm{~m}$ away from the field site, during the summer also confirmed incursions of $L$. bumile along the outer rows of the Pinot Gris block (Appendix A). 


\subsubsection{Installation of site infrastructure}

The centres of each of the eight trial plots represented in Figure 2.1 below were surveyed prior to weed eating two large areas of paddock encompassing plots \#1, \#2, \#3, \#4 and plots \#5, \#6, \#7, \#8. Herbicide was sprayed in each plot area with a margin of one metre around its perimeter. Waratahs were banged into the ground every few meters around the perimeter of each of the two larger blocks to secure wire fencing intended to keep out a couple of head of cattle which were to graze the pasture from time to time. However, electric fencing cordoning off all eight plots was erected after the cattle were found in the plot area. 

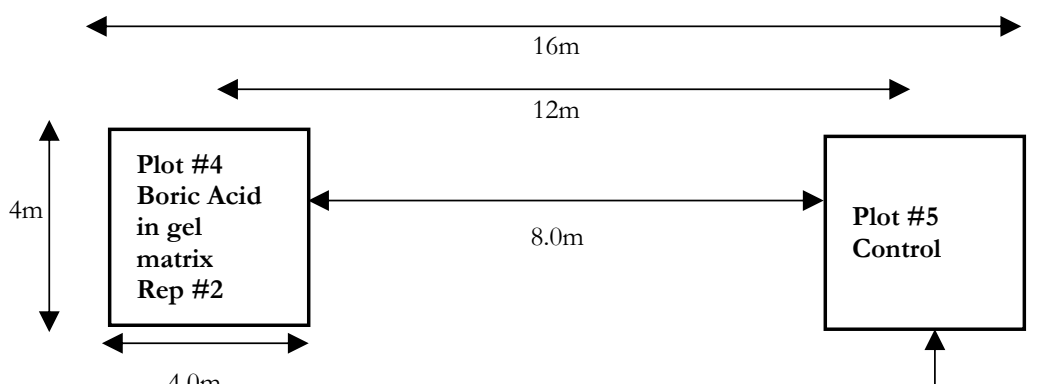

$4.0 \mathrm{~m}$

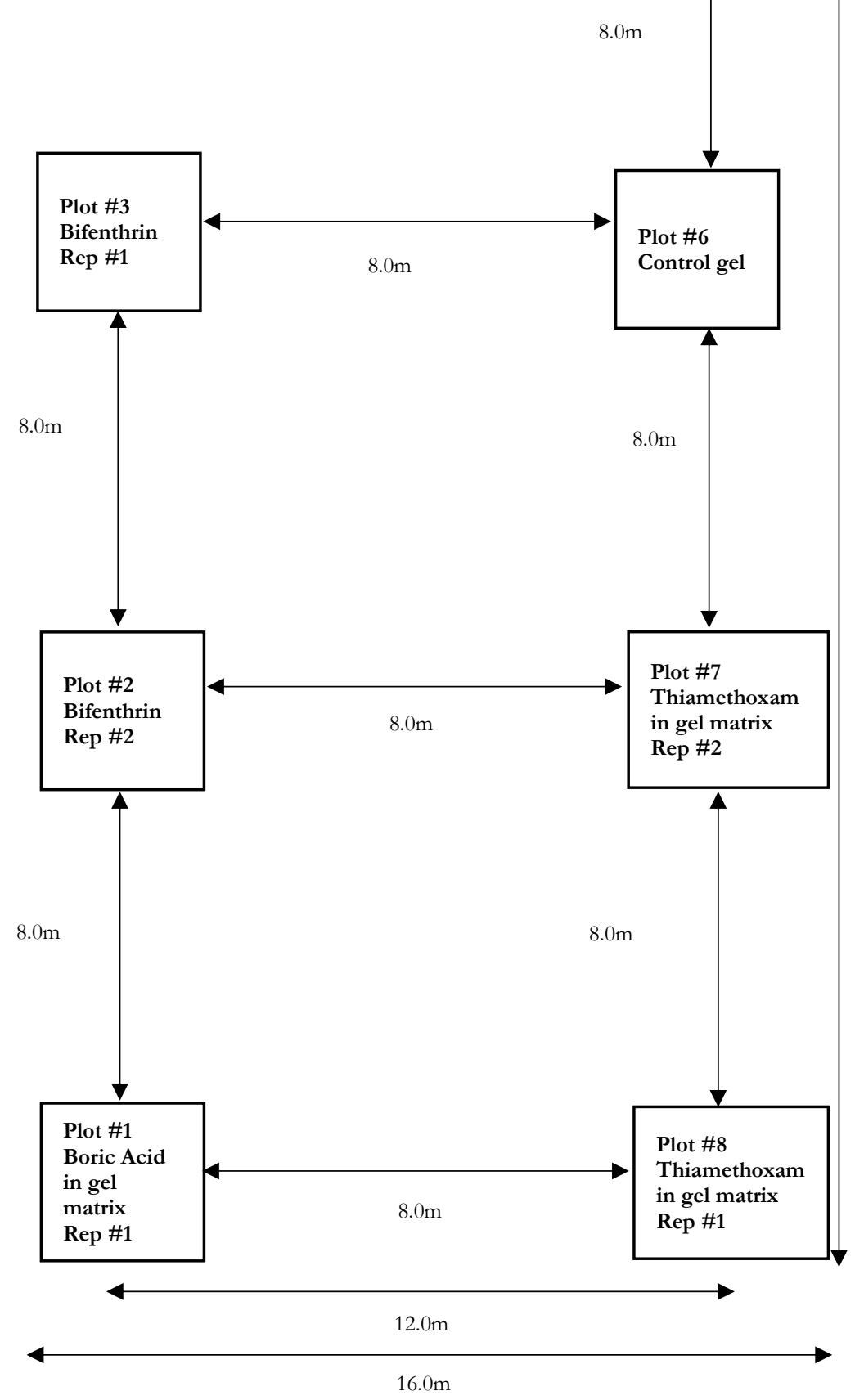

Figure 2.1: Dimensions (not to scale) and spatial arrangement of plots at Nelson ant toxin trial site 
Weed matting $(4 \mathrm{~m} \times 4 \mathrm{~m})$ was pegged into the ground in each plot. A wooden frame $(2.7 \mathrm{~m} \times$ $2.7 \mathrm{~m})$ to provide a more level base for the potted vines was placed on the weed matting and propped up with concrete pavers where required. A larger concrete paver $(500 \mathrm{~mm} \times 500 \mathrm{~mm})$ was placed in the centre of the plot to form a stable base for the ant nest infrastructure. Plastic pot plant saucers $(34 \mathrm{~cm}$ diam.) which were to become moats when filled with water to assist ant containment, were nailed to the wooden frame. Shade cloth was erected around the perimeter of each plot primarily to keep out the local pukeko population but also to provide wind protection for the vines. The initial stages of plot infrastructure installation are shown in Figure 2.2 below.
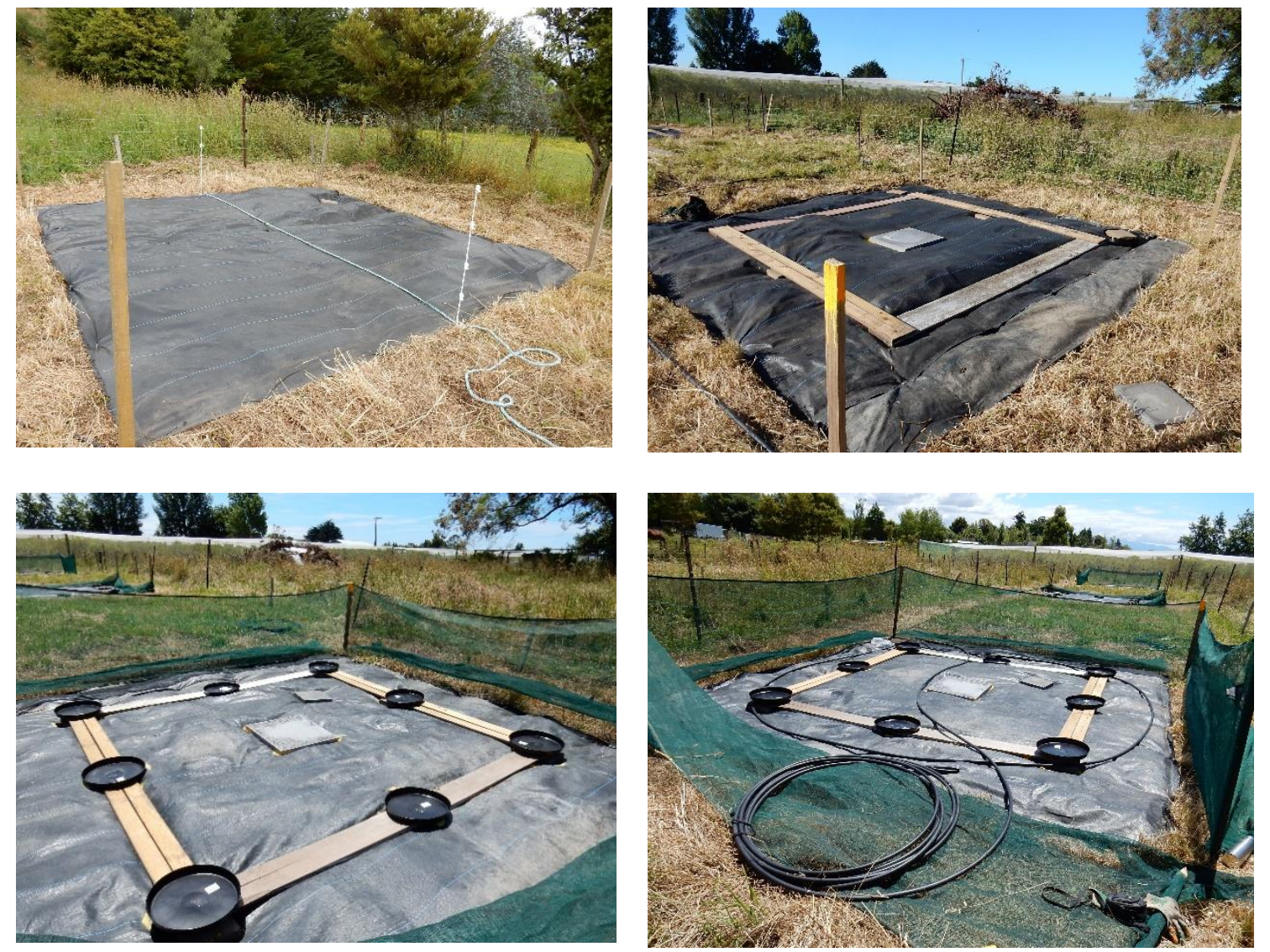

Figure 2.2: Initial stages of infrastructure installation at Nelson field site Source: Catherine Hardiman

Meanwhile seventy bare-rooted GFG2 Pinot Noir Abel grapevines on 3309 rootstock sourced from Riversun Nursery in Gisborne late in November 2016, were potted up in 5L plant containers with Scotts ${ }^{\circledR}$ Osmocote ${ }^{\circledR}$ Professional Premium Plus Potting Mix. The potted vines 
seen in Figure 2.3 below were nurtured off site until enough green foliage had developed and the irrigation installation at the site was complete.
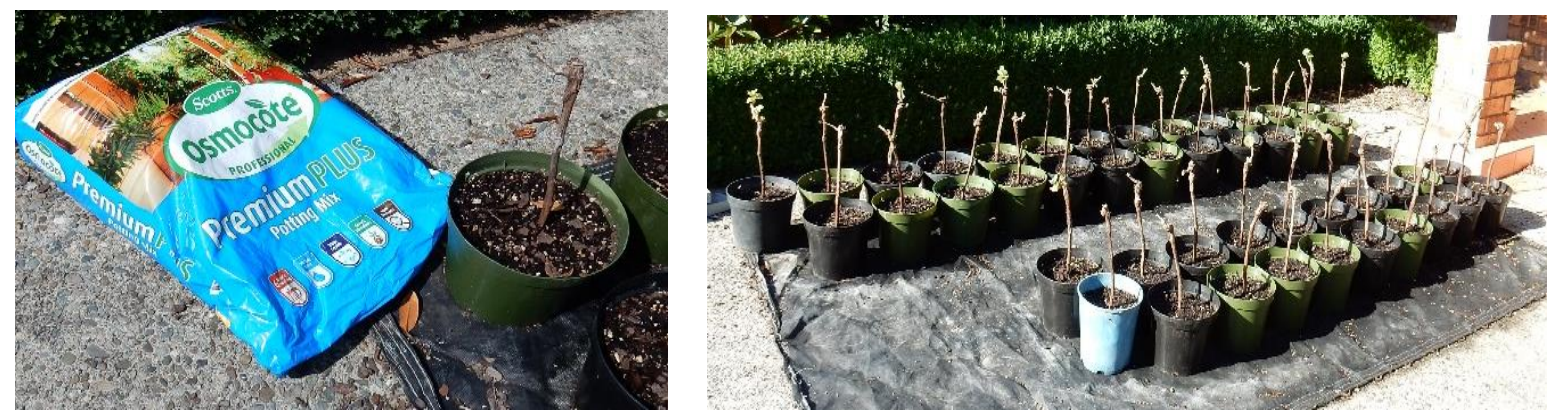

Figure 2.3: Newly potted up grafted Pinot Noir Abel grapevines Source: Catherine Hardiman

Black polyethylene piping (16mm i.d.) was laid out in a large circuit between the two blocks of plots. Near the corner of each plot a length irrigation piping which was linked into the main circuit via a T-join, was coiled around the wooden frame (Fig.2.4A) and joined back into itself (Tjoin) to create eight smaller circuits reticulating from the main circuit and maintaining a constant pressure when the lines were full of water. Another length of irrigation piping connected to the main circuit was threaded through the pasture and secured to a tap fitted with an electronic timing device (Fig. 2.4B). 

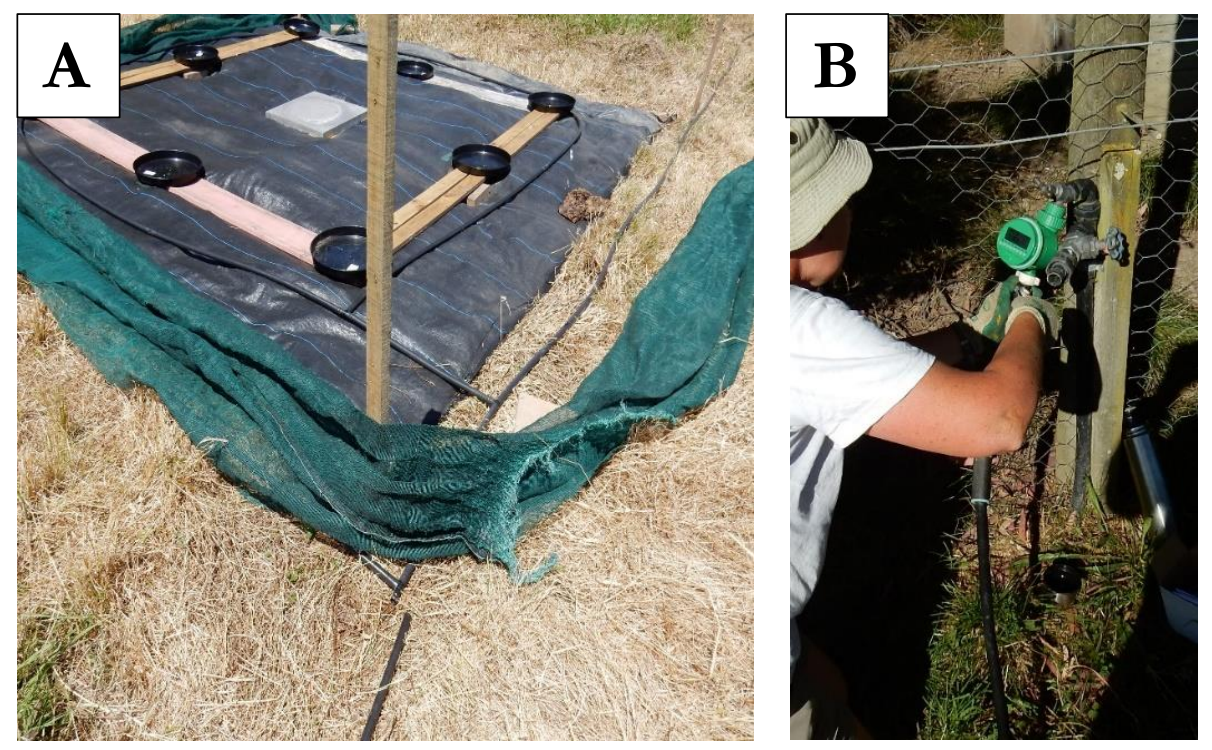

Figure 2.4: Irrigation installation at Nelson site. (A) Irrigation connections in plot and on main line (B) Connecting irrigation piping to electronic water timing device Source: Chris Hardiman

Sixty-four potted vines were brought onto the field site on $7^{\text {th }}$ January 2017 and randomly distributed around the eight plots. Each vine was mounted on wooden chocks above the water level in the plastic saucers. Spacing between vine centres was $1.2 \mathrm{~m}$. For each of the vines, a short length of whisker tubing $(0.89 \mathrm{~mm}$ i.d.) inserted directly into the irrigation line at one end, was poked through a small hole drilled in the plant container (Fig. 2.5A) and plugged into a piece of polyethylene piping which was inserted into the potting mix next to the vine trunk (Fig 2.5B). At one point of the irrigation circuit within each plot, the base of an empty pot plant container was pegged to the ground and into this a $2 \mathrm{~L}$ plastic bottle with $250 \mathrm{~mL}$ graduations marked on it was placed to provide a means of inline vine water delivery calibration and monitoring. As with the vines, a length of whisker tubing was inserted into the plot irrigation line and the calibration bottle (Fig. 2.5A). Within the two blocks of plots, between each plot, a $2.4 \mathrm{~L}$ plastic bottle with $250 \mathrm{~mL}$ graduations marked on it and supported with bricks, was similarly linked to the main irrigation line to monitor homogeneity of pressure and water delivery between plots (Fig. 2.6C). 

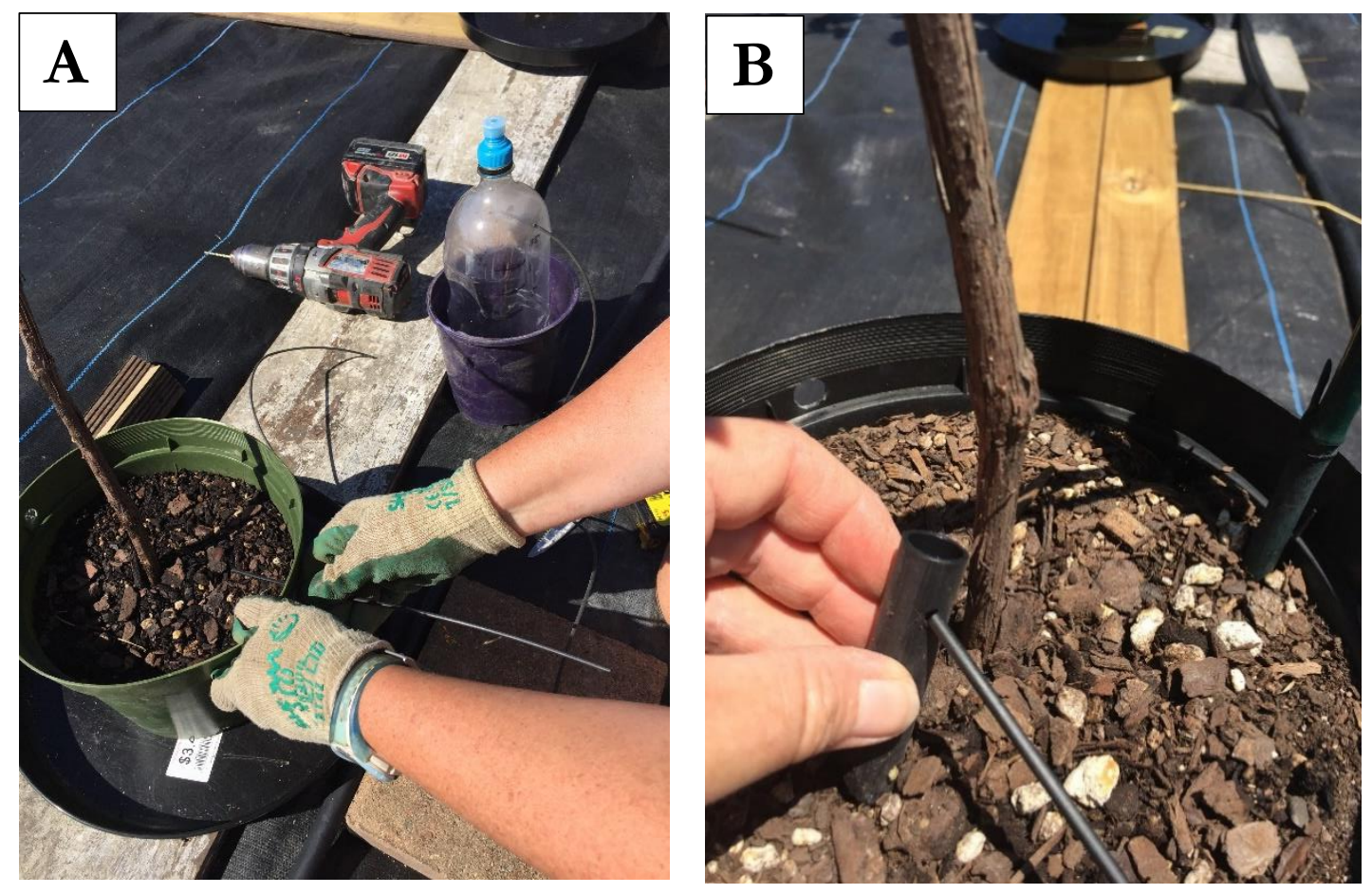

Figure 2.5: Connecting vines to irrigation system at Nelson field site (A) Connecting irrigation whisker between plot irrigation line and vine container (B) Plugging irrigation whisker into potting mix at base of vine

Source: Chris Hardiman

The irrigation system was calibrated to deliver $750 \mathrm{~mL}$ of water to each vine by recording the time in minutes that it took for the" in-line vine" and" between plots" water calibration bottles to fill to the $750 \mathrm{~mL}$ mark. The electronic water timing device at the tap was programmed to come on four times a week on a Monday, Wednesday, Friday and Saturday between $1700 \mathrm{hrs}$ and 1720hrs. The 3L reservoir bottle in the corner of each plot (Fig. 2.6A) which was connected to the irrigation line via $3 \mathrm{~mm}$ i.d. tubing, filled up each time the irrigation was on. The reservoir bottles were used to top up the "moats" beneath the vines, as were the "in-line vine" (Fig.2.6B) and "between plot" (Fig. 2.6C) calibration bottles. 

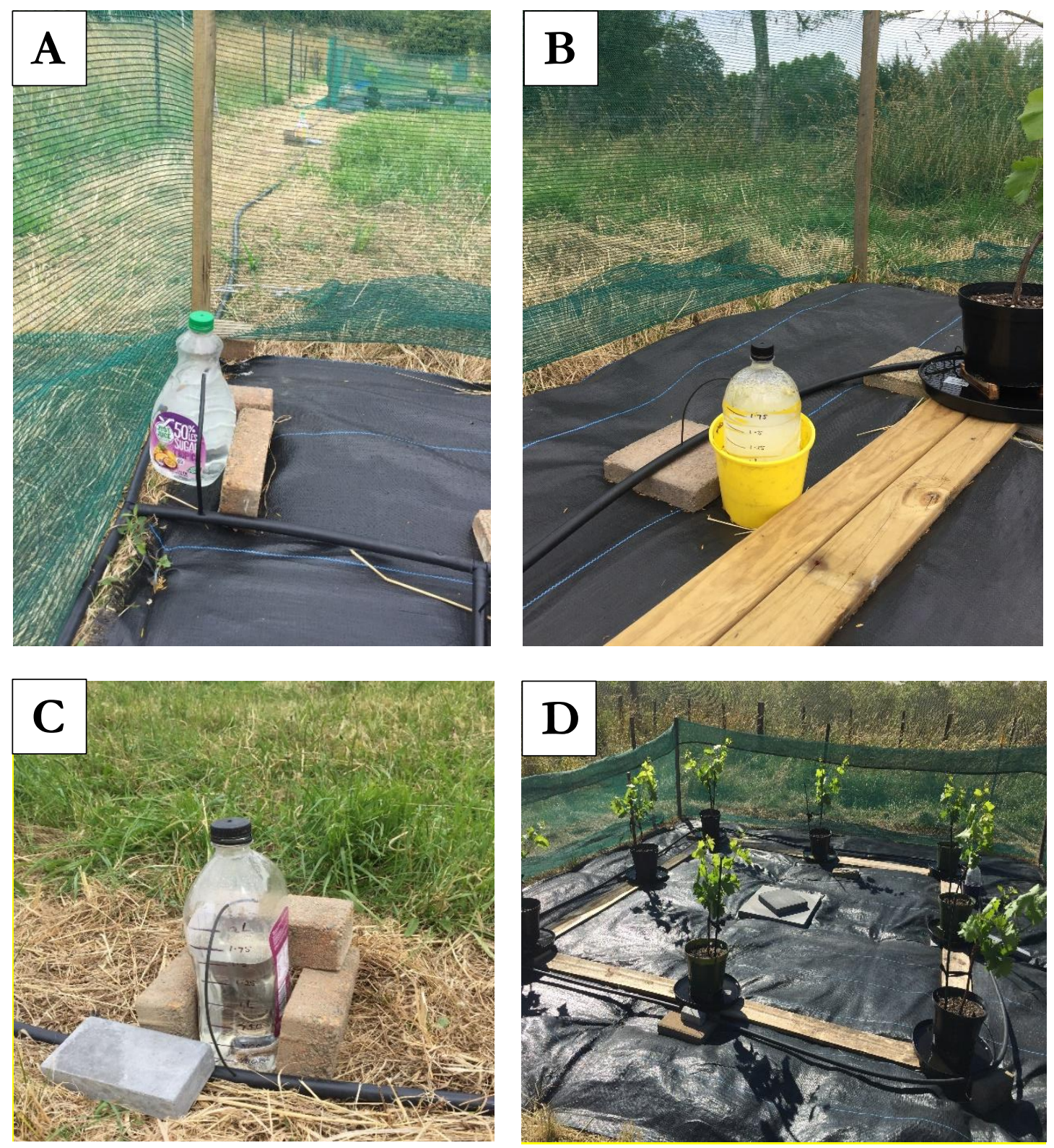

Figure 2.6: Irrigation calibration at Nelson field site (A) Water reservoir in corner of plots. (B) Inline vine water calibration. (C) Between plots water calibration. (D) Newly installed vines in plot Source: Catherine Hardiman 
Ant nest infrastructure installation in each plot involved firstly placing a piece of close-cell foam on top of the large concrete paver in the centre of each plot (Fig.2.7A) to insulate the ant nest box base from the heat of the paver during the day. Next clear inert PVC tubing (8mm i.d.) was inserted into each of the eight holes which had been drilled in the ant nest box (Fig. 2.7B). Blue rubber elastrator rings were rolled onto the tubing on each side of the nest box using a conical shaped wine bottle stopper to lock the tubing in place (Fig.2.7C). A removable plastic cover was then fitted over the nest box and tubing (Fig 2.7 D) to provide protection for the ants from sun exposure, adverse weather conditions and other fauna. The plastic cover was weighted down with a concrete paver $(270 \mathrm{~mm} \times 270 \mathrm{~mm})$ and another piece of close-cell foam was placed between the cover and the paver for insulation (Fig 2.7E and Fig.2.7F). 

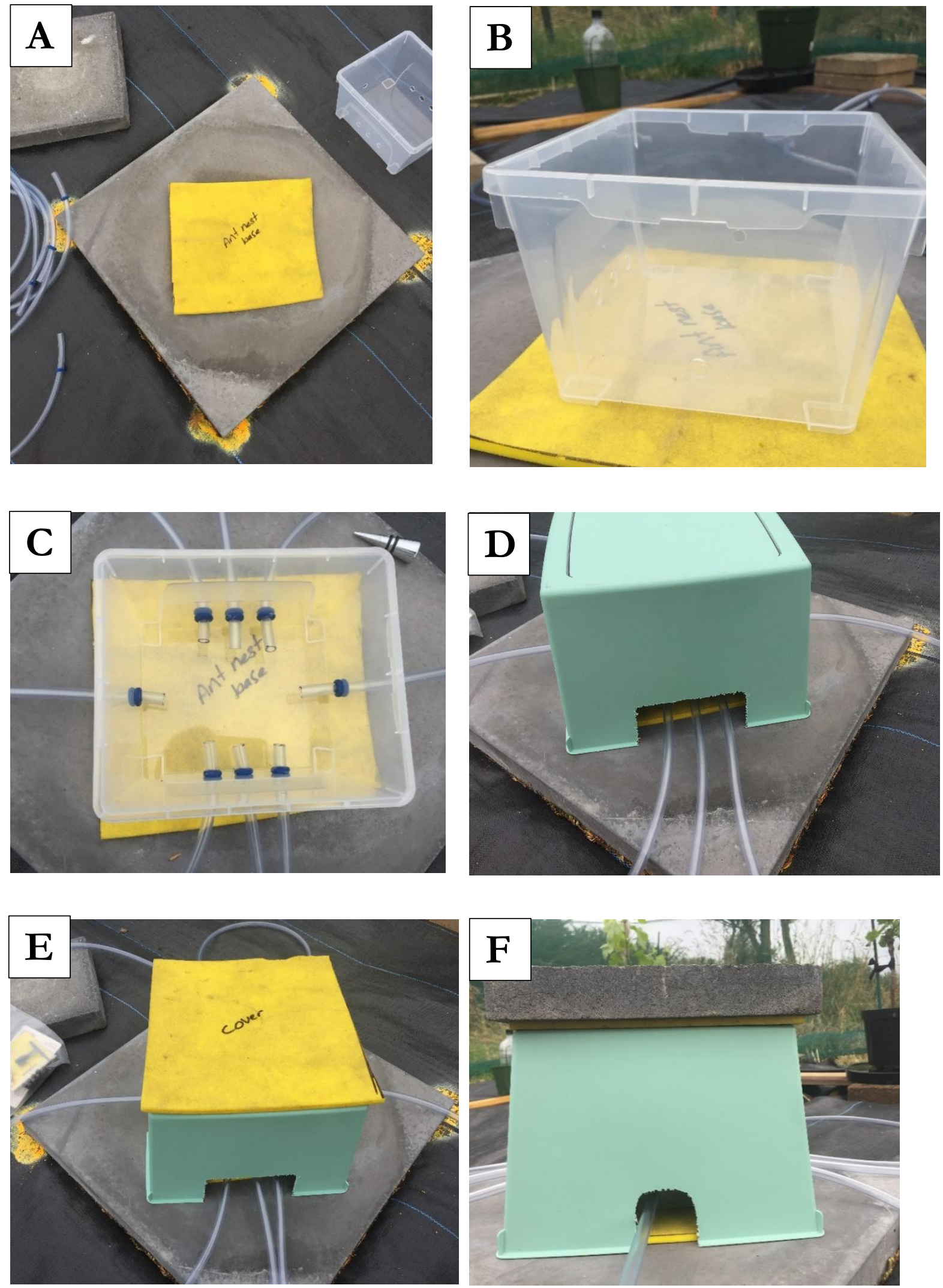

Figure 2.7: Ant nest infrastructure A) Concrete base in centre of plot (B) Ant nest box sitting on insulation foam. (C) PVC tubing secured to nest box with rubber elastrator rings (D) Removable nest box cover (E) Insulative layer between nest box cover and concrete paver (F) Concrete paver to weight nest box infrastructure to ground.

Source: Catherine Hardiman 
The other end of the PVC tubing was inserted into a hole drilled in the pot container, secured with elastrator rings on either side and directed to the base of the vine trunk (Fig.2.8) to give the ants vine access.

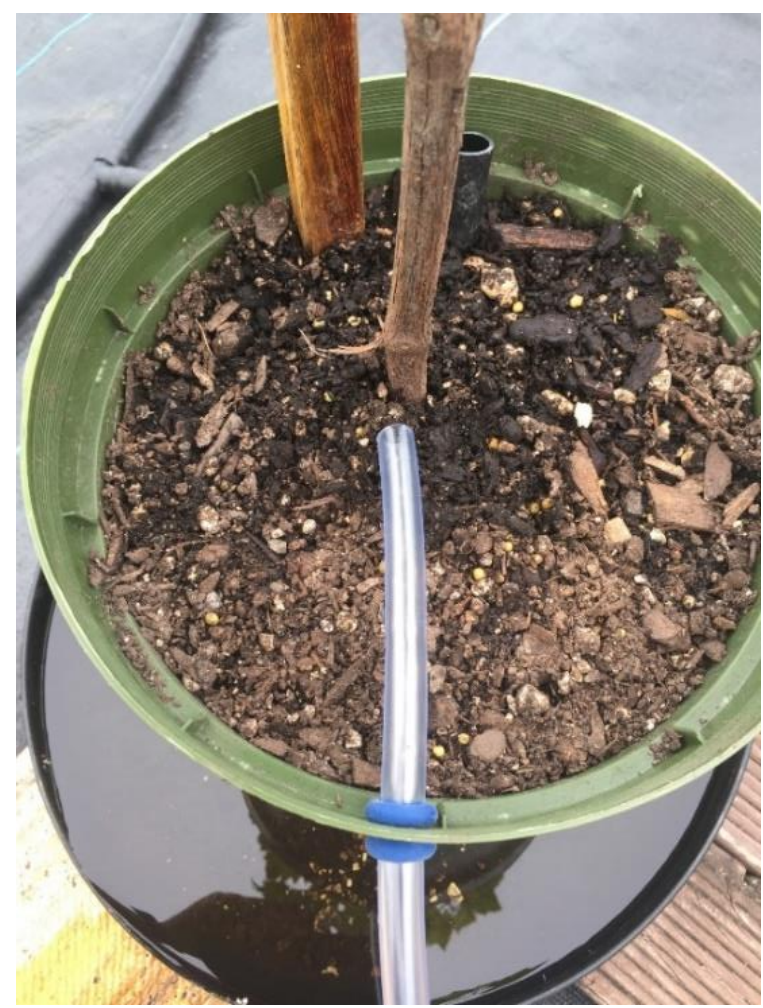

Figure 2.8: Ant conduit between vine and nest box Source: Catherine Hardiman 


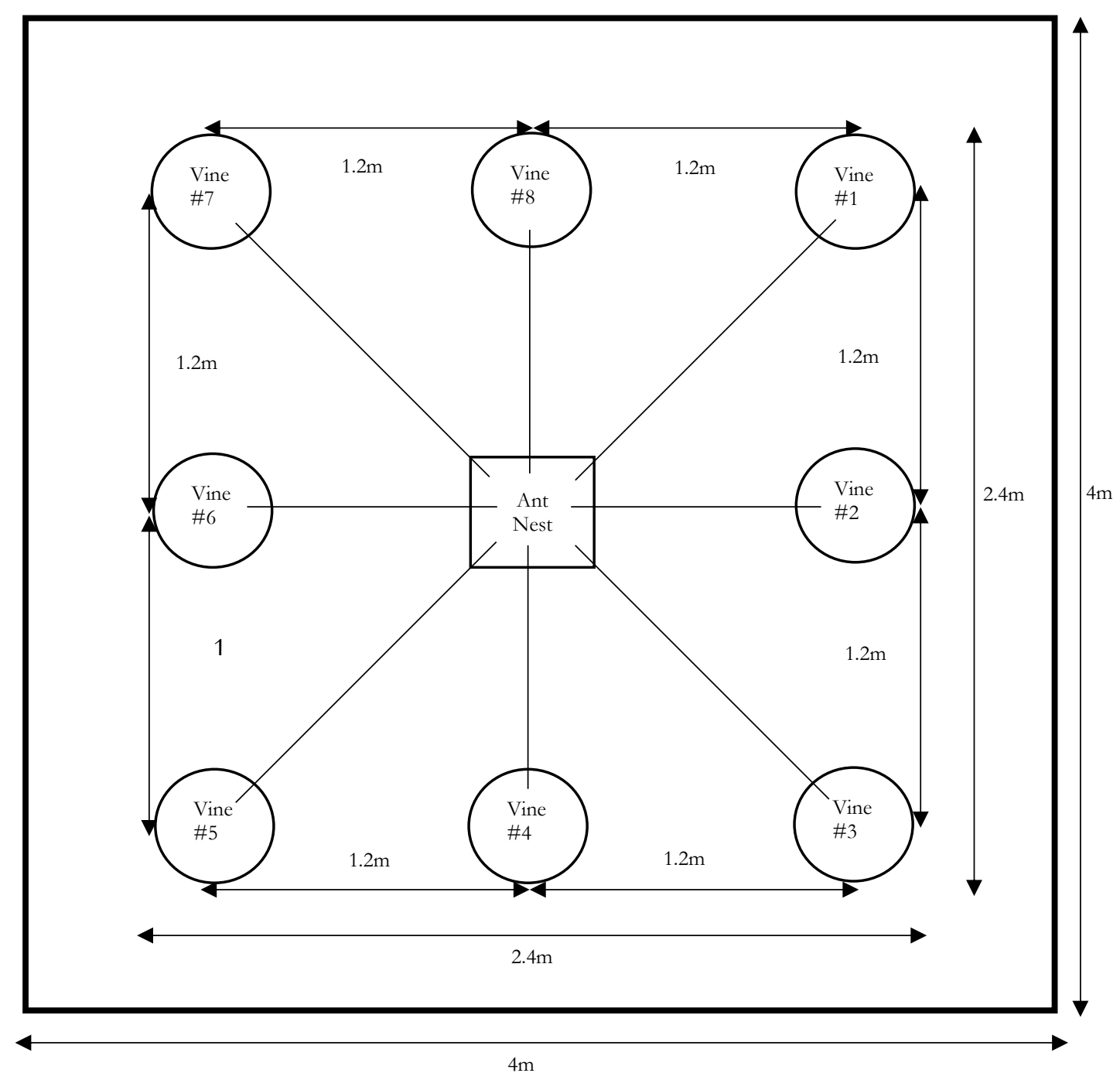

Figure 2.9: Dimensions (not to scale) and spatial arrangement of vines about ant nest infrastructure in plots at Nelson ant toxin trial site

During the night of $21^{\text {st }}$ January 2017 , before the ant nests were brought on site, a severe weather event went through the field site bringing $40 \mathrm{~mm}$ rain and $120 \mathrm{kmh}^{-1}$ wind which toppled 22 of the 64 vines. Consequently, rocks and broken pavers were placed in the base of the vines (Fig.2.10A) and rudimentary trellising was erected. Tomato stakes in the corners of each plot (Fig.2.10B) tethered by guy ropes and two levels of plastic clothesline cord attached to them formed the basis of the trellising. The vines were tied to the clothesline cord with strips of stretch fabric. 

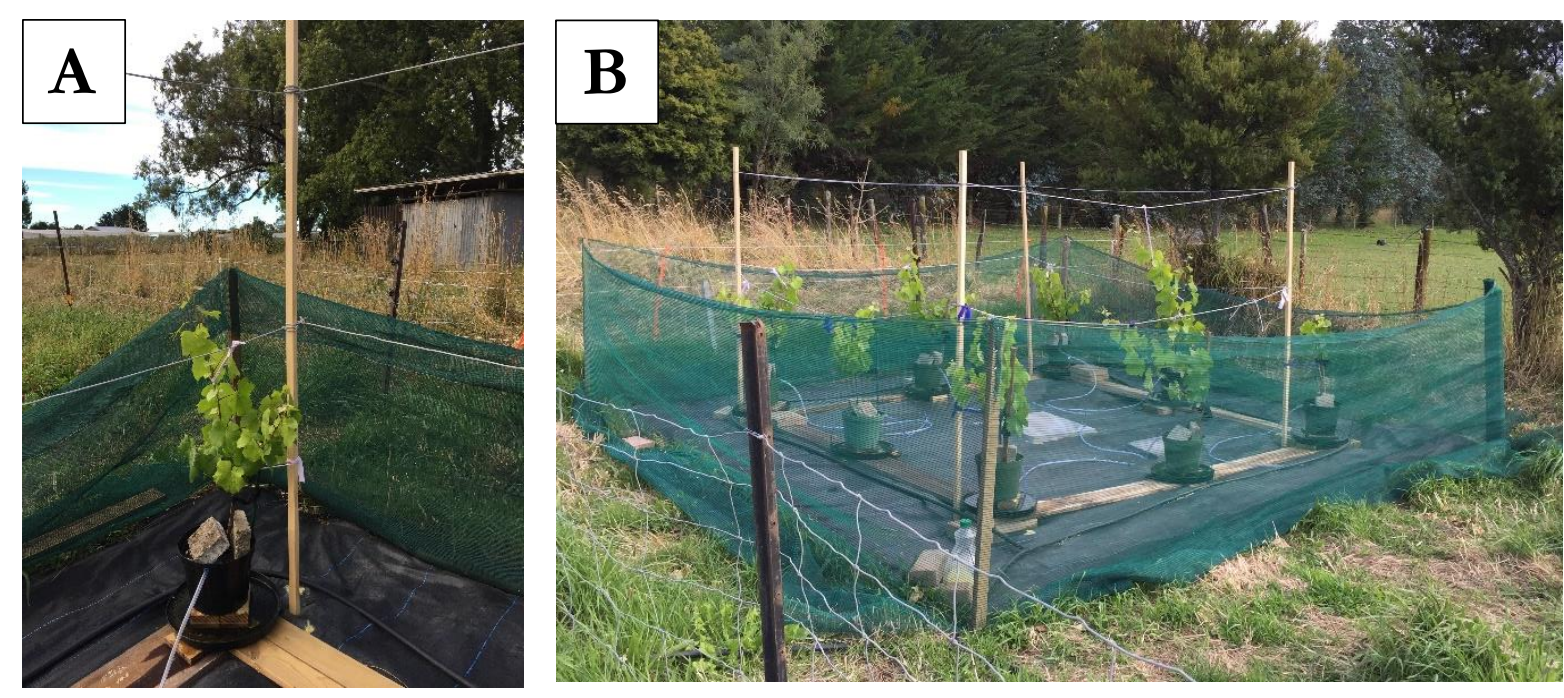

Figure 2.10: Vine reinforcement at Nelson field site (A) Rocks and broken pavers in base of vine (B) Two levels of plastic clothesline cord attached to tomato stakes in plot corner Source: Catherine Hardiman

The final measure to ensure ant containment at the site was the liberal use of Tanglefoot ${ }^{\circledR}$. Tanglefoot ${ }^{\circledR}$ was smeared in a wide band approximately $30 \mathrm{~cm}$ from ground level on the tomato stakes in the corners of each plot; above the top level of clothesline cord on each tomato stake and from where the guys ropes were attached to the upper part of the tomato stakes along a length of about $0.5 \mathrm{~m}$ (Fig.2.11A). Tanglefoot ${ }^{\circledR}$ was also applied around the inside rim of each vine container (Fig.2.11B), along a 10cm section where the PVC tubing entered the pot and similarly with the irrigation whisker of each pot. At the nest box end, Tanglefoot ${ }^{\circledR}$ was applied to the PVC tubing where it entered the nest box. Applications were also made to other points in the plots where ants could possibly escape. 

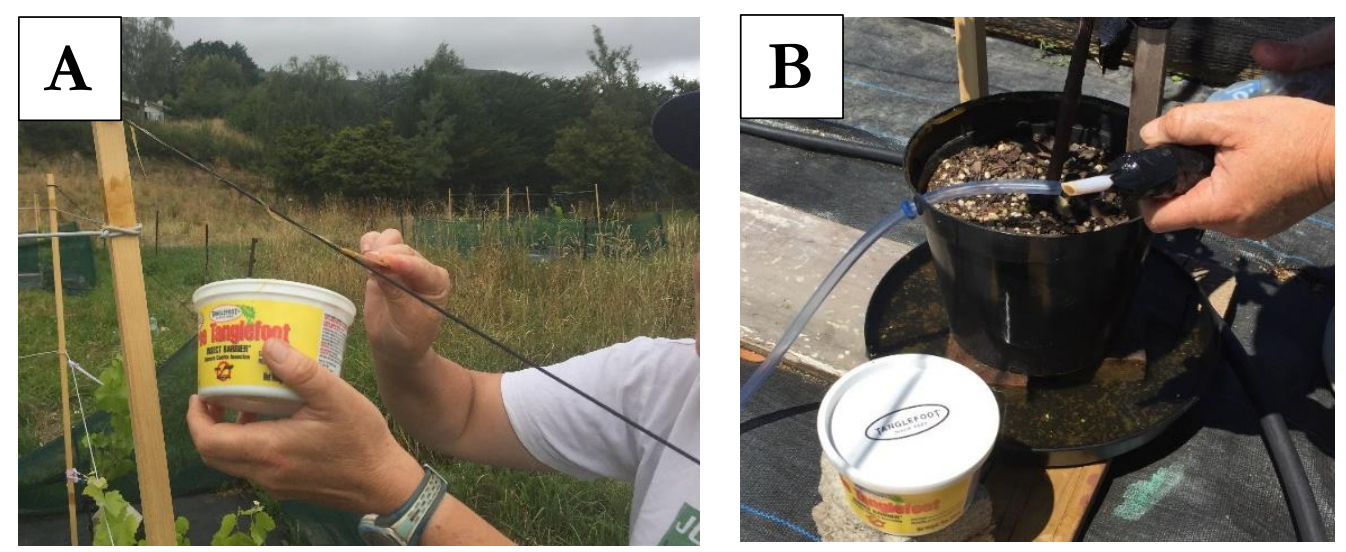

Figure 2.11: Tanglefoot ${ }^{\circledR}$ application (A) Top of tomato stake above clothesline cord and part way along top of guy ropes (B) Around inside rim of vine container, first section of PVC tubing on outside of vine container and where irrigation whisker connects to vine container Source: Chris Hardiman

\subsubsection{Ant colony collection and extraction}

On the $16^{\text {th }}$ January 2017, Argentine ant nest material was dug up from the trial site property and neighbouring properties and deposited in six high-sided plastic containers coated with Fluon (Chemours Insect-A-Slip PTFE DIS30) and with Tanglefoot ${ }^{\circledR}$ liberally smeared around the upper rims to prevent the ants from escaping. Prior to the ant extraction process, the interior of the plastic nest boxes $(21 \times 19 \times 13 \mathrm{~cm})$ were coated with Fluon and four aluminium foil covered $25 \mathrm{~mL}$ glass tubes each half filled with water and plugged with cotton wool were placed inside to provide housing opportunity and water for the ants. Two small squares of foil, one with half a teaspoon of tuna on it and the other with a cotton ball soaked with $20 \%$ honey solution were placed in the base of the nest boxes as a protein and carbohydrate source for the ants. The upper rim of each nest box was smeared with Tanglefoot ${ }^{\circledR}$ to prevent the ants from escaping.

Argentine ants were extracted from the collection bins to successive receival nest boxes using a method similar to that illustrated in Choe, Villafuerte, \& Tsutsui (2012) except that inert clear PVC tubing (8mm i.d.) connecting the collection bin to the nest box was used instead of a wire bridge. The process took place in a bath tub which was filled to a height of about $10 \mathrm{~cm}$ with detergenated water to break the surface tension and act as a moat should any ants get over the 
sides of the collection bin. The PVC tubing touching the side of an inverted cotton wool-bunged terracotta pot provided a corridor for the worker ants to evacuate larvae and queens when water was dripped from the tap at an approximate rate of one drop per second as shown in Figure 2.12 below.

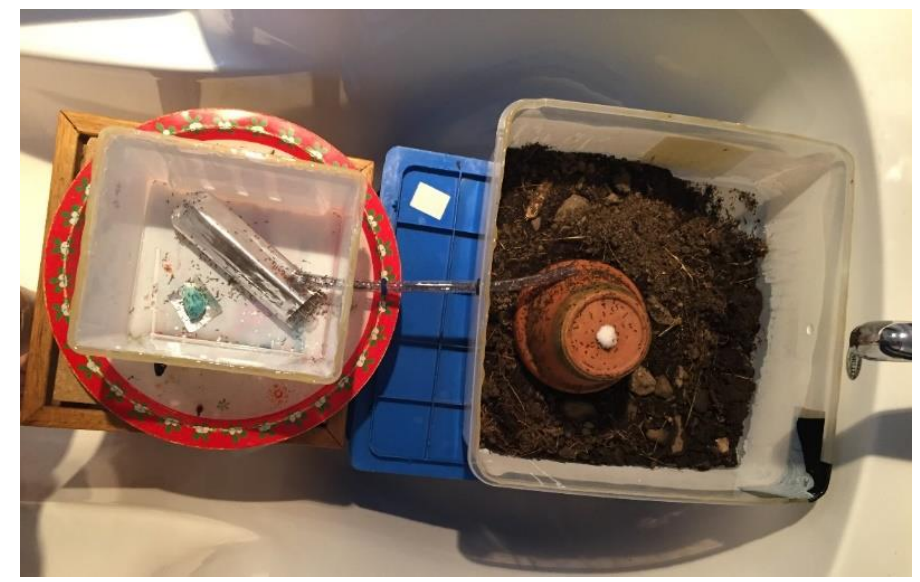

Figure 2.12: Argentine ant extraction process Source: Catherine Hardiman

Each nest box was weighed on a top pan electronic balance (Satorius; Model TE-2101; $\mathrm{d}=0.1 \mathrm{~g}$ ) before and after ant transfer to establish the mass of worker ants, larvae and queens collected (with the average mass in each container being equivalent to about 7,000 individuals based on the mass of one Argentine ant worker being $0.43 \mathrm{mg}$ ).

Before the nest boxes were installed at the field site on $3^{\text {rd }}$ February 2017, they were kept in a darkened room sitting in water baths and the ants fed with fresh $20 \%$ honey solution every couple of days and half a teaspoon of tuna once a week. At the field site, every couple of days, one scoop $(20 \mathrm{~mL})$ of $25 \%$ sucrose and $0.15 \%$ citric acid solution in a polyacrylamide gel matrix was placed on a plastic strip at the base of each vine to train the ants to venture out to the vine prior to the vines being inoculated with citrophilus mealybugs. Also, once a week for the duration of the experiment, the tuna in the nest boxes was replenished. Leaf litter from the site was used for 
bridging material for the ants to gain access to the PVC tubing (Fig. 2.13A) in the newly installed ant nest boxes (Fig. 2.13B).

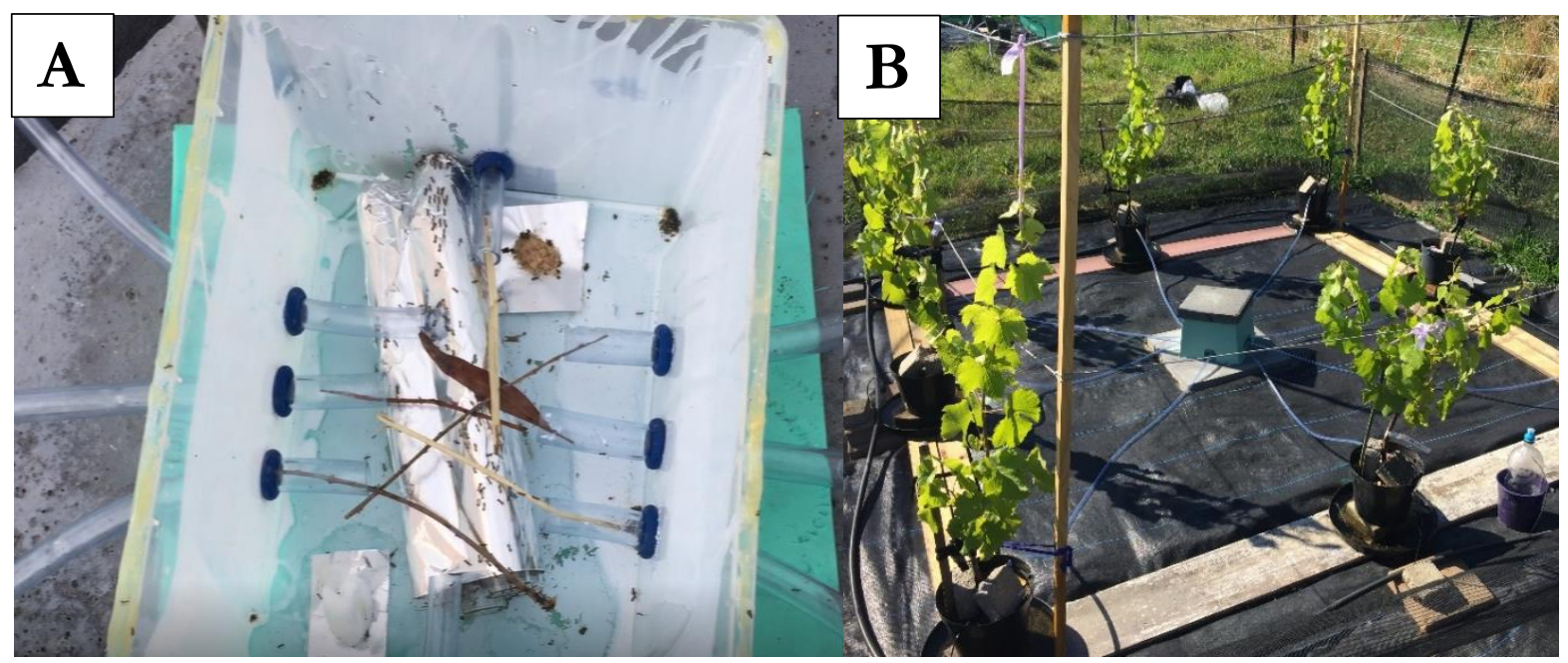

Figure 2.13: Ant nest installation (A) Leaf litter bridges in an ant nest box (B) Newly installed ant nest box in the centre of a plot

Source: Catherine Hardiman

\subsubsection{Pseudococcus calceolariae rearing and vine inoculation}

At the Riwaka Plant and Food Research facility, on $22^{\text {nd }}$ December 2016, sprouted Agria potatoes supporting citrophilus mealybugs, were seeded onto sprouted Aaray Banny seed potatoes, placed in covered, ventilated plastic containers on racks (Fig. 2.14A) and kept in a temperaturecontrolled room at $22^{\circ} \mathrm{C}$. Several times over the next five weeks more sprouted seed potatoes were added as the mealybugs populated the sprouted area. On $8^{\text {th }}$ February 2017 , P. calceolariae were inoculated onto all 64 potted vines by enclosing a piece of sprouted potato populated with citrophilus mealybugs in a strip of plastic onion bag, threading a twisty tie through the top of the mesh and securing it to a vine shoot close to the vine foliage (Fig. 2.14B). 

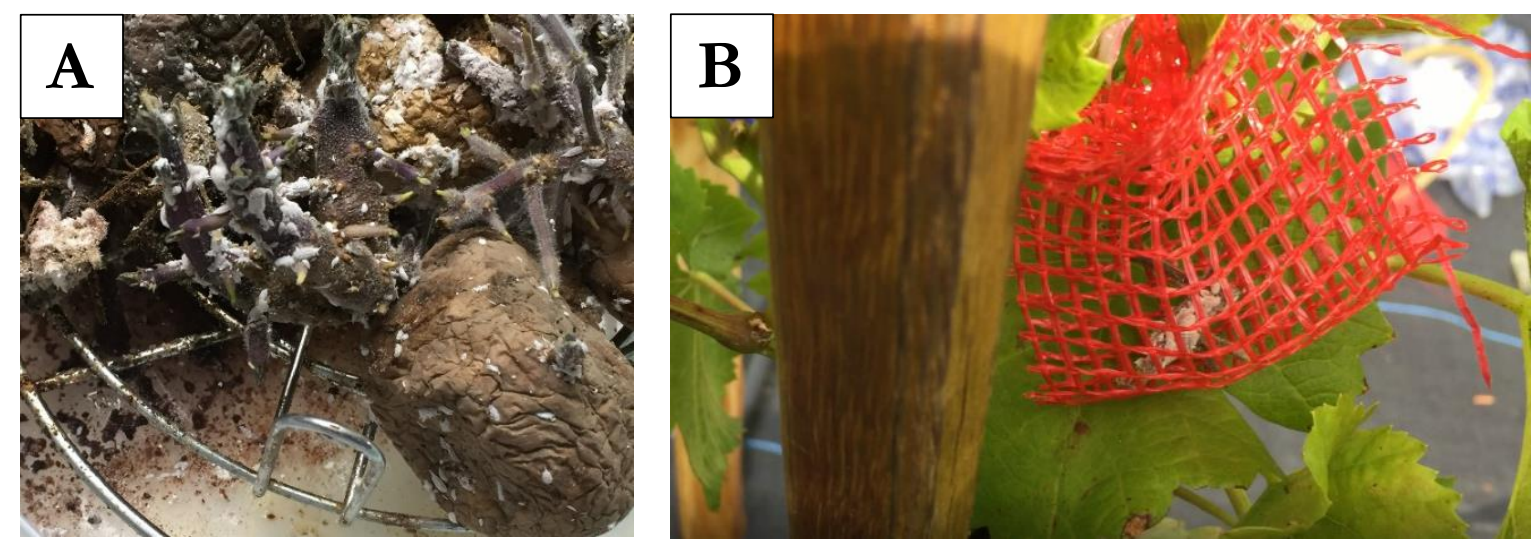

Figure 2.14: Citrophilus mealybug (A) P. calceolariae rearing at Plant and Food Research Riwaka. (B) Citrophilus mealybug vine inoculation

Source: Catherine Hardiman

\subsubsection{Insect data collection and treatment assignment}

Baseline data collection commenced on $16^{\text {th }}$ February 2017. There were four more pretreatment data collection occasions on $20^{\text {th }}, 21^{\text {st }}, 23^{\text {rd }}$, and $25^{\text {th }}$ February. Each time, data recording started between $1400 \mathrm{hrs}$ and $1600 \mathrm{hrs}$, in fine weather conditions with temperatures ranging from $22^{\circ} \mathrm{C}-27^{\circ} \mathrm{C}$. Post-treatment, data was collected ten times on $27^{\text {th }}$ February $1^{\text {st }}, 5^{\text {th }}, 9^{\text {th }}, 15^{\text {th }}, 16^{\text {th }}$, $20^{\text {th }}, 22^{\text {nd }}, 28^{\text {th }}$ and $31^{\text {st }}$ March 2017 starting between $1300 \mathrm{hrs}$ and1530hrs, in fine weather and with temperatures ranging from $19^{\circ}-24^{\circ} \mathrm{C}$.

On each data collection occasion, recording started at vine \#1 of plot \#1 and went in a clockwise direction in each plot, through plots \#1 to plot \#8 and finished at vine \#8 of plot \#8. Count data (clicker timer) for Argentine ant activity on all vine parts in a one-minute time interval (electronic timer) was recorded at each vine first followed by count data for citrophilus mealybugs seen in vine parts in a one-minute time interval. Treatments were randomly assigned to plots by a non-replacement ballot system and Figure 2.1 shows which treatment or control was assigned to each plot. There were two replicate plots for each treatment and one "control gel" plot to reference the boric acid in gel and thiamethoxam in gel treatments. The "control" plot referenced the two plots sprayed with bifenthrin. 


\subsubsection{Treatment preparation and application}

The gel control which was also used at the base of each vine to train the ants to come from the nest box to the vines, was prepared by adding 3 level teaspoons (15g) of Gardman Watergel water storing crystals to $1 \mathrm{~L}$ of $25 \%$ sucrose and $0.15 \%$ citric acid solution, made by dissolving $250 \mathrm{~g}$ sugar in $500 \mathrm{~mL}$ hot water, adding $1.5 \mathrm{~g}$ citric acid and making up to $1 \mathrm{~L}$ volume with cold water. The $0.5 \%$ boric acid in polyacrylamide gel treatment was prepared in the same way as the gel control except that $5.0 \mathrm{~g}$ of granular boric acid AR (Chem-Supply) was added before making up to $1 \mathrm{~L}$ volume.

The thiamethoxam in gel treatment was made by adding 1.5 level teaspoons $(7.5 \mathrm{~g})$ of Gardman Watergel water storing crystals to $500 \mathrm{~mL}$ of prepared $0.0006 \%$ thiamethoxam solution. The solution was prepared by dissolving $1.20 \mathrm{~g}$ of Syngenta's Actara ${ }^{\circledR}$ granules (250g thiamethoxam $/ \mathrm{kg}$ ) in deionised water, making up to volume in a $100 \mathrm{~mL}$ volumetric flask, then transferring $1.0 \mathrm{~mL}$ (micropipette) to a $500 \mathrm{~mL}$ volumetric flask and making up to volume with $25 \%$ sucrose and $0.15 \%$ citric acid solution.

The gel treatments were prepared at Plant and Food Research facility in Riwaka where chemicals and reagents were weighed using a Mettler electronic top pan balance (Model PE 1600; $\mathrm{d}=0.01 \mathrm{~g}$ ). The bifenthrin treatment was mixed in a spray unit at the field site by adding $60 \mathrm{~mL}$ of Key Industries' Biff Ant ${ }^{\circledR}$ suspension $\left(80 \mathrm{gL}^{-1}\right.$ bifenthrin) to $4 \mathrm{~L}$ of tap water to give an effective bifenthrin concentration of 1200ppm.

Late afternoon on $26^{\text {th }}$ February 2017 , in overcast conditions, treatments were applied in the plots. In plots \#1 and \#4, one good scoop $(20 \mathrm{~mL})$ of $0.5 \%$ boric acid in polyacrylamide gel was placed at the base of each vine on a plastic strip (Fig 2.15A) and similarly in plots \#6 and \#7, $0.0006 \%$ thiamethoxam in polyacrylamide gel was placed at the base of each vine. In plot \#6, one good scoop of $25 \%$ sucrose and $0.15 \%$ citric acid in polyacrylamide gel was placed at the base of each vine. Bifenthrin was sprayed on the vine trunks of each vine in plot \#2 and \#3. A cardboard 
collar was fitted around the foliage when spraying to shield any citrophilus mealybugs from the spray (Fig. 2.15B).

Since the trial was expected to continue for more than 30 days, a second application of freshly prepared gel treatments ( $0.5 \%$ boric acid and $0.0006 \%$ thiamethoxam) and the gel control $(25 \%$ sucrose and $0.15 \%$ citric acid) was applied 17 days later, on $15^{\text {th }}$ March 2017, after data collection that day. The tenth and final set of data post-treatment was collected on $31^{\text {th }}$ March, 32 days since the initial treatments were administered. The following day ( $1^{\text {st }}$ April), bifenthrin (1200ppm) was liberally sprayed in all the other treatment plots to euthanase all viable Argentine ants before removal of the vines and decommissioning of the research site.
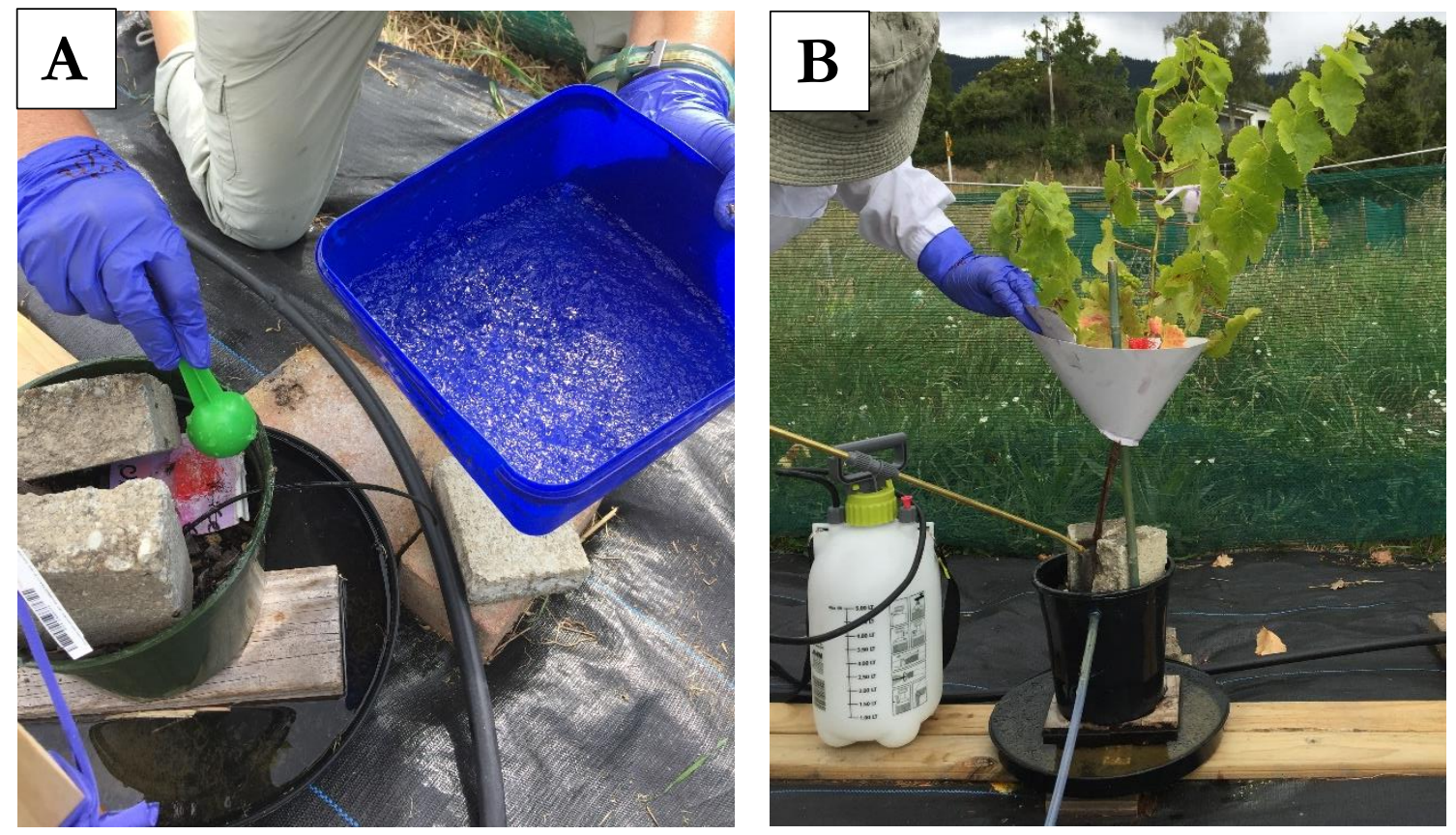

Figure 2.15: Treatment application (A) Boric acid or thiamethoxam in gel matrix (B) Bifenthrin spray application to vine trunks

Source: Chris Hardiman

\subsubsection{Statistical analysis}

Statistical analysis was performed in IBM® SPSS ${ }^{\circledR}$ Statistics 23 (2015). All citrophilus mealybug and Argentine ant repeated measures count data was subjected to Levenes test for equality of error variances using General Linear Model (GLM) univariate analysis. For each insect 
species, significantly different variance of the dependent variable across groups was found, (with Argentine ants, $\mathrm{F}_{4,955}=38.236, \mathrm{p}<0.001$ and for citrophilus mealybugs, $\left.\mathrm{F}_{4,955}=47.333, \mathrm{p}<0.001\right)$ so that classical Analysis of Variance (ANOVA) was not appropriate to use. Instead, Bolker et al. (2009) recommend employing Generalized Linear Mixed Models (GLMMs) analysis of nonnormal count data with non-homogeneity of variance and many zero counts which are not able to be transformed to normality.

To adjust for the non-uniformity of citrophilus mealybug numbers inoculated onto each vine at the start of the experiment, the count data was converted to percentage of baseline activity with time, using the baseline $\left(\mathrm{T}_{0}\right)$ count as the reference point. The Argentine ant counts were likewise converted to percentage of baseline activity. Treatment and control percentage of baseline activity for each insect species was analysed by GLMM for significance about its' means using a tweedie probability distribution with a log link function in the model. Plots of percentage of baseline insect activity with time were generated using Microsoft Excel 2016.

Irrigation was programmed to turn on between $1700 \mathrm{hrs}$ and $1720 \mathrm{hrs}$ on Monday, Wednesday, Friday and Saturday of each week. Data collection coincided with irrigation days on two of the five pre-treatment occasions $\left(20^{\text {th }}\right.$ and $25^{\text {th }}$ March $)$ and seven of the ten post-treatment days $\left(27^{\text {th }}\right.$ February $1^{\text {st }}, 5^{\text {th }}, 15^{\text {th }}, 20^{\text {th }}, 22^{\text {nd }}$ and $31^{\text {st }}$ March 2017$)$. To ascertain whether ant counts on vine parts were affected by irrigation coming on either before or during data collection in plots, General Linear Model (GLM) univariate analysis of variances was conducted.

\subsection{Results}

\subsubsection{Linepithema humile biomass}

The Argentine ant nest biomass in the nest box in the centre of each plot had been established before they were connected to the vines in each plot and the intention was to weigh the nest boxes again at the end of the experiment and determine any change in total biomass. However, the day after the nest boxes had been connected to the vines of each plot, I realised that quite a significant 
number of the ants had been able to escape by getting out of the holes at the base of the vine pot container and either tracking up onto the irrigation whisker or the PVC tubing where it joined the pot container. This was immediately remediated by smearing Tanglefoot ${ }^{\circledR}$ on those critical points. The initial biomass weights were therefore irrelevant and to augment the remaining Argentine ant population in each plot, I dug up more Argentine ants and extracted them into glass tubes to disperse in each plot. Once the plots were secured against future breakouts, the whole setup worked very well. From the time that I installed the nest boxes, it became apparent that the ants preferred to take up residence in the potting mix at the base of the vines so that gauging an accurate change in biomass was never going to be a simple matter. Whenever the irrigation was on, ants could be seen feverishly evacuating larvae and queens from the damp potting mix and conveying them along the PVC tubing back to the dry nest box in the centre of the plot. Presumably they conveyed them back to the potting mix at the base of the vines over the ensuing hours as this was observed quite frequently.

\subsubsection{Linepithema humile response to ant toxin vine treatments}

There were significant differences in the percentage of baseline Argentine ant activity on vines in plots treated with the various ant toxins. The most dramatic effect was with bifenthrin sprayed on the vine trunks where the percentage of baseline ant activity fell to $8.33 \%$ (Fig. 2.16A) within the first $24 \mathrm{hrs}$ of treatment and live ant counts on each of the 8 vines in the two replicate plots fell to zero thereafter. For the bifenthrin treatments, the Argentine ant percentage of baseline activity significantly declined to $9.85 \% \pm 6.00 \%$ on average (GLMM: $\left.\chi^{2}=15.922 ; d f=1 ; p<0.001\right)$ while percentage of baseline ant activity increased by half to $149.90 \% \pm 46.202 \%$ on average for the control vines. Compared with the control vines, there was an overall average percentage of baseline ant activity of $6.6 \%$ for ants on the bifenthrin treated vines (Table 2.1 ). For the boric acid and thiamethoxam treatments, each applied in a gel matrix at the base of the vines, average percentage of baseline ant activity steadily increased with time (Fig. 2.16B). There was no significant difference in percentage of baseline ant activity between the gel treatments and the 
control gel. For boric acid, average percentage of baseline ant activity was $97.02 \% \pm 15.63 \%$ $\left(\right.$ GLMM: $\left.\chi^{2}=2.197 ; d f=1 ; p=0.138\right)$ and for thiamethoxam $104.83 \% \pm 16.56 \%$ (GLMM: $\chi^{2}=$ $1.301 ; d f=1 ; p=0.254)($ Table 2.1).

Table 2.1: Summary of GLMM statistical analysis for the effect on L. bumile percentage of baseline activity in response to spraying vine trunks with bifenthrin compared with applying boric acid or thiamethoxam in gel to the base of potted grapevines in plots at the Nelson field site. The parameter $\operatorname{Exp}(\beta)$ is the exponentiated log-rate ratio $\beta$ and compares the treatment ant activity with the control ant activity.

\begin{tabular}{|c|c|c|c|c|c|c|c|c|c|}
\hline \multicolumn{4}{|c|}{ Estimated Marginal Means } & \multirow[b]{2}{*}{$\boldsymbol{\beta}$} & \multirow[b]{2}{*}{$\begin{array}{l}\text { Std. } \\
\text { Error }\end{array}$} & \multicolumn{3}{|c|}{ Hypothesis Test } & \multirow[b]{2}{*}{$\operatorname{Exp}(B)$} \\
\hline $\begin{array}{l}\text { Plot treatment } \\
\text { or control }\end{array}$ & $\mathbf{n}$ & $\begin{array}{c}\text { Mean \% } \\
\text { of } \\
\text { baseline } \\
\text { AA } \\
\text { activity }\end{array}$ & $\begin{array}{l}\text { Std. } \\
\text { Error }\end{array}$ & & & $\begin{array}{l}\text { Wald Chi } \\
\text { Square }\end{array}$ & df & $p$ & \\
\hline (intercept) & & & & 4.900 & 0.1485 & 1088.156 & 1 & 0.000 & 134.247 \\
\hline Boric Acid & 11 & 97.02 & 15.629 & -0.325 & 0.2191 & 2.197 & 1 & 0.138 & 0.723 \\
\hline Control gel & 11 & 134.25 & 19.940 & $-4.26 \mathrm{E}-16$ & 0.2101 & 0.000 & 1 & 1.000 & 1.000 \\
\hline Thiamethoxam & 11 & 104.83 & 16.564 & -0.247 & 0.2169 & 1.301 & 1 & 0.254 & 0.781 \\
\hline Control (gel) & 11 & 134.25 & 19.940 & 0 & & . & . & . & 1 \\
\hline (intercept) & & & & 5.010 & 0.3082 & 264.232 & 1 & 0.000 & 149.904 \\
\hline Bifenthrin & 11 & 9.85 & 5.995 & -2.723 & 0.6824 & 15.922 & 1 & 0.000 & 0.066 \\
\hline Control & 11 & 149.90 & 46.202 & 0 & & . & & . & 1 \\
\hline
\end{tabular}



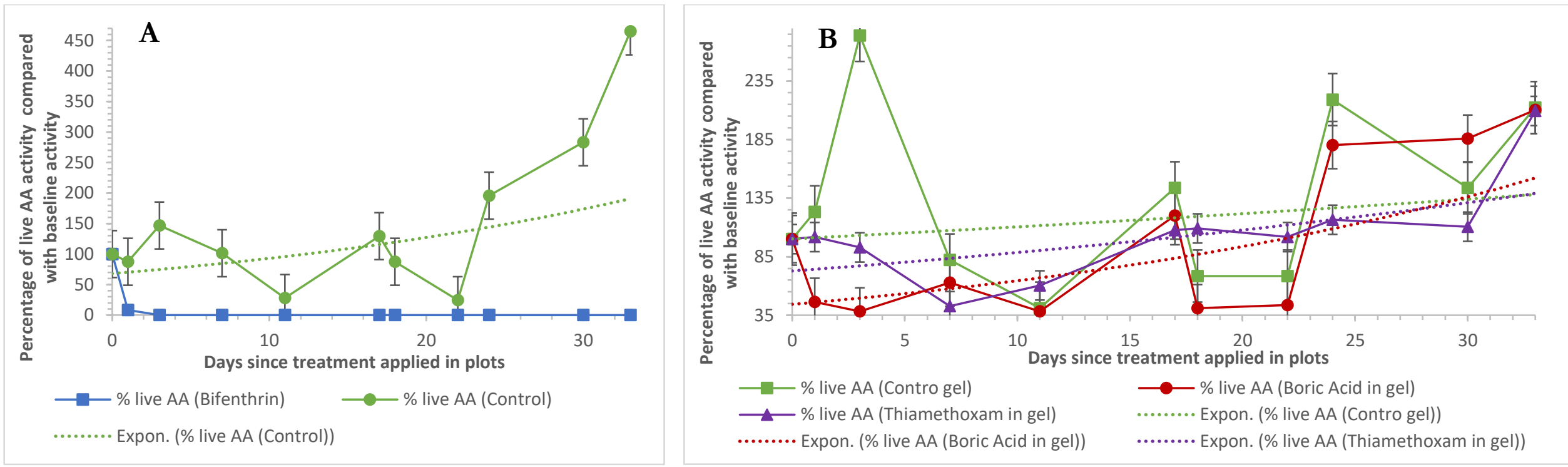

Figure 2.16: Mean percentage of baseline activity ( \pm SEM) of Argentine ants $(A A)$ on vine parts in plots treated with (A) bifenthrin sprayed on vine trunks (B) thiamethoxam or boric acid in gel applied at the base of vines. One-minute counts of ants in vine parts per vine in each treatment and control plot for each monitoring day were converted to a percentage of baseline $\left(T_{0}\right)$ counts. There were five pre-treatment monitoring days between 16th -25 th February 2017 where $\mathrm{n}=80$ for each treatment and $\mathrm{n}=40$ for the control or control gel plot. Post-treatment ant counts were recorded on ten separate days from February 27th -31 st March 2017 where $\mathrm{n}=16$ for each treatment and $\mathrm{n}=8$ for each control or control gel plot. On 15th March (day 17), after monitoring for that day, a second boric acid and thiamethoxam treatment was placed at the base of each vine 


\subsubsection{Pseudococcus calceolariae reponse to ant toxin vine treatments}

There were significant differences in mean percentage of baseline citrophilus mealybug activity rates among the treatments compared with the controls. In plots where vines had been treated with either thiamethoxam or boric acid in gel, the citrophilus mealybug percentage of baseline activity rates recovered to baseline levels by the conclusion of the experiment (Figure 2.17B) but compared with the control gel plot, the mean percentage of baseline activity were significantly different. For thiamethoxam, (GLMM: 99.24\% $\pm 16.45 \% ; \chi^{2}=14.636 ; d f=1 ; p<$ $0.001)$ and for boric acid (GLMM: $\left.53.26 \% \pm 10.32 \% ; \chi^{2}=37.209 ; d f=1 ; p<0.001\right)$ but for control gel the mean percentage of baseline citrophilus mealybug activity rate was $224.91 \% \pm 30.39 \%$ (Table 2.2). However, for citrophilus mealybugs in the bifenthrin treated plots, even though the percentage of baseline activity rate plummeted and never recovered during the experimental period (Figure $2.17 \mathrm{~A})$, compared with the control plot $(33.22 \% \pm 8.99 \%)$ there was no significant difference in the mean percentage of baseline activity rates (GLMM: 29.44\% $\pm 8.21 \% ; \chi^{2}=0.097$; $d f=1 ; p=0.756)($ Table 2.2).

Table 2.2: Summary of GLMM statistical analysis for the effect on P. calceolariae percentage of baseline activity in response to spraying vine trunks with bifenthrin compared with applying boric acid or thiamethoxam in gel to the base of potted grapevines in plots at the Nelson field site. The parameter $\operatorname{Exp}(\beta)$ is the exponentiated log-rate ratio $\beta$ and compares the treatment mealybug activity with the control mealybug activity.

\begin{tabular}{|c|c|c|c|c|c|c|c|c|c|}
\hline \multicolumn{4}{|c|}{ Estimated Marginal Means } & \multirow[b]{2}{*}{$\beta$} & \multirow[b]{2}{*}{$\begin{array}{l}\text { Std. } \\
\text { Error }\end{array}$} & \multicolumn{3}{|c|}{ Hypothesis Test } & \multirow[b]{2}{*}{$\operatorname{Exp}(B)$} \\
\hline $\begin{array}{l}\text { Plot treatment } \\
\text { or control }\end{array}$ & $\mathbf{n}$ & $\begin{array}{c}\text { Mean \% } \\
\text { of } \\
\text { baseline } \\
\text { CMB } \\
\text { activity }\end{array}$ & $\begin{array}{l}\text { Std. } \\
\text { Error }\end{array}$ & & & $\begin{array}{c}\text { Wald } \\
\text { Chi- } \\
\text { Square }\end{array}$ & df & $p$ & \\
\hline (intercept) & & & & 5.416 & 0.1351 & 1606.77 & 1 & 0.000 & 224.906 \\
\hline Thiamethoxam & 11 & 99.24 & 16.451 & -0.818 & 0.2139 & 14.636 & 1 & 0.000 & 0.441 \\
\hline Control (gel) & 11 & 224.91 & 30.386 & $1.25 \mathrm{E}-16$ & 0.1911 & 0.000 & 1 & 1.000 & 1.000 \\
\hline Boric Acid & 11 & 53.26 & 10.315 & -1.440 & 0.2361 & 37.209 & 1 & 0.000 & 0.237 \\
\hline Control gel & 11 & 224.91 & 30.386 & 0 & & & . & . & 1 \\
\hline (intercept) & & & & 3.593 & 0.2707 & 167.534 & 1 & 0.000 & 33.224 \\
\hline Bifenthrin & 11 & 29.44 & 8.213 & -0.121 & 0.3887 & 0.097 & 1 & 0.756 & 0.886 \\
\hline Control & 11 & 33.22 & 8.992 & 0 & & & . & . & 1 \\
\hline
\end{tabular}



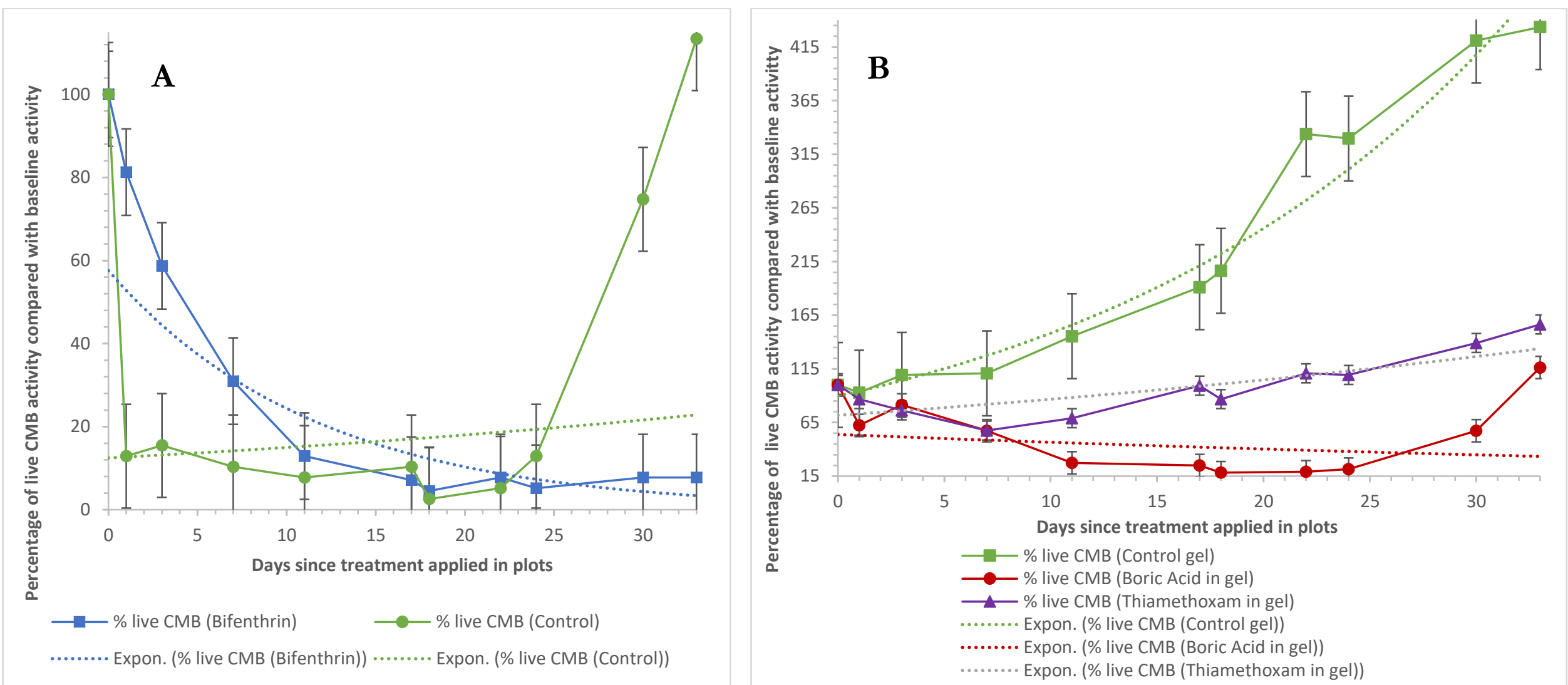

Figure 2.17: Mean percentage of baseline activity $( \pm S E M)$ of citrophilus mealybugs $(C M B)$ on vine parts in plots treated with (A) bifenthrin sprayed on vine trunks (B) thiamethoxam or boric acid in gel applied at the base of vines. One-minute counts of mealybugs in vine parts per vine in each treatment and control plot for each monitoring day were converted to a percentage of baseline $\left(T_{0}\right)$ counts. There were five pre-treatment monitoring days between 16th -25 th February 2017 where $n=80$ for each treatment and $\mathrm{n}=40$ for the control or control gel plot. Post-treatment mealybug counts were recorded on ten separate days from February 27th -31 st March 2017 where $n=16$ for each treatment and $n=8$ for each control or control gel plot. On 15th March (day 17), after monitoring for that day, a second boric acid and thiamethoxam treatment was placed at the base of each vine. 


\subsubsection{L. humile and $P$. calceolariae response to vine treatments}

In plots where vine trunks had been sprayed with bifenthrin, there was a sustained decline in both Argentine ant and citrophilus mealybug percentage of baseline activity rates (Figure 2.18A). In contrast, for the boric acid gel vine treatment, there was a two-fold increase in Argentine ant percentage of baseline activity and citrophilus mealybugs recovered to just above the percentage baseline level of activity by the end of the trial (Figure 2.18B). For the vines treated with thiamethoxam in gel, Argentine ant and citrophilus mealybug percentage of baseline activity steadily increased at a similar rate (Figure 2.18C) to nearly two-fold by the end of the trial.

\subsubsection{Effect on ant counts when irrigation days coincided with data collection days} Irrigation was programmed to turn on between $1700 \mathrm{hrs}$ and $1720 \mathrm{hrs}$ on Monday, Wednesday, Friday and Saturday of each week. Data collection coincided with irrigation days on two of the five pre-treatment occasions and seven of the ten post-treatment days. To ascertain whether ant counts on vine parts in a one-minute interval were affected by irrigation coming on either before or during data collection in plots, GLM univariate analysis of variances was conducted using "plot number" for the fixed factor, "time period" and "irrigation day" as the random factors and "monitoring day number" as the covariate. Irrigation day and "time period" did not affect the mean Argentine ant counts in plots (GLM: $\mathrm{F}=1.074 ; \mathrm{df}=10 ; p=0.379$ ). 

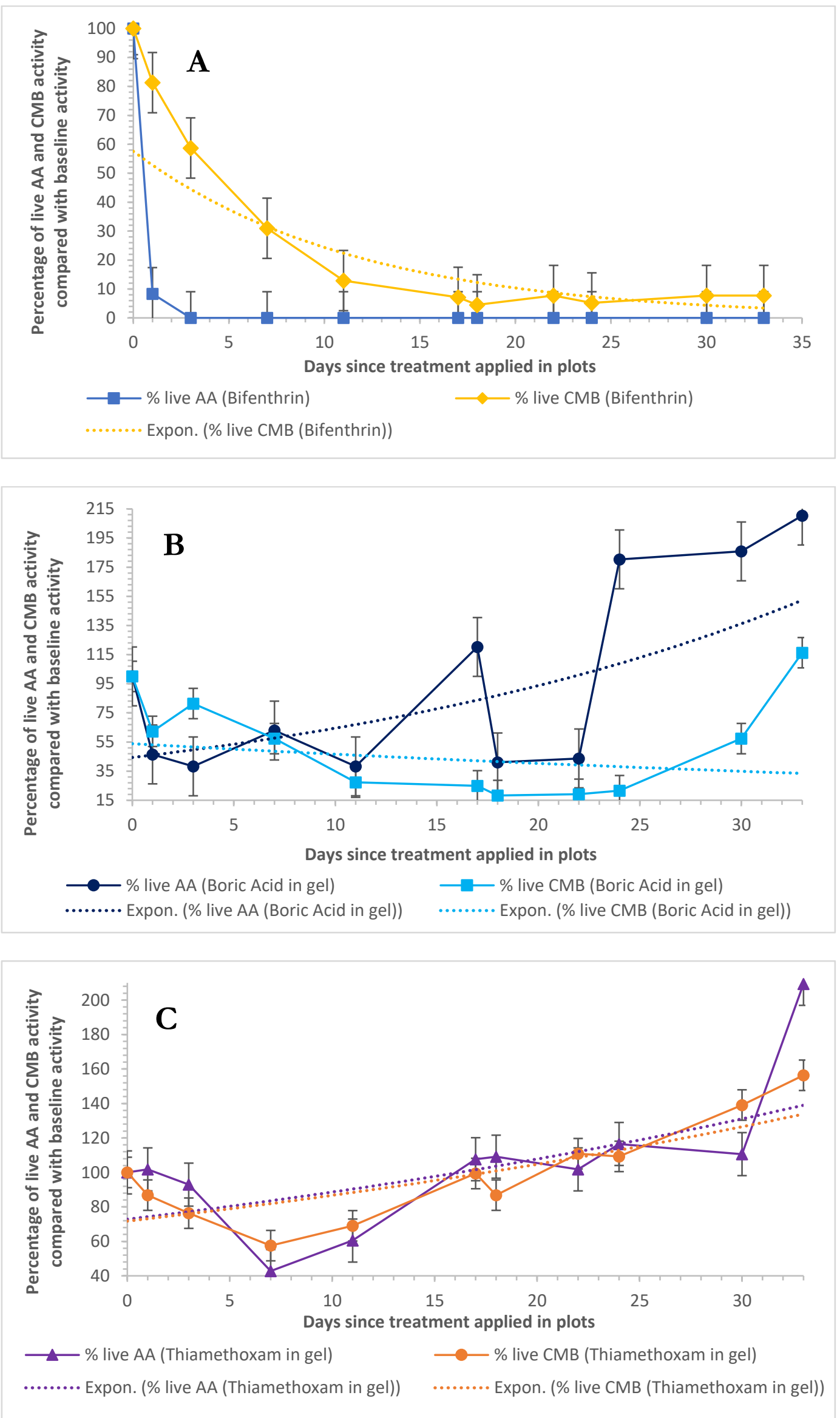

Figure 2.18: L. bumile and P. calceolariae response to vine treatments (A) bifenthrin (B) boric acid (C) thiamethoxam 


\subsection{Discussion}

The main objective of this study was to identify which of the three treatments trialled at the Nelson field site was the most effective for controlling Argentine ants in the canopy of potted grapevines which had been populated with inoculated citrophilus mealybugs and to see whether there was a concomitant reduction in mealybug numbers. The secondary objective was to assess the performance of the polyacrylamide gel bait format in the field.

Originally, I had planned to trial six ant toxin treatments. Three of these, thiamethoxam (in hydrogel) and bifenthrin and indoxacarb (each sprayed on vine trunks) would be suitable for conventionally managed vineyards. The other three, boric acid (in hydrogel), the Argentine ant trail pheromone (Z) - 9- hexadecanal (impregnated rope) and diatomaceous earth (DE) (fashioned into balls with $25 \%$ sucrose solution) would be suitable or organic/biodynamically managed vineyards. However, a month into establishing my field site at another rural property which had enough flat land area for more than a dozen plots, I became aware of council restrictions which would preclude me from bringing a containment pest like Argentine ants onto a property which did not already have an established Argentine ant population. Hence, I was confronted with having to find an alternative site and only three of the six proposed treatments were trialled.

Ideally it would have been more satisfactory to have had more "control" plots to compare with the bifenthrin treatment and more "control gel" plots to compare with the boric acid and thiamethoxam in gel treatments if more land area was available for them. With the benefit of hindsight, perhaps even three treatments were ambitious as the land area available was not sufficient for optimal replication of treatments or controls. This was particularly evident with the "control" plot used to compare the bifenthrin treated plots. Even though ant activity was relatively high in each control plot, for the "control" plot which was compared to the bifenthrin treatments, mealybug counts fell dramatically (Fig. 2.17A) and only recovered beyond the baseline level in the last week of the trial. From the outset, compared with the other plots, the mealybug count in the 
"control" plot was lower, and it appeared that the inoculation of citrophilus mealybugs onto the vines in this outside plot was not as successful. Some mealybugs could also have been blown off the vines in the windy conditions at the site too or been predated upon by natural predators such as ladybirds which were seen occasionally in the canopy of vines in this and other plots.

Of the three treatments trialled, bifenthrin (1200ppm) sprayed on vine trunks showed the most dramatic and sustained reduction in Argentine ant activity (Fig. 2.16A) compared with either the boric acid $(0.5 \%)$ or thiamethoxam $(0.0006 \%)$ in polyacrylamide gel matrix (Fig. 2.16B), despite a second application of the latter treatments 17 days after the initial treatment. In plots treated with bifenthrin, by the conclusion of the trial, mealybug activity had plummeted to $8 \%$ of baseline activity (Fig. 2.18A), but mealybug activity had increased for the boric acid treatment (Fig. 2.18B) by $20 \%$ and for the thiamethoxam treatment (Fig. 2.18C), by 55\%. Ant activity for the hydrogel bait treatments had doubled by the conclusion of the trial (Fig. 2.16B). Biff Ant ${ }^{\circledR}$ (bifenthrin) is resistant to light-medium rainfall, remains active for many weeks and is not repellent to Argentine ants, (Toft, 2011). When sprayed on the vine trunks, the Argentine ants would have unwittingly walked over the insecticide and transferred its lethal effects to nestmates, resulting in the dramatic decline in ant activity. The concomitant decline in plot mealybug numbers could have been because they were vulnerable to predation by their natural enemies in the absence of protection afforded them by the ants, or the mealybug decline could also be due to a horizontal transfer of bifenthrin by the ants whilst tending them for honeydew.

The lack of efficacy by thiamethoxam in polyacrylamide gel to significantly reduce Argentine ant activity was surprising, since thiamethoxam, at the same concentration of $0.0006 \%$ (in $25 \%$ sucrose) and carried in polyacrylamide gel, was successful in reducing Argentine ant densities by $78 \%$ initially in a coastal Southern Californian conservation reserve and by $99 \%$ four months later using four monthly applications of the bait (Boser et al., 2014). In a Western Cape commercial plum orchard in South Africa, $0.0007 \%$ thiamethoxam (in 25\% sucrose) and also in polyacrylamide 
gel, effectively reduced Argentine ant densities by 94\% $\pm 2 \%$ within 14 days (Buczkowski, Roper, Chin, et al., 2014).

Abiotic conditions at the field site could have contributed to the hydrogels not performing as expected. At the Nelson site, when the Argentine ant nest boxes were first installed in the centre of each plot and before the vines were inoculated with citrophilus mealybugs, a scoop of $25 \%$ sucrose solution and $0.15 \%$ citric acid in polyacrylamide gel was placed at the base of each vine every few days to provide a carbohydrate food source for the ants and to condition them to the medium that the bait would be carried in. On the first treatment occasion, at 6 o'clock in the evening, thiamethoxam and boric acid hydrogel baits were placed at the vine bases in overcast conditions and $20^{\circ} \mathrm{C}$, but a very windy night ensued. Seventeen days later, after $6 \mathrm{pm}$ in the evening, the second dose was applied in fine and calm conditions and $19^{\circ} \mathrm{C}$. The summer of $2016 / 2017$ in Nelson was characterized by atypical windy conditions which could have had a desiccating effect on the polyacrylamide gel matrix, therefore making it less attractive to the ants.

In laboratory based studies, Rust et al. (2015) found that once hydrogel baits lost $50 \%$ of their moisture, they became less attractive to ants but that higher relative humidity prolonged hydrogel bait attractiveness. They also found that at 33\% R.H. the time taken for $50 \%$ desiccation of hydrated polyacrylamide crystals to occur varied according to the solute concentration they had been conditioned in, so that deionised water took 19.94hours, $25 \%$ sucrose solution $(12.32 \mathrm{~h})$ and $25 \%$ sucrose solution $+0.000015 \%$ thiamethoxam $(9.74 \mathrm{~h})$. In laboratory conditions $\left(25^{\circ} \pm 2^{\circ} \mathrm{C}\right.$; $60 \pm 10 \%$ R.H; 14:10h D:L), Buczkowski, Roper, \& Chin (2014) reported that polyacrylamide crystals conditioned in $25 \%$ sucrose and $0.0007 \%$ thiamethoxam bait lost $70 \%$ of their mass in the first eight hours but appreciably less thereafter and were attractive to Argentine ants in the first 24 hours resulting in the death of all castes and life stages of L. bumile within about 6 days. Hence, given the more windy than usual conditions in Nelson this last summer, the hydrogel baits could have desiccated more rapidly before Argentine workers had extracted sufficient bait from them to 
ensure extermination of all castes and life stages in nests present in the potting mix of vine containers and in the central nest boxes in the plots. In similar laboratory conditions to Buczkowski, Roper and Chin (2014), Silverman \& Roulston (2001) demonstrated that in choice assays, more worker Argentine ants preferred to forage on 25\% sucrose hydrogel than $25 \%$ sucrose liquid but that despite workers feeding for eight times longer on the gel, they consumed five times less sucrose than ants feeding on the $25 \%$ sucrose solution.

In a laboratory based study, Reierson, Rust, \& Hampton-Beesley (1998), established that on average, foraging Argentine ants consumed about $0.3 \mathrm{mg}$ of $50 \%$ sugar water (nearly their body mass) each visit to the feeding station, which equates to about 3300 ant visits for every gram of sugar water consumed. In a Californian coastal vineyard with high Argentine ant density, $>30 \mathrm{~g}$ of $25 \%$ sugar water, equivalent to 100,000 ant visits, had been removed per day from monitoring tubes placed 26m apart, so that without frequent replenishment of toxic baits, the efficacy of lowtoxicity bait deployment in areas with high Argentine ant density could be limited (Daane et al., 2006). At the start of the Nelson trial, each plot was provisioned with a nest box that contained on average about 7,000 individuals, (based on the mass of one Argentine worker being about $0.43 \mathrm{mg}$ ), which over the 8 vines in each plot equated to about 900 ants, (including queens and larvae) between each vine and the nest box. At the Nelson site, the Argentine ants were contained within each plot and burgeoning in population. Considering the findings of Daane et al. (2006), it is conceivable that with high densities of Argentine ants residing in the potting mix of vine containers within each plot, workers were unable to imbibe sufficient low-toxicity doses of either boric acid or thiamethoxam to poison all nest inhabitants. Taking into consideration also the windy conditions at the site which would exacerbate polyacrylamide gel desiccation and loss of bait appeal for the ants, then this could in some part explain how the boric acid and thiamethoxam low-toxicity gel baits failed to suppress Argentine ant populations in those treatment plots. 
The correct formulation of liquid baits can be challenging, since the concentration of active ingredient must be sufficiently high enough to effect ant mortality, yet low enough to ensure delayed toxicity of one to four days to maximise the spread of toxicant throughout the colony and still remain attractive to foraging ants (Cooper et al., 2008). Low-toxicity liquid baits, containing boric acid $(0.5 \%)$ and thiamethoxam $(0.0001 \%)$ in $25 \%$ sucrose solution have been trialled in South African and Californian coastal vineyards (Daane et al., 2006; Nelson \& Daane, 2007; Nyamukondiwa \& Addison, 2011). Rust, Reierson, \& Klotz (2004) found that for boric acid in $25 \%$ sucrose solution to have a delayed toxic effect, a concentration of at least $0.55 \%$ was required and for thiamethoxam, the concentration ranged from $0.00002 \%-0.0003 \%$. In the field though, Rust et al. (2015) found that for thiamethoxam to have an impact on the entire nest, the concentration needed to be at least $0.0006 \%$ to allow for toxicant dilution due to trophallaxis.

The ratio of polyacrylamide crystals added to liquid bait could also affect its' performance in the field. At the Nelson field site, I added 15g of polyacrylamide gel crystals to one litre of liquid bait but after the fact I became aware that Buczkowski, Roper, Chin, Mothapo, \& Wossler (2014) added $20 \mathrm{~g}$ of polyacrylamide gel crystals to one litre of $0.0007 \%$ thiamethoxam bait deployed at the base of plum trees in a commercial orchard targeting Argentine ants. By adding one third more hydrogel crystals per litre of bait used at the Nelson site, the bait mounds at the base of vines would have been more perky and therefore less likely to flow outwards and expose more surface area to premature desiccation. I placed baited hydrogels on a strip of plastic at the base of vines, but Buczkowski, Roper, Chin, Mothapo, \& Wossler (2014) showed that there was no significant difference in the percentage of water lost from the hydrogel baits whether they were placed directly on the ground or on a plastic base.

A high-density deployment $\left(521 \mathrm{Ha}^{-1}\right)$ of the low-toxicity baits in the polyacrylamide gel matrix for the suppression of Argentine ant activity early in the season is cost-effective. Based on $20 \mathrm{~g}$ of hydrogel crystals added to one litre of $25 \%$ sucrose and $0.15 \%$ citric acid solution, the cost 
per $20 \mathrm{~mL}$ dose of bait for $0.55 \%$ boric acid is $3.6 \varnothing$ and $4.5 \phi$ for $0.0006 \%$ thiamethoxam. An early season deployment of baits at a density of 521 baits per hectare would cost $\$ 18.75 \mathrm{Ha}^{-1}$ for the $0.55 \%$ boric acid treatment and $\$ 23.45 \mathrm{Ha}^{-1}$ for $0.0006 \%$ thiamethoxam when $20 \mathrm{~mL}$ of bait is placed at the base of the first post of every bay ( $8 \mathrm{~m}$ apart), of every row spaced $2.4 \mathrm{~m}$ apart. The treatment would need to be repeated seven days later in order to achieve similar results to Buczkowski, Roper, Chin, Mothapo, \& Wossler (2014) baiting with 0.0007\% thiamethoxam and recording a reduction in Argentine ant activity of $94 \pm 2 \%$ after two weeks.

The bifenthrin treatment compared with the hydrogel treatments is not as cost effective to administer. Bifenthrin (1200ppm) sprayed in a $10 \mathrm{~cm}$ band on vine trunks above the irrigation conduit using a backpack spray unit with a ring sprayer attachment as depicted in Addison (2002) and delivering $50 \mathrm{~mL}$ per vine, would cost $7.9 \phi$ per vine to dose. For a vineyard with an average vine density of 2,604 vines per hectare (based on $2.4 \mathrm{~m}$ row spacing and $1.6 \mathrm{~m}$ vine spacing), the cost per hectare for Argentine ant control, would be $\$ 206$. However, given the findings of this thesis, there would be a two for the price of one cost benefit since mealybug populations would also be impacted. Alternatively, bifenthrin could be sprayed in Argentine ant hotspots in the vineyard and since it is non-repellent to ants and the residual effect of bifenthrin can be seen for up to two months (Toft, 2011), only one treatment would be required during the growing season.

Based on the parameters mentioned above, chemical inputs per hectare and per square meter for each of the three treatments would be (1) $0.0006 \%$ thiamethoxam, $62.5 \mathrm{mg} \mathrm{Ha}^{-1}$ or $6.25 \times 10^{-3}$ $\mathrm{mg} \mathrm{m} \mathrm{m}^{-2}$; (2) $0.55 \%$ boric acid, $57.30 \mathrm{~g} \mathrm{Ha}^{-1}$ or $5.73 \mathrm{mg} \mathrm{m}^{-2}$; (3) $1200 \mathrm{ppm}$ bifenthrin, $156.24 \mathrm{~g} \mathrm{Ha}^{-1}$ or $15.62 \mathrm{mg} \mathrm{m}^{-2}$. The minimal chemical inputs per hectare for the low-toxicity liquid baits, thiamethoxam and boric acid in hydrogel, (and to a lesser extent, bifenthrin sprayed on vine trunks) would meet the requirements of sustainable farming practices (Daane et al., 2006) and be consistent with the values of Sustainable Winegrowing New Zealand (SWNZ). Given the low chemical inputs of boric acid and thiamethoxam per hectare, it would be worthwhile trialling these 
toxins again in the hydrogel format in an actual vineyard. Boric acid is a slow-acting inorganic insecticide (Cochran, 1995) so would be suitable for organic or biodynamically certified vineyards in conjunction with IPM. The thiamethoxam and bifenthrin treatments would be suitable for use in conventionally managed vineyards but their compatibility with IPM would be contingent upon establishing whether beneficials were directly affected by them.

\subsection{Conclusion}

Bifenthrin (1200ppm) sprayed on vine trunks was most effective at suppressing ant activity and indirectly mealybug activity. More work needs to be done to establish whether ants transfer the toxicant bifenthrin to vine mealybugs whilst tending them and whether beneficial insects in the vine canopy acquire any toxic effect from bifenthrin via interactions with either ants or mealybugs. Should bifenthrin be shown not to have any negative impact on beneficial insects in the vine canopy, then it would be suitable to be used in conjunction with an IPM program targeting problem ants in vineyards. The thiamethoxam and boric acid treatments in the hydrogel format are cost effective and convenient to administer in discreet piles but proved here not to be as effective as anticipated perhaps due to abiotic conditions at the field site or because the correct ratio of polyacrylamide crystals to liquid bait for the conditions was not achieved. 


\section{Chapter 3: Toxic effect of bifenthrin on non-target Pseudococcus calceolariae: Is bifenthrin transferred horizontally from Linepithema humile to non-target species $P$. calceolariae?}

\subsection{Abstract}

Horizontal toxicity occurs within ant species mediated by social interactions such as trophallaxis, but inter-specific horizontal transfer of toxicants may be possible between ants and other pest insect species with which they form mutualisms. In the vine canopy, the invasive Argentine ant, Linepithema bumile is known to form a trophobiotic relationship with the vine mealybug, Psendococcus calceolariae, providing protection from its natural enemies in exchange for the honeydew it excretes. In the absence of $P$. calceolaria's natural enemies, a bioassay was performed to establish whether the concomitant reduction seen in the citrophilus mealybug populations in the previous experiment targeting Argentine ants with bifenthrin, could instead be attributed to horizontal toxicity acquired by the homopterans whilst being tended by Argentine ants. In a mealybug-excluded zone, Argentine ants were exposed to either bifenthrin or water in a separate environment and then connected to a forage arena containing a piece of sprouted potato supporting a colony of citrophilus mealybugs. Bifenthrin or water was directly sprayed on potato pieces colonised by citrophilus mealybugs as a control to observe mealy bug survival in the absence of ants. For half of the ant/mealybug treatment and control replicates a blue powdered dye was employed to visually mark any mealybugs tended by ants to gather direct observational data of potential horizontal transfer of toxicant. Pre- and -post-treatment counts of each insect species foraging on the potato in a one-minute time interval were expressed as a percentage of baseline activity and analysed for statistical significance using GLMM. Compared with the water controls, there was a significant decrease in average citrophilus mealybug survival rate $(p<0.001)$ for the control bifenthrin, bifenthrin only and bifenthrin/dye treatments. The study concluded that there is evidence for inter-species horizontal toxicity between the Argentine ants and citrophilus mealybugs. The concept of inter-species horizontal toxicity could become a model for targeted pest management by exploiting different insect mutualisms in various horticultural cropping systems.

Keywords: Inter-species horizontal toxicity, Argentine ant, Linepithema bumile, citrophilus mealybug, Pseudococcus calceolariae, bifenthrin 


\subsection{Introduction}

In New Zealand commercial vineyards, mealybugs, notably Pseudococcus longispinus and P. calceolariae, (Homoptera: Pseudococcidae), are culpable for the transmission of the Ampelovirus GLRaV-3 as they feed and travel from grapevine to grapevine and the ensuing leafroll disease has deleterious effects on vine health and ultimately wine quality (N. Douglas \& Krüger, 2008; Lo et al., 2009; Maree et al., 2013; Martelli et al., 2002; Petersen \& Charles, 1997). The invasive Argentine ant, Linepithema bumile, is one of several ant species known to form a trophobiotic relationship with the honeydew excreting homopterans; enhancing their populations in Californian citrus groves as well as in the vine canopies of South African and Californian vineyards where they disrupt mealybug biological control by interfering with the activities of the mealybug's natural enemies (Daane et al., 2007; Markin, 1970; Mgocheki \& Addison, 2009b).

Various stem barrier treatments targeting ants (including L. humile) have been employed effectively in vineyards and citrus groves including the organophosphates chlorpyrifos and terbufos and the pyrethroid $\alpha$-cypermethrin (Addison, 2002; James, Stevens, \& O’Malley, 1998; Klotz et al., 2003). Non-repellent contact insecticides allow the insect species to acquire the toxicant without detecting it and then transfer it horizontally to other fit nestmates (Neoh, Yeoh, \& Lee, 2014; Rust, Reierson, \& Klotz, 2003; Shelton \& Grace, 2003).

Horizontal toxicity, or transfer of toxicant by ants to other ants in the colony can occur in a number of ways such as via trophallaxis; cooperative grooming; ant-to-ant tarsal or antennal contact by workers along foraging and recruitment trails; necrophoric behaviour whereby ant corpses are removed to discreet refuse piles after ants have died either in or near the nest, or, horizontal toxicity can occur when the toxicant is transferred passively by contaminated ants to food and water resources or other substrates (Choe \& Rust, 2008; Soeprono \& Rust, 2004; Wiltz, Suiter, \& Gardner, 2010). 
Bifenthrin is used by urban pest management personnel as a barrier treatment around homes, hospitals, nursing facilities and in electrical casing, targeting termites and ants including the invasive ant species L. bumile and Solenopsis invicta (Choe \& Rust, 2008; Klotz, Rust, Costa, \& Reierson, 2002; Neoh et al., 2014; Pranschke, Hooper-Bùi, \& Moser, 2003). Bifenthrin (Fig. 3.1) is a synthetic pyrethrin belonging to the pyrethroid family and has a neurotoxic effect on insects which come in contact with it (Johnson, Luukinen, Gervais, Buhl, \& Stone, 2010).

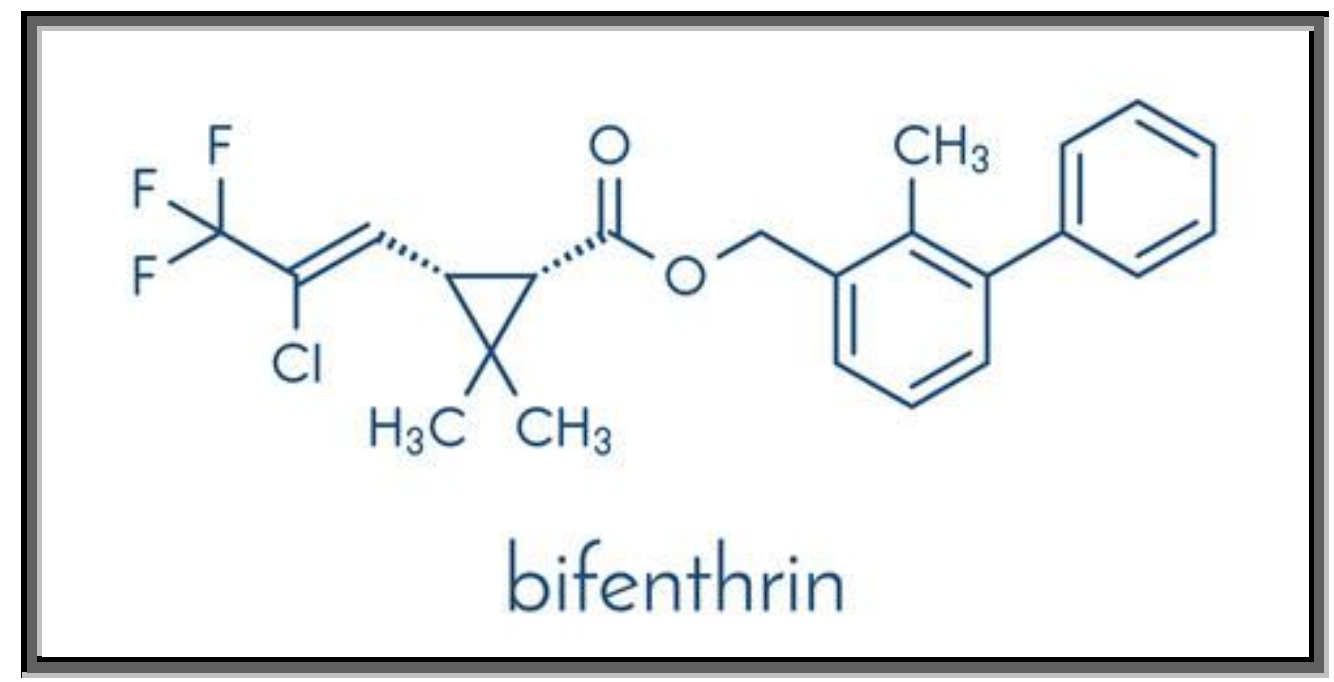

Figure 3.1: Bifenthrin molecule

Source: https://t4.ftcdn.net/jpg/01/69/21/31/240 F 169213109 nPrJnfoq63lvYd9xtIgSbycxiYZTcMmG.jpg

Biff Ant ${ }^{\circledR}$ (bifenthrin A.I.), is a new surface treatment formulated to be non-repellent to Argentine ants and other pest ants in urban areas, resistant to light-medium rain and have residual activity for up to three months (Toft, 2011). This was one of three products trialled at the Nelson field site the previous summer $(2016 / 2017)$ and it displayed the greatest efficacy for controlling Argentine ants in the canopy of potted grapevines when the product (bifenthrin 1200ppm) was sprayed on vine trunks. A dramatic and sustained decline in the populations of vine inoculated citrophilus mealybugs in plots treated with bifenthrin was also observed. This could have been accounted for because in the absence of the Argentine ants to protect them from their natural enemies recruited to the vines, the citrophilus mealybugs were being predated upon. Or perhaps inter-species horizontal toxicity was occurring while the ants were tending the mealybugs for their 
honeydew and in this way the toxin was transferred to the mealybug or contaminated the green vine parts that they fed on.

Here the results of a laboratory-based study conducted at Mt. Albert Plant and Food Research during April/May 2017 are reported in which Argentine ants, in a mealybug-excluded zone, were exposed to bifenthrin sprayed on the base of their nest box, at the recommended field rate of 1200ppm for targeting Argentine ants, then given access to a container housing citrophilus mealybugs which had colonised a piece of sprouted potato. For half of the bifenthrin treatments and water controls, a blue powdered dye was flicked on the base of the nest boxes prior to the nest box bases being sprayed with either bifenthrin or water, so that a visual mark would be left on any mealybugs with which the ants had had contact.

Within the confines of a laboratory-based study, it is hypothesised that in the absence of $P$. calceolaria's natural enemies, any decline in mealybug survival with time could in part be due to the horizontal transfer of the bifenthrin toxicant to P. calceolariae by L. humile whilst tending them or because the Argentine ants have contaminated the potato substrate on which the mealybugs move and feed. The discovery of any deceased, dye-marked mealybugs should corroborate evidence for the horizontal transfer of the toxicant by the ants to mealybugs whilst tending them.

\subsection{Materials and methods}

\subsubsection{Ant colony collection and extraction}

Nest material of the invasive Argentine ant species L. bumile was dug up from a rural location in Auckland $\left(-36.9158^{\circ}, 174.6119^{\circ}\right)$ on 17 April 2017 and transferred to a high sided plastic bin. The bin interior had been coated with Fluon (Chemours Insect-A-Slip PTFE DIS30) and its upper rim liberally smeared with Tanglefoot ${ }^{\circledR}$ to prevent the ants from escaping.

Argentine ants were extracted from the collection bin to successive receival nest boxes using a contained setup involving a water bath under each plastic container and with detergent added to the water to break surface tension. The interior of the plastic nest boxes $(21 \times 19 \times 13 \mathrm{~cm})$ were 
coated with Fluon and contained two foil covered test tubes each half filled with water and plugged with cotton wool. The upper rim of each nest box was smeared with Tanglefoot ${ }^{\circledR}$. Inert clear PVC tubing ( $8 \mathrm{~mm}$ i.d.) connecting the collection bin to the nest box provided a conduit for ant evacuation when water was dripped from the tap at an approximate rate of one drop per second (Fig 3.2).

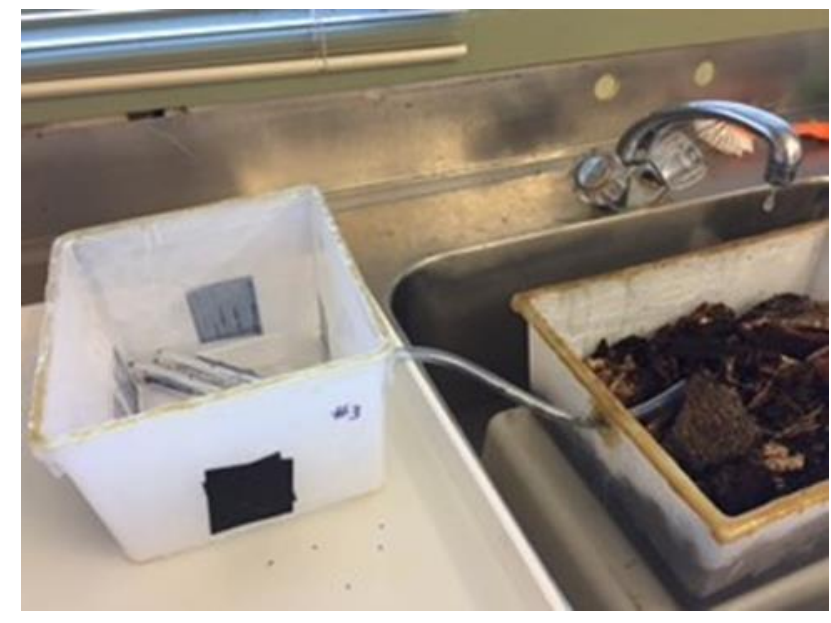

Figure 3.2: Ant extraction set-up Source: Catherine Hardiman

Each nest box was weighed on a top pan electronic balance (Denver Instrument; Model TP2102; $\mathrm{d}=0.01 \mathrm{~g}$ ) before and after ant transfer to establish the mass of worker ants, larvae and (winged) queens collected (Appendix B). The average mass of ants in each nest box was estimated to be equivalent to about 1500 individuals based on the mass of one Argentine worker ant being about $0.43 \mathrm{mg}$.

Prior to the start of the experiment, ants in each nest box were feed three times a week with $20 \%$ honey water soaked in a cotton ball and once a week with half a teaspoon of flaked tuna in spring water. 


\subsubsection{Vine mealybug colony}

Colonies of the vine mealybug P. calceolariae reared at Mt. Albert Plant and Food Research had been inoculated onto sprouted Agria potatoes, transferred to racks inside ventilated plastic Sistema "click-clack" containers and then stowed in a Skope incubator maintained at $21-22^{\circ} \mathrm{C}$ (Figure 3.3).
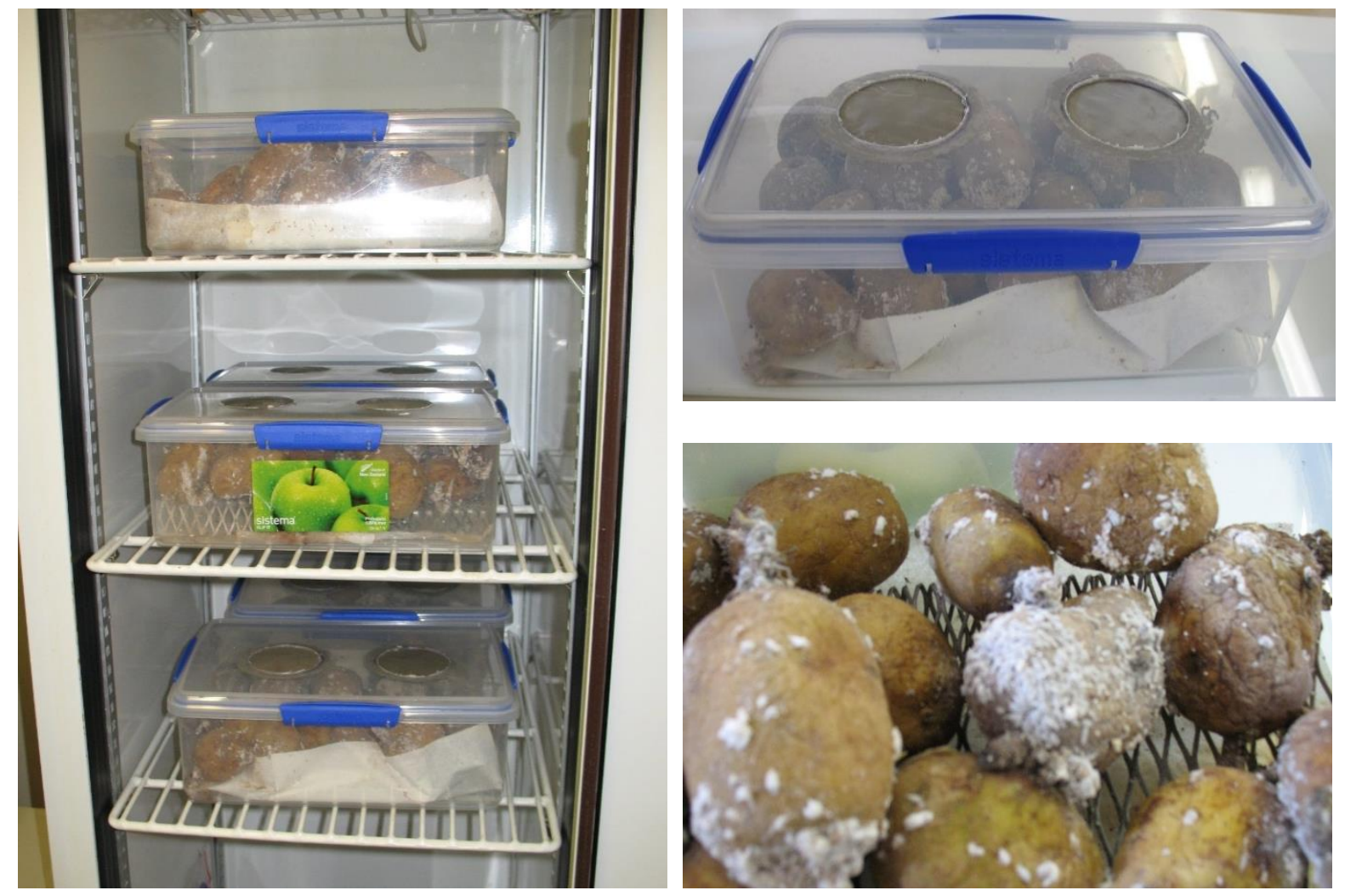

Figure 3.3: P. calceolariae rearing at Mt. Albert Plant and Food Research Source: Vicky Davis

Ten nest boxes were each connected via an $18 \mathrm{~cm}$ length of inert clear PVC tubing ( $8 \mathrm{~mm}$ i.d.) to Fluon coated plastic containers of similar dimensions and with Tanglefoot ${ }^{\circledR}$ applied to the upper rim. Each pair of containers was set on a plastic tray with detergenated water covering the base (Fig. 3.4). A small section of spouted potato approximately $6 \mathrm{~cm}^{3}$ and supporting about $11-$ 44 citrophilus mealybugs on each was placed in the container connected to the nest box. The number of individual citrophilus mealybugs on each potato substrate was retained and not made homogenous to avert physical damage to the colony during extrication. Instead, any variation in baseline counts was to be accounted for in the way data was treated. A splinter of wood was placed 
against the ends of the tubing on either side to provide a bridge for the ants to access both containers.
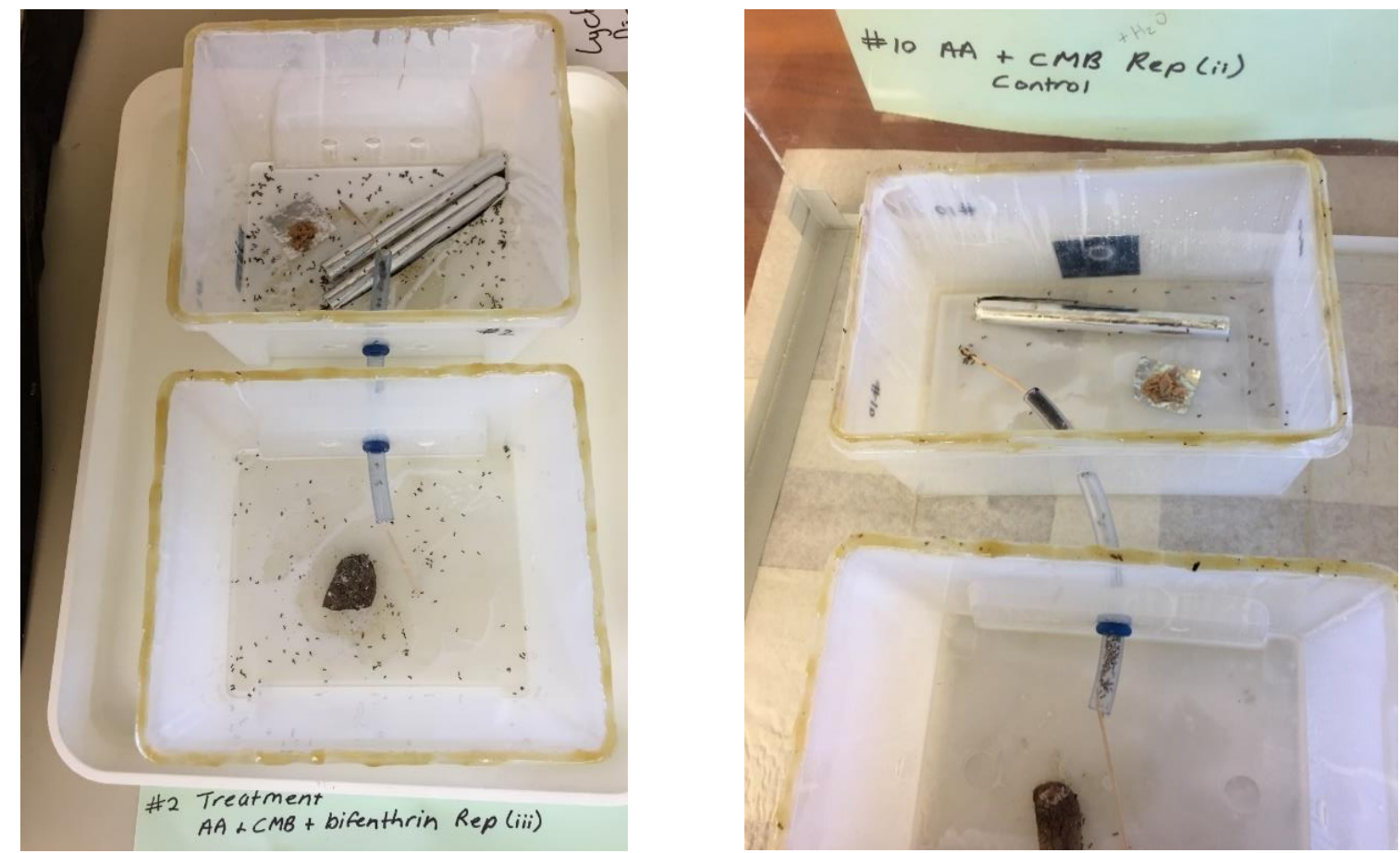

Figure 3.4: Experimental set-up showing ant nest box connected to container holding potato section supporting P. calceolariae

Source: Catherine Hardiman

Four plastic "click-clack" containers which each had a mesh covered hole in the lid for ventilation (Fig. 3.5) were designated to be "no ants" treatment and controls. Into each of these a piece of spouted potato was also placed. All insect colonies were maintained in the laboratory at $20 \pm 1^{\circ} \mathrm{C}$ with a $12: 12$ (L:D) hour photoperiod and $65 \%$ R.H.
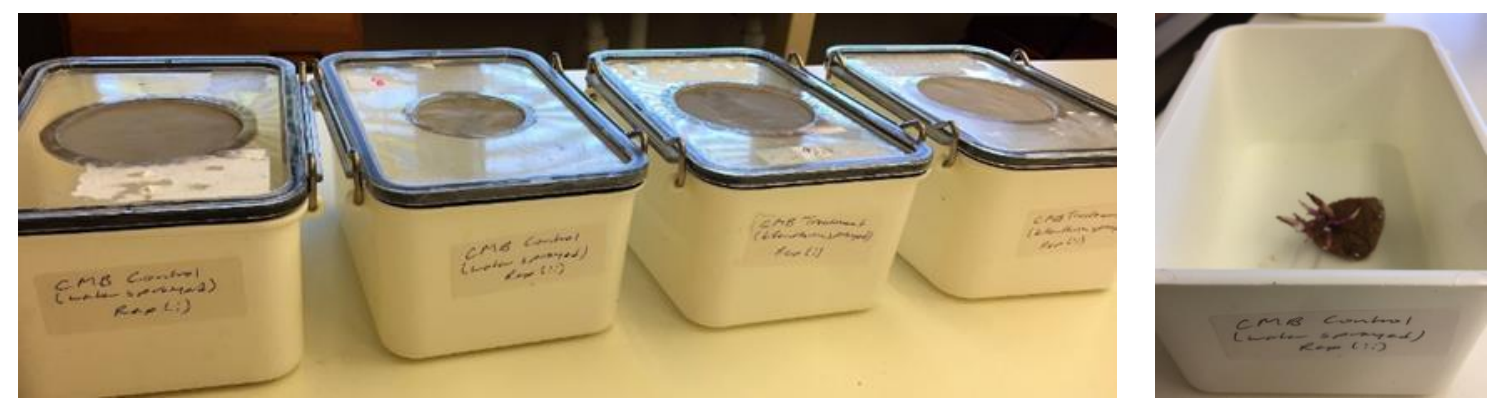

Figure 3.5: "No ants" treatment and control containers bearing potato section supporting $P$. calceolariae Source: Catherine Hardiman 


\subsubsection{Baseline monitoring and treatment assignment}

Three times per day, the number of Argentine ants foraging on the piece of potato and the number of live citrophilus mealybugs counted on the piece of potato in a one- minute time interval was recorded using a clicker counter and an electronic timer, for each container bearing a mealybug populated potato. All containers housing the cryptic P. calceolaria were covered (Fig.3.6) while the mealybugs were not being enumerated least they retreated from sight to the underside of the section of potato.
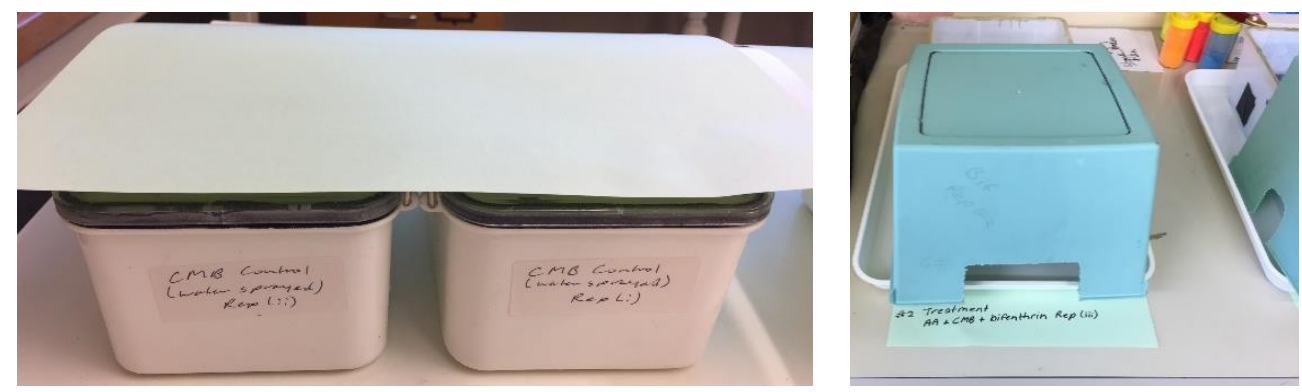

Figure 3.6: Covered containers housing citrophilus mealybugs Source: Catherine Hardiman

Three "bifenthrin/dye" and three "bifenthrin only" treatments together with two "water/dye" and two "water only" controls were randomly assigned to the ten nest boxes using a non-replacement ballot system. Likewise, with the four "no ants" containers, two were assigned as "water only" controls and the other two as "bifenthrin" treatments.

\subsubsection{Treatment preparation and application}

Key Industries 'Biff Ant ${ }^{\mathrm{TM}}$ suspension was diluted to an effective bifenthrin concentration of $1200 \mathrm{ppm}$ by drawing up $1.5 \mathrm{~mL}$ (micropipette) and adding it to $100 \mathrm{ml}$ of tap water in a $125 \mathrm{~mL}$ spray bottle. Early evening on 1 May 2017, bifenthrin was sprayed directly onto the base of the nest boxes of the three "bifenthrin only" treatments and directly onto the potato of each of the two "no ants" treatments. Water was sprayed directly onto the nest box bases of the two "water only" controls and directly onto the potato of each of the two "no ants" controls. 
For the dye treatments and controls, a dry paint brush was used to flick a layer of DayGlo® Horizon Blue ${ }^{\mathrm{TM}}$ Pigment (A-19) onto the base of the three treatment and two control nest boxes. The purpose of the blue powdered dye was to be visual confirmation of ants having physical contact with mealybugs. Bifenthrin was then sprayed over the layer of blue powdered dye in the treatment nest boxes and water was sprayed over the dye in the two control nest boxes (Fig.3.7).

Prior to any of the treatment applications, tuna on foil pieces were removed and replaced with fresh tuna afterwards.
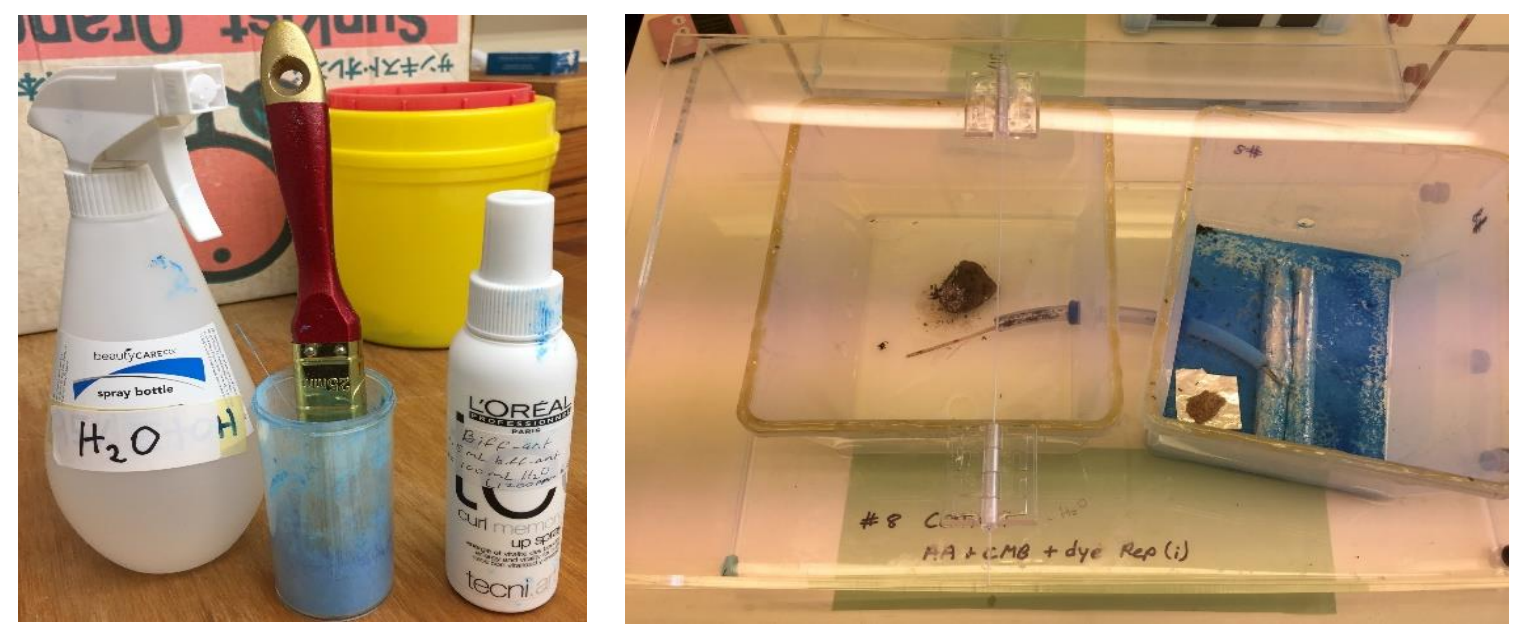

Figure 3.7: Application of blue powdered dye and bifenthrin to base of ant nest boxes Source: Catherine Hardiman

\subsubsection{Ant and mealybug monitoring}

Post-treatment, on average twice a day, both insect species were counted on the potato pieces in a one-minute time interval. The citrophilus mealybugs and the Argentine ants were enumerated a total of nine and eleven times respectively over a period of eight days until 9th May 2017, when there were no longer any vital signs in any of the bifenthrin treated ant colonies marking the conclusion of the experiment.

\subsubsection{Statistical analysis}

Statistical analysis was performed in IBM ${ }^{\circledR}$ SPSS $®$ Statistics 23 (2015). 
All citrophilus mealybug and Argentine ant repeated measures count data was subjected to Levene's test for equality of error variances. For each insect species, significantly different variance of the dependent variable across groups was found, (with citrophilus mealybugs, $\mathrm{F}_{5,162}=8.787, p$ $<0.001$ and for Argentine ants, $\left.F_{3,136}=17.853, p<0.001\right)$ so that classical Analysis of Variance (ANOVA) was not appropriate to use. Instead, Bolker et al. (2009) recommend employing Generalized Linear Mixed Models (GLMMs) analysis of non-normal count data with nonhomogeneity of variance and many zero counts which are not able to be transformed to normality.

To adjust for the non-uniformity of citrophilus mealybug numbers on each section of potato at the start of the experiment, the count data was converted to percentage of baseline activity with time, using the baseline count as the reference point. The Argentine ant counts were likewise converted to percentage of baseline activity data. Treatment and control percentage of baseline activity data for each insect species was analysed by GLMM for significance about its' means using a tweedie probability distribution with a $\log$ link function in the model. Plots of insect survival percentage with time were generated using Microsoft Excel 2016.

\subsection{Results}

\subsubsection{Effect of bifenthrin treatments on P. calceolariae}

When bifenthrin or water was sprayed directly onto the spouted potato sections supporting citrophilus mealybug as with the "no ants" bifenthrin treatments and the "no ants" water controls, there was a dramatic initial decline in the percentage of baseline mealybug activity for the bifenthrin treatment compared with the control (Fig.3.8). In the first two days, percentage of baseline activity fell from $100 \%$ to $40 \%$ on the treated potato sections. There was a significantly lower percentage of baseline mealybug activity (GLMM: $\left.\chi^{2}=12.193 ; d f=1 ; p<0.001\right)$ with the treatment $(38.88 \%$ $\pm 5.39 \%)$ compared with the control $(73.46 \% \pm 8.9 \%)$. Overall, for mealybugs on potatoes directly sprayed with bifenthrin there was $52.9 \%$ of the baseline activity (Table 3.1). 


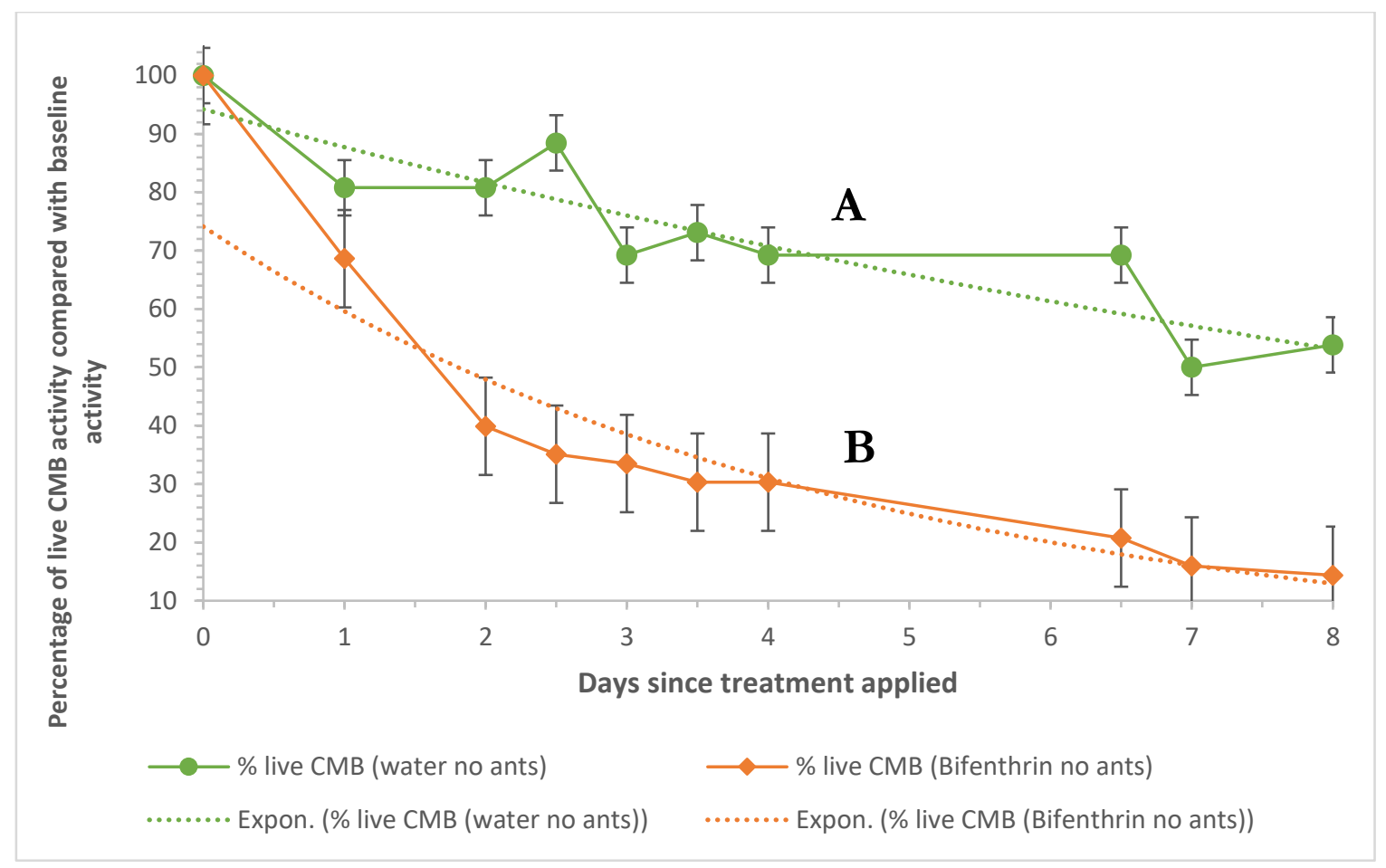

Figure 3.8: Mean percentage activity ( \pm SEM) of citrophilus mealybugs (CMB) on potato section sprayed directly with (A) water and (B) bifenthrin. There were three pre-treatment monitoring occasions on 1st May 2017 where $\mathrm{n}=6$ for the control and $\mathrm{n}=6$ for the treatment. Post-treatment mealybug counts were recorded on nine separate occasions on 2nd, 3rd, 4th, 5th, 8th and 9th May 2017 where $\mathrm{n}=18$ for the control and $n=18$ for the treatment. One-minute counts of live mealybugs on the potato section of the "no ants" controls and "no ants" treatments each monitoring occasion were converted to a percentage of baseline $\left(\mathrm{T}_{0}\right)$ counts. Missing data points between day 4 and day 6 correspond with the weekend. 
Table 3.1: Summary of GLMM statistical analysis for the effect on P. calceolariae percentage of baseline activity in response to directly spraying water or bifenthrin on potato sections supporting citrophilus mealybugs (no ants) and spraying water or bifenthrin in the base of ant nest boxes. The parameter $\operatorname{Exp}(\beta)$ is the exponentiated log-rate ratio $\beta$ and compares the treatment mealybug activity with the control mealybug activity.

\begin{tabular}{|c|c|c|c|c|c|c|c|c|c|}
\hline \multicolumn{4}{|c|}{ Estimated Marginal Means } & \multirow[b]{2}{*}{$\beta$} & \multirow[b]{2}{*}{ Std. Error } & \multicolumn{3}{|c|}{ Hypothesis Test } & \multirow[b]{2}{*}{$\begin{array}{c}\operatorname{Exp}(\beta) \\
\text { Rate ratio } \\
\end{array}$} \\
\hline Parameter & $\mathbf{n}$ & $\begin{array}{r}\text { Mean \% } \\
\text { live CMB }\end{array}$ & Std. Error & & & $\begin{array}{c}\text { Wald Chi- } \\
\text { Square }\end{array}$ & df & $p$ & \\
\hline (intercept) & & & & 4.955 & 0.070 & 5083.078 & 1 & 0.000 & 141.813 \\
\hline Bifenthrin & 10 & 80.93 & 6.471 & -0.561 & 0.106 & 28.040 & 1 & 0.000 & 0.571 \\
\hline Bifenthrin (no ants) & 10 & 38.88 & 3.734 & -1.294 & 0.119 & 119.153 & 1 & 0.000 & 0.274 \\
\hline Bifenthrin/dye & 10 & 109.55 & 8.121 & -0.258 & 0.102 & 6.453 & 1 & 0.011 & 0.773 \\
\hline Control/water & 10 & 118.40 & 9.073 & -0.180 & 0.103 & 3.043 & 1 & 0.081 & 0.835 \\
\hline Control/water (no ants) & 10 & 73.46 & 6.017 & -0.658 & 0.107 & 37.493 & 1 & 0.000 & 0.518 \\
\hline Control/water/dye & 10 & 141.81 & 9.855 & 0 & . & . & . & . & 1 \\
\hline (intercept) & & & & 4.995 & 0.045 & 12001.671 & 1 & 0.000 & 141.813 \\
\hline Bifenthrin & 10 & 80.93 & 4.220 & -0.561 & 0.069 & 66.206 & 1 & 0.000 & 0.571 \\
\hline Bifenthrin/dye & 10 & 109.55 & 5.285 & -0.258 & 0.066 & 15.236 & 1 & 0.000 & 0.773 \\
\hline Control/water & 10 & 118.40 & 5.905 & -0.180 & 0.067 & 7.185 & 1 & 0.007 & 0.835 \\
\hline Control/water/dye & 10 & 141.81 & 6.414 & 0 & . & . & . & . & 1 \\
\hline (intercept) & & & & 4.955 & 0.043 & 13475.231 & 1 & 0.000 & 141.813 \\
\hline Bifenthrin/dye & 10 & 109.55 & 4.987 & -0.258 & 0.062 & 17.106 & 1 & 0.000 & 0.773 \\
\hline Control/water/dye & 10 & 141.81 & 6.052 & 0 & . & . & . & . & 1 \\
\hline (intercept) & & & & 4.774 & 0.053 & 8219.609 & 1 & 0.000 & 118.398 \\
\hline Bifenthrin & 10 & 80.93 & 4.446 & -0.380 & 0.076 & 24.998 & 1 & 0.000 & 0.684 \\
\hline Control/water & 10 & 118.4 & 6.235 & 0 & . & . & . & . & 1 \\
\hline (intercept) & & & & 4.297 & 0.118 & 1320.576 & 1 & 0.000 & 73.462 \\
\hline Bifenthrin (no ants) & 10 & 38.88 & 5.390 & -0.636 & 0.182 & 12.193 & 1 & 0.000 & 0.529 \\
\hline Control/water (no ants) & 10 & 73.46 & 8.686 & 0 & . & & . & . & 1 \\
\hline
\end{tabular}

With the "bifenthrin only" (Fig. 3.9A) and "bifenthrin/dye" (Fig. 3.9B) treatments, where bifenthrin had been sprayed on the base of the ant nest boxes, there was a significantly lower mealybug percentage of baseline activity compared with their control groups. For the "bifenthrin only" treatment (GLMM: $\chi^{2}=24.998 ; d f=1 ; p<0.001$ ), the mean percentage of baseline mealybug activity was $80.93 \% \pm 4.45 \%$ and for the water control, $118.40 \% \pm 6.24 \%$, with an overall treatment percentage of baseline activity of $68.4 \%$ (Table 3.1). The percentage of baseline mealybug activity for the "bifenthrin/dye" treatment was $109.55 \% \pm 4.99 \%$ and $141.81 \% \pm 6.05 \%$ for the water/dye control (GLMM: $\left.\chi^{2}=17.106 ; d f=1 ; p<0.001\right)$, with an overall percentage of baseline mealybug activity of $77.3 \%$ (Table 3.1). 

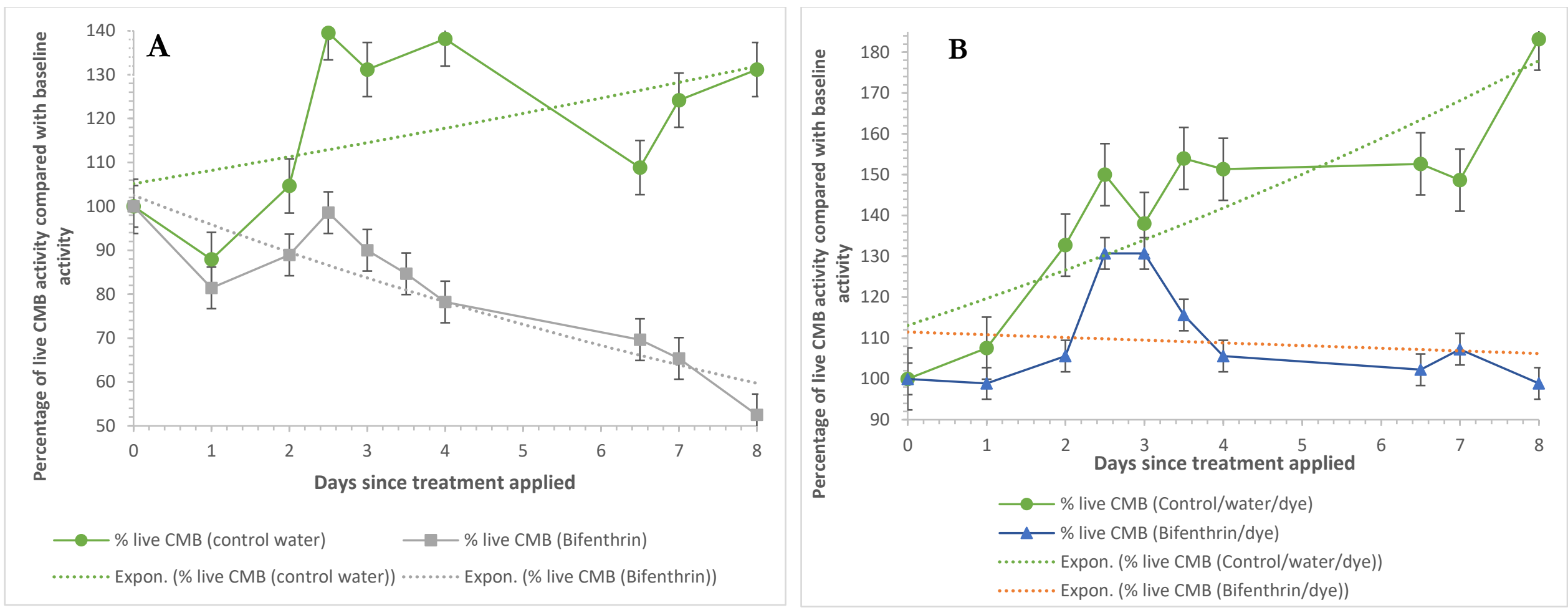

Figure 3.9: Mean percentage of baseline activity $( \pm$ SEM) of citrophilus mealybugs (CMB) on potato sections where (A) bifenthrin was sprayed in the base of the ant nest boxes (B) bifenthrin was sprayed over the top of blue powdered dye in the base of the ant nest boxes. There were three pre-treatment monitoring occasions on 1st May 2017 where $n=6$ for each the controls and $n=9$ for each of the treatments. Post-treatment mealybug counts were recorded on nine separate occasions on 2nd, 3rd, 4th, 5th, 8th and 9th May 2017 where $n=18$ for each of the controls and $n=27$ for each of the treatments. One-minute counts of live mealybugs on the potato sections of the "water only" and "water/dye" controls and "bifenthrin only" and "bifenthrin/dye" treatments each monitoring occasion were converted to a percentage of baseline ( $\left.\mathrm{T}_{0}\right)$ counts. Missing data points between day 4 and day 6 correspond with the weekend 
The percentage of baseline mealybug activity in response to each bifenthrin treatment is compared in Fig. 3.10 below. The decline in percentage of baseline mealybug activity was most pronounced for the bifenthrin "no ants" treatment, followed by the "bifenthrin only" and the bifenthrin/dye treatments. This is reflected in the negative slopes given in Table 3.1 for bifenthrin “no ants" (-1.294 \pm 0.119), "bifenthrin only" (-0.561 \pm 0.106$)$ and bifenthrin/dye (-0.258 \pm 0.102$)$.

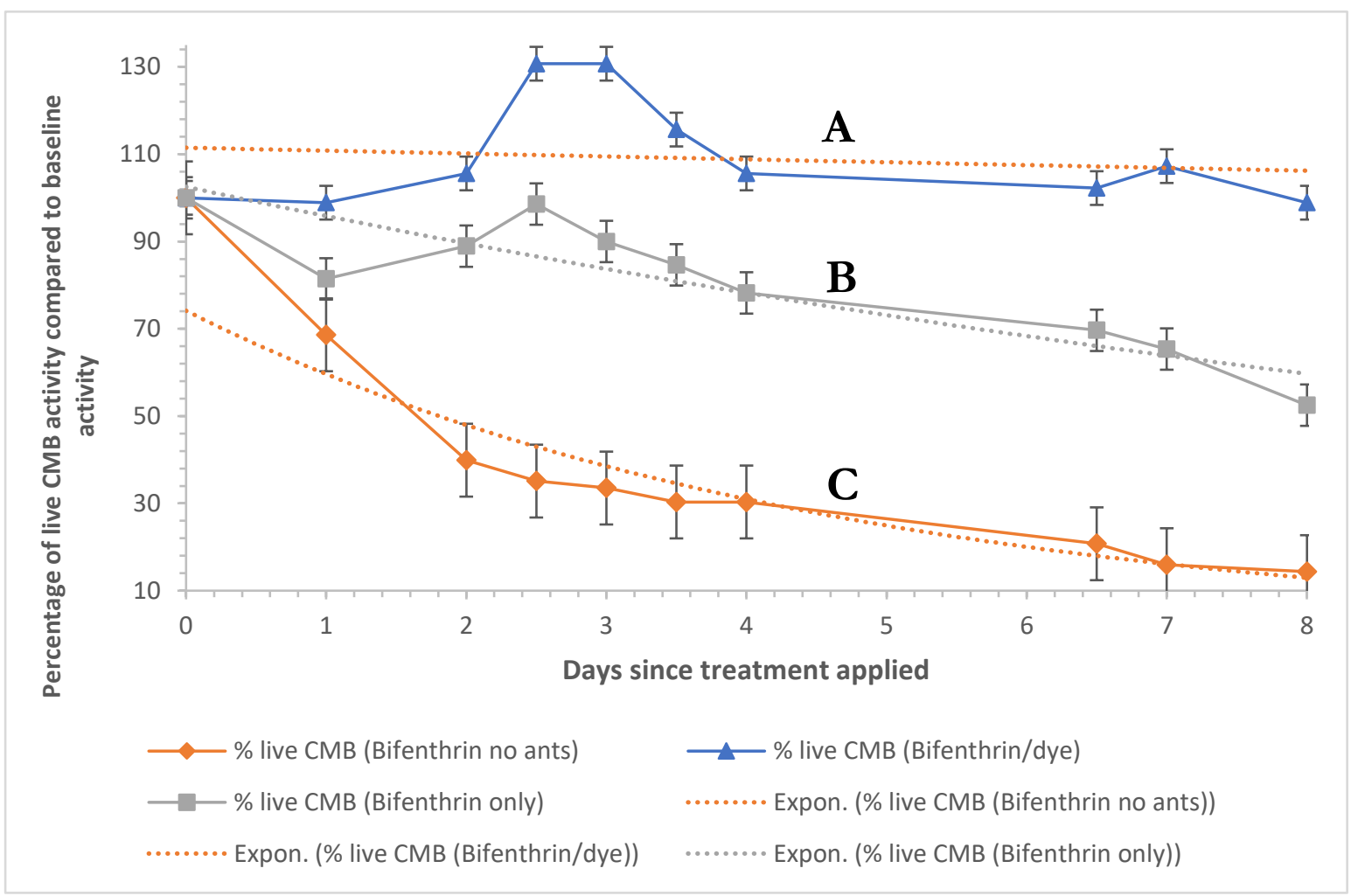

Figure 3.10: Mean percentage of baseline activity ( $(\mathrm{SEM})$ for citrophilus mealybugs (CMB) on potato sections of (A)bifenthrin/dye (B)bifenthrin only and (C) bifenthrin "no ants" treatments. Missing data points between day 4 and day 6 correspond with the weekend

\subsubsection{Effect of bifenthrin on L. humile}

The Argentine ant percentage of baseline activity was significantly different between the control and treatment groups. Bifenthrin (GLMM: $\chi^{2}=35.797 ; d f=1 ; p<0.001$ ) and bifenthrin/dye (GLMM: $\left.\chi^{2}=35.222 ; d f=1 ; p<0.001\right)$ contrasted with the control/water group (GLMM: $\left.\chi^{2}=2.740 ; d f=1 ; p=0.098\right)$ where the percentage of baseline ant activity was not significantly different to the control/water/dye group (Table 3.2). The mean percentage of 
baseline ant activity for the bifenthrin treatment was $(10.15 \% \pm 4.28 \%)$ and $(10.68 \% \pm 4.45 \%)$ for the bifenthrin/dye treatments compared with $100.31 \% \pm 23.85 \%$ for the "water only" control and $169.33 \% \pm 35.33 \%$ for the "water/dye" control groups.

Table 3.2: Summary of GLMM statistical analysis for the effect on L. humile percentage of baseline activity in response to spraying bifenthrin or water in the base of the ant nest boxes. The parameter $\operatorname{Exp}(\beta)$ is the exponentiated log-rate ratio $\beta$ and compares the treatment ant activity with the control ant activity.

\begin{tabular}{|c|c|c|c|c|c|c|c|c|c|}
\hline \multicolumn{4}{|c|}{ Estimated Marginal Means } & \multirow[b]{2}{*}{ B } & \multirow[b]{2}{*}{ Std. Error } & \multicolumn{3}{|c|}{ Hypothesis Test } & \multirow[b]{2}{*}{$\begin{array}{c}\text { Exp (B) } \\
\text { Rate ratio }\end{array}$} \\
\hline Parameter & $\mathbf{n}$ & $\begin{array}{c}\text { Mean \% } \\
\text { live AA }\end{array}$ & Std. Error & & & $\begin{array}{c}\text { Wald Chi- } \\
\text { Square }\end{array}$ & df & $p$ & \\
\hline (intercept) & & & & 5.132 & 0.2086 & 605.088 & 1 & 0.000 & 169.333 \\
\hline Bifenthrin & 12 & 10.15 & 4.278 & -2.815 & 0.4705 & 35.797 & 1 & 0.000 & 0.060 \\
\hline Bifenthrin/dye & 12 & 10.68 & 4.446 & -2.764 & 0.4657 & 35.222 & 1 & 0.000 & 0.063 \\
\hline Control/water & 12 & 100.31 & 23.854 & -0.524 & 0.3163 & 2.740 & 1 & 0.098 & 0.592 \\
\hline Control/water/dye & 12 & 169.33 & 35.327 & 0 & . & . & . & . & 1 \\
\hline
\end{tabular}

\subsubsection{Dye in base of ant nest boxes}

The purpose of the blue powdered dye was to be visual confirmation of ants having physical contact with mealybugs. Blue powered dye had been flicked into the ant nest box bases of the bifenthrin/dye treatments and the water/dye controls before being wetted by either bifenthrin or water in the expectation that mealybugs tended by ants would be marked with the dye. Apart from a blue smudge on the mound of tuna in a couple of the ant nest boxes and a streak of blue in the base of one or more of the containers housing the mealybugs on sprouted potato, no traces of blue dye were found on any mealybugs when inspected with a hand-held magnifying lens.

\subsection{Discussion}

The objective of this bioassay performed in the absence of $P$. calceolariae's natural enemies was to test the hypothesis from a previous experiment that the sustained decline in vine inoculated mealybugs which was observed on the potted vines in plots where the vine trunks had been sprayed with bifenthrin targeting Argentine ants in the vine canopy could in fact be due to horizontal toxicity transferred either directly by the ants during their ministrations of the mealybugs, or indirectly by the ants contaminating vine parts that the mealybugs fed on. It is understood that in 
vineyards, ants protect mealybugs from their natural enemies and in so doing, ensure for themselves an ongoing supply of honeydew excreted by the homopterans (Daane et al., 2007).

With the "no ants" bifenthrin treatment and the "no ants" water control, compared to the "no ants" water control, when bifenthrin was sprayed topically on the mealybugs colonising the piece of potato, there was a dramatic decline in mealybug survival rate in the first two days (Fig. 3.8) suggesting that a proportion of mealybugs had succumbed to the toxic effects of bifenthrin. Topical spraying of the insecticide is more likely to affect first and second instar nymphs since the waxy secretions covering the more mature mealybugs resists wetting and protects them from insecticidal sprays (Furness \& Charles, 1994). Potentially all mealybug life stages on the potato substrate could be affected by bifenthrin sprayed directly on the potato surface as they move about and feed on the potato sprout.

The purpose of the blue powdered dye flicked on the base of treatment and control ant nest boxes prior to being sprayed with either bifenthrin or water was to be visual confirmation of ants having physical contact with mealybugs. However, the idea did not work with a powdered dye. Instead, perhaps a liquid dye which could be carried in either the bifenthrin treatment or the water control could have been used to spray over the base of ant nest boxes and then any dead mealybugs viewed under U.V. light for visual confirmation that their mortality could be attributed to the Argentine ants making physical contact with them and transferring the toxin to them. This could be followed up with Gas Chromatography - Mass Spectroscopy (GC - MS) or Liquid Chromatography - MS (LC - MS) to confirm the presence of bifenthrin residues on the dyemarked mealybugs.

The powdered blue dye also seemed to affect ant behaviour. The bifenthrin treatments had been applied early in the evening and the following morning there was appreciably more ant activity in the water only and water/dye controls compared with the bifenthrin only and bifenthrin/dye treatments. However, compared with the water only controls, there was a noticeable difference in 
ant behaviour in the controls where blue dye had been flicked in the nest box bases before spraying with water. With the water only controls, upon sensing that their immediate foraging area had become somewhat damp, worker Argentine ants began evacuating the nest from the foil covered glass tubes housing it and carried nestmates into the clear PVC tubing connecting the ant nest box with the container housing the mealybugs supported on the piece of potato. Instead of evacuating their fellow nestmates in like manner, worker Argentine ants in the water/dye control nest boxes could be seen sitting on top of the foil covered tubes trying to divest themselves of the blue dye particles. With reference to Table 3.1 and Figure 3.10, if Argentine worker ants in the bifenthrin/dye treatments behaved in like manner to the ants in the water/dye control, then this could possibly account for the higher average percentage of baseline citrophilus mealybug activity of $109.55 \%$ for the bifenthrin/dye treatment compared with $80.93 \%$ for the bifenthrin only treatment. Post-treatment, compared with worker Argentine ants in the bifenthrin/dye control, Argentine ants in the bifenthrin only treatment would have spent more time interacting with mealybugs on the sprouted piece of potato and therefore would have had opportunity to transfer the toxicant by either direct contact or by contaminating the potato subtract before succumbing to the toxic effects of bifenthrin.

The presence of winged queens affected ant behaviour too. For example, with one of the "control/water/dye" replicates, a queen was observed on the sprouted potato. This caused a spike in ant activity until the queen could be coaxed off the potato sprout and back into the connection tube (where the ants had taken refuge since water was sprayed in the base of the nest box) between the ant nest box and the mealybug motel. This spike is evident in Table 3.2 where average ant activity for the "control/water/dye" is $70 \%$ more than for the "control/water".

Intra-specific horizontal toxicity or transfer of toxicant by ants to other ants within the colony has been demonstrated, mediated by such ant social behaviours as cooperative grooming and trophallaxis, necrophoresis or passive contamination by ants transferring toxicant to shared food 
and water resources or other substrates (Choe \& Rust, 2008; Soeprono \& Rust, 2004; Wiltz et al., 2010). However, in the absence of $P$. calceolariae's natural enemies, the significant decline in mealybug survival can only be accounted for by either the Argentine ants, which had previously been exposed to bifenthrin, directly transferring the target substance to the mealybugs whilst tending them, or because the mealybug have acquired the target substance passively by moving about and feeding on the sprouted potato substrate which had become contaminated with bifenthrin by the ants. Taken together, there appears to be evidence for the occurrence of interspecific horizontal toxicity from the Argentine ants and citrophilus mealybugs.

Relating to the Nelson field site ant toxin trial, I hypothesised that mealybug mortality was the result of horizontal transfer of the target substance bifenthrin from live Argentine ants to citrophilus mealybugs whilst tending them and not because in the absence of ants to protect them, they were vulnerable to the predation of their natural enemies in the vine canopy. If my hypothesis is correct, then this could spawn a novel approach to the management of these insect pests in viticultural and in other horticultural systems. Argentine ants have been reported in association with various other honeydew excreting hemipteran insects on a number of other crops including citrus, pipfruit, stone fruit, tamarillo and tomatoes (Lester et al., 2003). However, the concept of a live insect donor delivering a lethal dose of a toxicant to the target pest insect species with which it shares a mutualism, could become a model for pest management in other horticultural systems.

Where an ant-hemipteran mutualism exists on a crop, the toxicant sprayed on a vine/tree trunk would need to be non-repellent to the ants conveying the toxicant to the target species and at a concentration that facilitates delayed toxicity if the ants are physiologically affected by the toxicant as well. Ideally though, in such a system, the toxicant would be a contact insecticide with a mode of action which affects the target species only and not the species conveying it. Perhaps the mode of action could be something like impairment of lipid biosynthesis so that the target species is prone to desiccation resulting from leaky membranes. Considerable work would need to be done 
around establishing the minimal amount of toxicant required to affect the greatest mortality rate of the target pest species. Ideally the toxicant would be chemically and environmentally stable to guarantee season long persistence requiring minimal chemical inputs and the toxicant would not have a negative impact on beneficials. Spraying the toxicants directly onto vine trunks or tree trunks as opposed to a broadcast spray regime would limit chemical inputs in the farming system and therefore be more sustainable.

For an ant-mealybug mutualism in a viticultural system, this would entail spraying a contact insecticide onto vine trunks which is both non-toxic and non-repellent to ants. The ants would then seek out (and destroy) the target cryptic insect pest in the vine canopy and deliver the toxicant while tending them for honeydew exudate. Targeting mealybugs in this way would augment the period during the growing season for mealybug chemical control in ant / mealybug hotspots within the vineyard. Once mealybug populations were reduced, chemical control of ants could be achieved by distributing low-toxicity liquid baits in a polyacrylamide gel throughout the vineyard.

\subsection{Conclusion}

There is evidence for inter-species horizontal toxicity occurring between the ants and the mealybugs in the experimental setup. Where Argentine ants had either been subjected to the bifenthrin/dye treatment or the bifenthrin only treatment, despite the absence of $P$. calceolariae's natural enemies, the average citrophilus mealybug survival rate was significantly less than for the corresponding water only and water/dye control, suggesting that there is evidence to support the hypothesis that mealybug mortality may be attributed to horizontal toxicity. This may provide an innovative approach to pest management strategies and may offer opportunities to develop substances which do not affect the donor species but can be delivered to target pests through a vector insect species such as tending ants. The concept of inter-species horizontal toxicity has so much potential, considering all the various permutations of insect mutualisms on various crops 
that could be exploited in different horticultural systems and could become a model for targeted pest management. 


\section{Chapter 4: General Discussion}

\subsection{Summary}

In recent years, incursions of the invasive Argentine ant, Linepithema bumile, have been reported in commercial vineyards in Gisborne and the Gimblett Gravels winegrowing appellation of Hawke's Bay and now in Nelson (Charles, Bell, Lo, Cole, \& Chhagan, 2010; Westermann, Bell, Suckling, \& Lester, 2016; Westermann, Bell, Suckling, \& Lester, 2016). Argentine ants are highly social unicolonial insects which can displace native ant species when worker densities exceed native ant species, enabling them to discover food resources and recruit to them more quickly so that they soon monopolize the resources in an entire habitat (Chen \& Nonacs, 2000; Holway, 1998a). In the vine canopy, Argentine ants form a mutualistic relationship with mealybugs, protecting them from their natural predators in exchange for honeydew exudate (Mgocheki \& Addison, 2009b).

Mealybugs, being phloem feeders, vector Grapevine Leafroll-associated Virus 3 (GLRaV-3) as they feed and travel, from one vine to the next (Charles et al., 2006b; N. Douglas \& Krüger, 2008). Virused vines exhibiting the leafroll disease symptoms typically have lower grape yields; juice with diminished flavour, sugar levels and $\mathrm{pH}$ together with raised acidity, leading to a reduction in wine quality (Charles et al., 2006a; Maree et al., 2013; Naidu et al., 2014). The economic losses associated with a vineyard which has reached a $100 \%$ GLRaV-3 infection rate has been estimated at about $\$ 57,000$ per hectare (New Zealand Winegrowers, 2015).

Currently in New Zealand vineyards, the deployment of the low-toxicity bait, $0.5 \%$ boric acid in $25 \%$ sucrose solution dispensed in $50 \mathrm{~mL}$ containers and replenished monthly until harvest is recommended by Reid (2010), but there are no chemical insecticidal sprays targeting ants in vineyards featured in the New Zealand Winegrowers Export Wine Grape Spray Schedule (Fantail Viticulture Consultants, 2012). In this thesis, my overall objective was to identify an effective insecticidal treatment requiring low chemical inputs which targeted Argentine ants in the vine canopy and could be adopted by winegrowers to control this invasive insect species from spreading 
throughout their vineyards, enhancing vine mealybug populations and therefore GLRaV-3 infection rates.

In Chapter two, I found that compared with the low-toxicity liquid baits $(0.5 \%$ boric acid and $0.0006 \%$ thiamethoxam) in polyacrylamide gel, bifenthrin (1200ppm), sprayed on vine trunks, significantly reduced Argentine ant activity on the potted vines to $9.85 \%$ of baseline activity. At the same time there was a dramatic and sustained reduction in citrophilus mealybug activity on vines in plots where bifenthrin had been sprayed on vine trunks. There was no significant decline in Argentine ant or citrophilus mealybug activity on vines treated with either the boric acid or thiamethoxam carried in polyacrylamide gel. It was concluded that the lack of bait attractiveness to the ants for these two treatments was probably the premature desiccation of the hydrogels mitigated by climatic conditions at the field site.

In chapter three, I showed that there was evidence for inter-species horizontal toxicity given the significant decline in the percentage baseline activity for citrophilus mealybug interacting with Argentine ants that had been exposed to the bifenthrin treatments. This supported my hypothesis that the decline in citrophilus mealybug activity observed in plots at the Nelson field site treated with bifenthrin (1200ppm) was not necessarily because they were vulnerable to predation by their natural enemies in the absence of ants to protect them, but that the toxicant bifenthrin was being horizontally transferred to the mealybugs while the ants were tending them for their honeydew exudate or contaminating the substrate which the mealybugs fed on.

\subsection{Synthesis}

Stem barrier treatments including the organophosphates chlorpyrifos and terbufos and the pyrethroid $\alpha$-cypermethrin SC have been successfully trialled in South African vineyards to control ants (including L. bumile) and break their association with vine mealybugs in the vine canopy while at the same time having minimal impact on beneficial insects in the vine canopy (Addison, 2002). Likewise low-toxicity liquid baits, containing boric acid $(0.5 \%)$ and thiamethoxam $(0.0001 \%)$ in 
$25 \%$ sucrose solution have been trialled in South African and Californian coastal vineyards (Daane et al., 2006; Nelson \& Daane, 2007; Nyamukondiwa \& Addison, 2011). Spring is a critical time for intensive deployment of low-toxicity liquid baits to target the developing reproductive Argentine ant brood and also a time when liquid baits are more attractive to ants because the mealybugs having emerged from overwintering under grapevine bark are mainly feeding on vine trunks and canes so that honeydew production is reduced compared with summer time when green growing shoots and ripening grape clusters provide a rich carbohydrate source for them (Daane et al., 2006).

The correct formulation of liquid baits can be challenging, since the concentration of active ingredient must be sufficiently high enough to effect ant mortality, yet low enough to ensure delayed toxicity of one to four days to maximise the spread of toxicant throughout the colony and still remain attractive to foraging ants (Cooper et al., 2008). Rust, Reierson, \& Klotz (2004) found that for boric acid in $25 \%$ sucrose solution to have a delayed toxic effect, a concentration of at least $0.55 \%$ was required and for thiamethoxam, the concentration ranged from $0.00002 \%$ $0.0003 \%$. In the field though, Rust et al. (2015) found that for thiamethoxam to have an impact on the entire nest, the concentration needed to be at least $0.0006 \%$ to allow for toxicant dilution due to trophallaxis.

Delivery of low-toxicity liquid baits in a polyacrylamide gel matrix targeting Argentine ants, is a novel more cost-effective alternative to deployment of low-toxicity liquid baits in dispensers (Rust et al., 2015). Without the cost of bait station dispensers, low-toxicity liquid baits in hydrogel can be distributed throughout ant infested areas at higher densities and still be economically comparable with alternative insecticidal spray treatments for ants (Nelson \& Daane, 2007). At the Nelson field site, I added 15g of polyacrylamide gel crystals to one litre of liquid bait but after the fact I became aware that Buczkowski, Roper, Chin, Mothapo, \& Wossler (2014) added 20g of polyacrylamide gel crystals to one litre of $0.0007 \%$ thiamethoxam bait deployed at the base of plum 
trees in a commercial orchard targeting Argentine ants. By adding one third more hydrogel crystals per litre of bait used at the Nelson site, the bait mounds at the base of vines would have been more perky and therefore less likely to flow outwards and expose more surface area to premature desiccation. I placed baited hydrogels on a strip of plastic at the base of vines, but Buczkowski, Roper, Chin, Mothapo, \& Wossler (2014) showed that there was no significant difference in the percentage of water lost from the hydrogel baits whether they were placed directly on the ground or on a plastic base.

The deployment of the boric acid and thiamethoxam hydrogel baits in the field would be very cost effective. Based on $20 \mathrm{~g}$ of hydrogel crystals added to one litre of $25 \%$ sucrose and $0.15 \%$ citric acid solution, the cost per $20 \mathrm{~mL}$ dose of bait for $0.55 \%$ boric acid is $3.6 \not$ and $4.5 \varnothing$ for $0.0006 \%$ thiamethoxam. An early season deployment of baits at a density of 521 baits per hectare would cost $\$ 18.75 \mathrm{Ha}^{-1}$ for the $0.55 \%$ boric acid treatment and $\$ 23.45 \mathrm{Ha}^{-1}$ for $0.0006 \%$ thiamethoxam when $20 \mathrm{~mL}$ of bait is placed at the base of the first post of every bay ( $8 \mathrm{~m}$ apart), of every row spaced $2.4 \mathrm{~m}$ apart. The treatment would need to be repeated seven days later in order to achieve similar results to Buczkowski, Roper, Chin, Mothapo, \& Wossler (2014) baiting with $0.0007 \%$ thiamethoxam and recording a reduction in Argentine ant activity of $94 \pm 2 \%$ after two weeks.

The bifenthrin treatment compared with the hydrogel treatments is not as cost effective to administer. Bifenthrin (1200ppm) sprayed in a $10 \mathrm{~cm}$ band on vine trunks above the irrigation conduit using a backpack spray unit with a ring sprayer attachment as depicted in Addison (2002) and delivering $50 \mathrm{~mL}$ per vine, would cost $7.9 \notin$ per vine to dose. For a vineyard with an average vine density of 2,604 vines per hectare (based on $2.4 \mathrm{~m}$ row spacing and $1.6 \mathrm{~m}$ vine spacing), the cost per hectare for Argentine ant control, would be $\$ 206$. However, given the findings of this thesis, there would be a two for the price of one cost benefit since mealybug populations would also be impacted. Alternatively, bifenthrin could be sprayed in Argentine ant hotspots in the 
vineyard and since it is non-repellent to ants and the residual effect of bifenthrin can be seen for up to two months (Toft, 2011), only one treatment would be required during the growing season.

Based on the parameters mentioned above, chemical inputs per hectare and per square meter for each of the three treatments would be (1) $0.0006 \%$ thiamethoxam, $62.5 \mathrm{mg} \mathrm{Ha}^{-1}$ or $6.25 \times 10^{-3}$ mg m $\mathrm{m}^{-2}$; (2) $0.55 \%$ boric acid, $57.30 \mathrm{~g} \mathrm{Ha}^{-1}$ or $5.73 \mathrm{mg} \mathrm{m}^{-2}$; (3) $1200 \mathrm{ppm}$ bifenthrin, $156.24 \mathrm{~g} \mathrm{Ha}^{-1}$ or $15.62 \mathrm{mg} \mathrm{m}^{-2}$. The minimal chemical inputs per hectare for the low-toxicity liquid baits, thiamethoxam and boric acid in hydrogel, (and to a lesser extent, bifenthrin sprayed on vine trunks) would meet the requirements of sustainable farming practices (Daane et al., 2006) and be consistent with the values of Sustainable Winegrowing New Zealand (SWNZ). Boric acid is a slowacting inorganic insecticide (Cochran, 1995) so would be suitable for organic or biodynamically certified vineyards in conjunction with IPM. The thiamethoxam and bifenthrin treatments would be suitable for use in conventionally managed vineyards but their compatibility with IPM would be contingent upon establishing whether beneficials were directly affected by them.

Most insect vectors of plant viruses are from the order Hemiptera including whiteflies (Family Aleyrodidae), leafhoppers (F. Cicadellidae), aphids (F. Aphididae), mealybugs (F. Pseudococcidae) and scale insects (F. Coccidae) (Nault, 1997). Within the virus family Closteroviridae, aphids vector plant virus species of the genus Closterovirus such as Citrus tristera virus; mealybugs and scale transmit plant virus species from the genus Ampelovirus such as Grapevine Leafroll-associated virus-3; while whiteflies vector plant viruses of the genus Crinivirus such as Tomato chlorosis virus (Charles et al., 2006a; Martelli et al., 2002). The invasive Argentine ant, having a predilection for homopteran honeydew, forms food-for-protection mutualisms with a number of hemipteran insects (including some of the above mentioned) on a range of crops in agricultural systems, enhancing their populations to very high densities and the potential to spread plant viruses (Holway, Lach, Suarez, Tsutsui, \& Case, 2002; Lester et al., 2003). 
In South Africa and California in different horticultural and conservation systems, lowtoxicity liquid baits variously containing either boric acid, fipronil, fenoxycarb, spinosad, thiamethoxam or imidacloprid together with the stem barrier treatments chlorpyrifos and $\alpha$ cypermethrin have been trialled for the control of Argentine ants (Addison, 2002; Boser et al., 2014; Buczkowski, Roper, Chin, et al., 2014; Daane et al., 2006; Nelson \& Daane, 2007; Nyamukondiwa \& Addison, 2011). Intra-specific horizontal toxicity or transfer of toxicant by ants to other ants within the colony has been demonstrated previously, mediated by such ant social behaviours as cooperative grooming and trophallaxis, necrophoresis or passive contamination by ants transferring toxicant to shared food and water resources or to other substrates (Choe \& Rust, 2008; Soeprono \& Rust, 2004; Wiltz et al., 2010).

Relating to the Nelson field site ant toxin trial, I hypothesised that the high mealybug mortality rate in plots where vines were treated with bifenthrin, was the result of inter-species horizontal transfer of the target substance bifenthrin from live Argentine ants to citrophilus mealybugs whilst ants were tending them and not because in the absence of ants to protect them, they were vulnerable to the predation of their natural enemies in the vine canopy. If my hypothesis is correct, then this could spawn a novel approach to the management of these insect pests in viticultural and in other horticultural systems. Argentine ants have been reported in association with various other honeydew excreting hemipteran insects on a number of other commercial crops including citrus, pip fruit, stone fruit, tamarillo and tomatoes (Lester et al., 2003). However, the concept of a live insect donor delivering a lethal dose of a toxicant to the target pest insect species with which it shares a mutualism could become a model for pest management in other horticultural systems.

For such a pest management model to be successful in a commercial cropping system, there are several things that need to be taken into consideration. For example, the toxicant sprayed on a vine/tree trunk would need to be non-repellent to the ants conveying the lethal payload to the 
target species and at a concentration that facilitates delayed toxicity if the ants are physiologically affected by the toxicant as well. Ideally though, in such a system, the toxicant would be a contact insecticide with a mode of action which affects the target species only and not the species conveying it. Perhaps the mode of action could be something like impairment of lipid biosynthesis so that the target species is prone to desiccation resulting from leaky membranes. Considerable work would need to be done around establishing the minimal amount of toxicant required to affect the greatest mortality rate of the target pest species. Ideally also the toxicant would be chemically and environmentally stable guaranteeing season long persistence and therefore requiring minimal chemical inputs. A spray application of the toxicant to vine/tree trunks as opposed to a broadcast spray regime throughout plant canopies would limit chemical inputs and therefore be more sustainable. Preferably the toxicant would not have a negative impact on beneficials. In other horticultural systems for example, neonicotinoid insecticides, used on crops, have been implicated in the decline of bee colonies after being found in trace amounts in nectar and pollen (Blacquière, Smagghe, van Gestel, \& Mommaerts, 2012; Whitehorn, O’Connor, Wackers, \& Goulson, 2012). The concept of inter-species horizontal toxicity when applied to targeted pest management has so much potential when all the various permutations of insect mutualisms on different crops in different farming systems are exploited.

\subsection{Constraints and future research}

In October 2016, I commenced site works on a property which had enough flat land area for more than a dozen plots. However, when I became aware of council restrictions which would preclude me from bringing a containment pest like Argentine ants onto a property which did not already have an established Argentine ant population, I was confronted with having to find an alternative site. I was fortunate enough to be able to secure another site in rural Nelson where we did identify a resident Argentine ant population. However, there was only enough flat area for eight plots in a paddock which was also grazed by a couple of head of cattle and that meant putting 
in a considerable amount of infrastructure to keep the cattle away from the plot areas and protect the integrity of the experimental setup.

Originally, I had planned to trial six ant toxin treatments. Three of these, thiamethoxam (in hydrogel) and bifenthrin and indoxacarb (each sprayed on vine trunks) would be suitable for conventionally managed vineyards. The other three, boric acid (in hydrogel), the Argentine ant trail pheromone (Z) - 9- hexadecanal (impregnated rope) and diatomaceous earth (DE) (fashioned into balls with $25 \%$ sucrose solution) would be suitable or organic/biodynamically managed vineyards. However, I had to reduce these to three treatments, namely, bifenthrin, boric acid and thiamethoxam because of constraints with available land area for replication and the extra resources (extra vines, PVC tubing etc) required. It would have been ideal to have had more land area and therefore more replication of treatments.

The Argentine ant nest biomass in the nest box in the centre of each plot had been established before they were connected to the vines in each plot by weighing the empty nest box and again after the ants were extracted into it. The intention was to weigh the nest boxes again at the end of the experiment and determine any change in total biomass. The day after the nest boxes had been connected to the vines of each plot, I realised that quite a number of the ants had been able to escape by getting out of the holes at the base of the vine pot container and either tracking up onto the irrigation whisker or the PVC tubing where it joined the pot container. This was immediately remediated by smearing Tanglefoot ${ }^{\circledR}$ on those critical points. The initial biomass weights were therefore irrelevant and to augment the remaining Argentine ant population in each plot, I dug up more Argentine ants and extracted them into glass tubes to disperse in each plot. Once the plots were secured against future breakouts, the whole setup worked very well. From the time that I installed the nest boxes, it became apparent that the ants preferred to take up residence in the potting mix at the base of the vines so that gauging an accurate change in biomass was never going to be a simple matter. Whenever the irrigation was on, ants could be seen feverishly evacuating 
larvae and queens from the damp potting mix and conveying them along the PVC tubing back to the dry nest box in the centre of the plot. (Presumably they conveyed them back to the potting mix at the base of the vines over the ensuing hours as this was observed quite frequently).

Even though ant activity was relatively high in each control plot, for the "control" plot which was compared to the bifenthrin treatment, mealybug counts fell dramatically (Fig. 2.17A) and only recovered beyond the baseline level in the last week of the trial. From the outset, compared with the other plots, the mealybug count in the "control" plot was lower, and it appeared that the inoculation of citrophilus mealybugs onto the vines in this outside plot was not as successful. Some mealybugs could also have been blown off the vines in the windy conditions at the site too or been predated upon by natural predators such as ladybirds which were seen occasionally in the canopy of vines in this and other plots. Ideally it would have been more satisfactory to have had more "control" plots to compare with the bifenthrin treatment and more "control gel" plots to compare with the boric acid and thiamethoxam in gel treatments if more land area was available for them.

Replication could have been enhanced for the bioassay conducted at Mt. Albert Plant and Food Research also. I had ten Argentine ant nests in all and three of these were used for the "bifenthrin only" treatment and two for the "water" control; three for the "bifenthrin/dye" treatment and two for the "water/dye" control. It would have been more ideal to have had the capacity to increase each treatment or control to five replicates each. To do this I would have needed more bench space to accommodate 20 water bath trays containing the ant/mealybug setup in each and more purpose made boxes to contain the ant nest on one side and the mealybug motel on the other. Sourcing more Argentine ants was not a limitation though. I had two "no ants" bifenthrin treatments and two "no ants" water controls and likewise it would have been preferable to increase each of these to five replicates. If I had the opportunity to repeat this bioassay I would use five replicates for each treatment or control and instead of using the blue powdered dye flicked on the base of the ant nest boxes, I would use a liquid dye carried in the bifenthrin treatment and 
the water control which could be viewed under U.V. light for visual confirmation of potential horizontal transfer of the toxicant from the ants to the mealybugs. This could be followed up with Gas Chromatography - Mass Spectroscopy (GC - MS) or Liquid Chromatography - MS (LC MS) to confirm the presence of bifenthrin residues on the dye-marked mealybugs.

While I was at Mt. Albert Plant and Food Research I also intended to conduct a bioassay to determine the extent to which $L$. bumile disrupted the successful oviposition of the parasitoid wasp Coccophagus gurneyi. In an ant-excluded zone, my plan was let about 10 female $C$. gurneyi parasitoids share accommodation in the mealybug motel (where citrophilus mealybugs were supported on sprouted potato) and let them do their thing for a couple of days before removing them. The percentage of mealybug mummies could then be assessed and from these the percentage of $C$. gurneyi that emerged. There would be 5 replicates. In a parallel setup also with 5 replicates, Argentine ants would be able to access the mealybug motel shared with the parasitoids and likewise the percentage of mealybug mummies and emerged parasitoids could be ascertained and compared with the ant-free setup. However, I was unable to amass the requisite number of fit females from the C. gurneyi colony, so this was not possible but could be attempted again sometime in the future.

Another area of enquiry related to the Nelson site would be to assess the compatibility of bifenthrin and thiamethoxam (at the concentrations used in the field) with an IPM program regarding whether beneficial insects are harmed by these toxicants. Bifenthrin and thiamethoxam could be potentially transferred to beneficial insects while interacting with mealybugs or ants in the vine canopy. Regular surveys of beneficial insect species which have recruited to the vines, would need to be conducted prior to and after treatment deployment. Visiting bee pollinators could also be included in this survey as there is the potential for them to be attracted to the sucrose attractant in the hydrogel baits.

A high-density deployment $\left(521 \mathrm{Ha}^{-1}\right)$ of the low-toxicity baits in the polyacrylamide gel matrix for the suppression of Argentine ant activity early in the season is cost-effective. For $20 \mathrm{~mL}$ 
doses of $0.55 \%$ boric acid this would cost $3.6 \varnothing$ per dose or $\$ 18.75 \mathrm{Ha}^{-1}$ compared with $4.5 \phi$ per $20 \mathrm{~mL}$ dose for $0.0006 \%$ thiamethoxam or $\$ 23.45 \mathrm{Ha}^{-1}$. Given the very low chemical inputs, it would be good to have the opportunity to retrial the boric acid and thiamethoxam hydrogel treatments in a commercial vineyard. Instead of using $0.5 \%$ boric acid, I would use $0.55 \%$ boric acid in accordance with the findings of Rust, Reierson, \& Klotz (2004) and I would add 20g of polyacrylamide crystals to one litre of liquid bait (Buczkowski, Roper, Chin, et al., 2014) carried in $25 \%$ sucrose and $0.15 \%$ citric acid solution instead of $15 \mathrm{~g}$ polyacrylamide crystals per litre of liquid bait.

\section{Conclusions}

The invasive Argentine ant, L. bumile is found in association with a number of insect vectors of plant viruses on various crops (including grapes) in horticultural systems and enhances their populations to unacceptably high densities as well as disrupting their biological control (Cid, Pereira, Cabaleiro, Faoro, \& Segura, 2007; Holway, Lach, et al., 2002; Lester et al., 2003; Mgocheki \& Addison, 2009b). Chemical controls targeting vine mealybugs Pseudococcus sp., the vector of GLRaV-3 in New Zealand vineyards are applied up until just prior to flowering. For targeting $L$. bumile in vineyards, insecticides sprayed in a band on vine trunks and low-toxicity liquid baits deployed at regular intervals along the length of vine rows, can be applied beyond flowering.

The significant finding which emerged through the field and lab-based studies of this research was evidence supporting the notion of inter-species horizontal toxicity; a mechanism whereby a donor insect species conveys a lethal dose of a target substance to another insect pest species with which it shares a mutualism. This may provide an innovative approach to targeted pest management strategies and opportunities to develop target substances which do not affect the species conveying them to the target pest species. For an ant-mealybug mutualism in a viticultural system, this would entail spraying a contact insecticide onto vine trunks which is both non-toxic and non-repellent to ants. The ants would then seek out (and destroy) the target cryptic insect pest 
in the vine canopy and deliver the toxicant while tending them for honeydew exudate. Targeting mealybugs in this way would augment the period during the growing season for mealybug chemical control in ant / mealybug hotspots within the vineyard. Once mealybug populations were reduced, chemical control of ants could be achieved by distributing low-toxicity liquid baits in a polyacrylamide gel throughout the vineyard. The concept of inter-species horizontal toxicity has so much potential, considering all the various permutations of insect mutualisms on various crops that could be exploited in different horticultural systems and could become a model for targeted pest management.

\section{References}

Addison, P. (2002). Chemical stem barriers for the control of ants (Hymenoptera: Formicidae) in vineyards. South African Journal of Enology and Viticulture, 23(1), 1-8.

Addison, P., \& Mgocheki, N. (2010). Improving ant management in vineyards. SA Fruit Journal, 9(2), 30-31.

Addison, P., Mgocheki, N., Nyamukondiwa, C., \& Wohlfarter, M. (2011). Development of new ant control methods in vineyards, with focus on integration with biological control of vine mealybugs. $\quad 23$ Retrieved March 2013, from http://wineland.co.za/archive/index.php?option $=$ com_zine\&view $=$ article\&id $=984$ :develo pment-of-new-ant-control-methods-in-vineyards-with-focus-on-integration-with-biologicalcontrol-of-vine-mealybug

Atallah, S. S., Gómez, M. I., Fuchs, M. F., \& Martinson, T. E. (2012). Economic impact of grapevine leafroll disease on Vitis vinifera cv. Cabernet franc in Finger Lakes vineyards of New York. American Journal of Enology and Viticulture, 63(1), 73-79. https://doi.org/10.5344/ajev.2011.11055

Bach, C. E. (1991). Direct and indirect interactions between ants (Pheidole megacephala), scales (Coccus viridis) and plants (Pluchea indica). Oecologia, 87(2), 233-239.

Bayer Crop Science. (2013). Movento 100SC user guide for grapes. Retrieved 11 October 2017, from https://www.cropscience.bayer.co.nz/ /media/internet/BCSNZ/CP/CropScience NZ/Product Downloads/Insecticides/Movento 100SC/Movento 100SC User Guide for Grapes.ashx

Blacquière, T., Smagghe, G., van Gestel, C. A. M., \& Mommaerts, V. (2012). Neonicotinoids in bees: A review on concentrations, side-effects and risk assessment. Ecotoxicology, 21(4), 973992. https://doi.org/10.1007/s10646-012-0863-x

Blanc, S., Uzest, M., \& Drucker, M. (2011). New research horizons in vector-transmission of plant viruses. Current Opinion in Microbiology, 14(483-491). https://doi.org/10.1016/j.mib.2011.07.008

Blight, O., Provost, E., Renucci, M., Tirard, A., \& Orgeas, J. (2010). A native ant armed to limit the spread of the Argentine ant. Biological Invasions, 12(11), 3785-3793. 
https://doi.org/10.1007/s10530-010-9770-3

Blight, O., Renucci, M., Tirard, A., Orgeas, J., \& Provost, E. (2010). A new colony structure of the invasive Argentine ant (Linepithema humile) in Southern Europe. Biological Invasions, 12(6), 1491-1497. https://doi.org/10.1007/s10530-009-9561-x

Bolker, B. M., Brooks, M. E., Clark, C. J., Geange, S. W., Poulsen, J. R., Stevens, M. H. H., \& White, J.-S. S. (2009). Generalized linear mixed models: A practical guide for ecology and evolution. Trends in Ecology and Evolution, 24(3), 127-135. https://doi.org/10.1016/j.tree.2008.10.008

Bond, W., \& Slingsby, P. (1984). Collapse of an ant-plant mutalism: The Argntine ant (Iridomyrmex bumilis) and myrmecochorous Proteaceae. Ecology, 65(4), 1031-1037.

Bonfiglioli, R., \& Hoskins, N. (2006). Managing virus in New Zealand vineyards. The Australian and New Zealand Grapegrower and Winemaker, (515), 43-46.

Boser, C. L., Hanna, C., Faulkner, K. R., Cory, C., Randall, J. M., Morrison, S. A., .. Morrison, S. A. (2014). Argentine ant management in conservation areas: Results of a pilot study. Monographs of the Western North American Naturalist, 7, 518-530. Retrieved from http://www.bioone.org/doi/full/10.3398/042.007.0140

Bosque-Pérez, N. A., \& Eigenbrode, S. D. (2011). The influence of virus-induced changes in plants on aphid vectors: Insights from luteovirus pathosystems. Virus Research, 159(2), 201-205. https://doi.org/10.1016/j.virusres.2011.04.020

Bottrell, D. G., \& Smith, R. F. (1982). Integrated pest management: This economical approach to environmentally sound pest control has dim prospects for increased federal support. Environmental Science and Technology, 16(5), 282A-288A. https://doi.org/10.1021/es00099a726

Bronstein, J. L. (2001). The costs of mutualism. American Zoologist, 41(4), 825-839. https://doi.org/10.1093/icb/41.4.825

Bruck, E., Elbert, A., Fischer, R., Krueger, S., Kuhnhold, J., Klueken, M. A., ... van Waetermeulen, X. (2009). Movento, an innovative ambimobile insecticide for sucking insect pest control in agriculture: Biological profile and field performance. Crop Protection, 28(10), 838-844. https://doi.org/10.1016/j.cropro.2009.06.015

Buczkowski, G., Roper, E., \& Chin, D. (2014). Polyacrylamide hydrogels: An effective tool for delivering liquid baits to pest ants (Hymenoptera: Formicidae). J. Econ. Entomol., 107(2)(2), 748-757. https://doi.org/http://dx.doi.org/10.1603/EC13508

Buczkowski, G., Roper, E., Chin, D., Mothapo, N., \& Wossler, T. (2014). Hydrogel baits with lowdose thiamethoxam for sustainable Argentine ant management in commercial orchards. Entomologia Experimentalis et Applicata, 153(3), 183-190. https://doi.org/10.1111/eea.12239

Cabaleiro, C., Couceiro, C., Pereira, S., Cid, M., Barrasa, M., \& Segura, A. (2008). Spatial analysis of epidemics of Grapevine leafroll associated virus-3. European Journal of Plant Pathology, 121(2), 121130. https://doi.org/10.1007/s10658-007-9254-1

Castle, S., \& Naranjo, S. E. (2009). Sampling plans, selective insecticides and sustainability: The case for IPM as 'informed pest management'. Pest Management Science, 65(12), 1321-1328. https://doi.org/10.1002/ps.1857

Chandler, D., Bailey, A. S., Tatchell, G. M., Davidson, G., Greaves, J., \& Grant, W. P. (2011). The development, regulation and use of biopesticides for integrated pest management. Philosophical Transactions of the Royal Society B: Biological Sciences, 366(1573), 1987-1998. 
https://doi.org/10.1098/rstb.2010.0390

Charles, J. G., Bell, V. A., Lo, P. L., Cole, L. M., \& Chhagan, A. (2010). Mealybugs (Hemiptera: Pseudococcidae) and their natural enemies in New Zealand vineyards from 1993-2009. New Zealand Entomologist, 33(1), 84-91. https://doi.org/10.1080/00779962.2010.9722195

Charles, J. G., Cohen, D., Walker, J. T. S., Forgie, S. A., Bell, V. A., \& Breen, K. C. (2006a). A review of Grapevine Leafroll associated Virus type 3 (GLRaV-3) for the New Zealand wine industry. $\quad$ Retrieved 23 March 2013, from http:/ / wineinf.nzwine.com/research_outputs.asp?id=7\&cid=2\&type $=\mathrm{r}$

Charles, J. G., Cohen, D., Walker, J. T. S., Forgie, S. A., Bell, V. A., \& Breen, K. C. (2006b). A review of the ecology of Grapevine leafroll associated virus type 3 (GLRaV-3). New Zealand Plant Protection, 59, 330-337.

Charles, J. G., Froud, K. J., van den Brink, R., \& Allan, D. J. (2009). Mealybugs and the spread of Grapevine leafroll-associated virus 3 (GLRaV-3) in a New Zealand vineyard. Australasian Plant Pathology, 38(6), 576-583. https://doi.org/10.1071/AP09042

Chen, J. S. C., \& Nonacs, P. (2000). Nestmate recognition and intraspecific aggression based on environmental cues in Argentine ants (Hymenoptera: Formicidae). Annals of the Entomological Society of America, 93(6), 1333-1337. https://doi.org/10.1603/00138746(2000)093[1333:NRAIAB]2.0.CO;2

Choe, D.-H., \& Rust, M. K. (2008). Horizontal transfer of insecticides in laboratory colonies of the Argentine ant (Hymenoptera: Formicidae). Journal of Economic Entomology, 101(4), 1397405. 0493(2008)101[1397:HTOIIL]2.0.CO;2

Choe, D. H., Villafuerte, D. B., \& Tsutsui, N. D. (2012). Trail pheromone of the Argentine ant, Linepithema bumile (Mayr) (Hymenoptera: Formicidae). PLoS ONE, 7(9), 1-7. https://doi.org/10.1371/journal.pone.0045016

Cid, M., Pereira, S., Cabaleiro, C., Faoro, F., \& Segura, A. (2007). Presence of Grapevine leafrollassociated virus 3 in primary salivary glands of the mealybug vector Planococcus citri suggests a circulative transmission mechanism. European Journal of Plant Pathology, 118(1), 23-30. https://doi.org/10.1007/s10658-006-9090-8

Clearwater, J. (2003). The ecology of mealybugs in Gisborne vineyards. Retrieved 23 March 2013, from http:/ / wineinf.nzwine.com/research_outputs.asp?id=4\&cid=2\&type $=\mathrm{r}$

Cochran, D. G. (1995). Toxic effects of boric acid on the German cockroach. Experentia, 51, 561563.

Cooper, M. L., Daane, K. M., Nelson, E. H., Varela, L. G., Battany, M. C., Tsutsui, N. D., \& Rust, M. K. (2008). Liquid baits control Argentine ants sustainably in coastal vineyards. California Agriculture, 62(4), 177-183. https://doi.org/10.3733/ca.v062n04p177

Daane, K. M., Sime, K. R., Fallon, J., \& Cooper, M. L. (2007). Impacts of Argentine ants on mealybugs and their natural enemies in California's coastal vineyards. Ecological Entomology, 32(6), 583-596. https://doi.org/10.1111/j.1365-2311.2007.00910.x

Daane, K. M., Sime, K. R., Hogg, B. N., Bianchi, M. L., Cooper, M. L., Rust, M. K., \& Klotz, J. H. (2006). Effects of liquid insecticide baits on Argentine ants in California's coastal vineyards. Crop Protection, 25(6), 592-603. https://doi.org/10.1016/j.cropro.2005.08.015

Detrain, C., Verheggen, F. J., Diez, L., Wathelet, B., \& Haubruge, E. (2010). Aphid-ant mutualism: 
How honeydew sugars influence the behaviour of ant scouts. Physiological Entomology, 35(2), 168-174. https://doi.org/10.1111/j.1365-3032.2010.00730.x

Douglas, A. E. (1998). Nutritional interactions in insect-microbial symbioses: Aphids and their symbiotic bacteria Buchnera. Annual Review of Entomology, 43(1), 17-37. https://doi.org/10.1146/annurev.ento.43.1.17

Douglas, N., \& Krüger, K. (2008). Transmission efficiency of Grapevine leafroll-associated virus 3 (GLRaV-3) by the mealybugs Planococcus ficus and Pseudococcus longispinus (Hemiptera: Pseudococcidae). European Journal of Plant Pathology, 122(2), 207-212. https://doi.org/10.1007/s10658-008-9269-2

Ehler, L. E. (2006). Integrated pest management (IPM): Definition, historical development and implementation, and the other IPM. Pest Management Science, 62, 787-789. https://doi.org/10.1002/ps

Enríquez, M. L., Abril, S., Díaz, M., \& Gómez, C. (2013). Nest site selection by the Argentine ant and suitability of artificial nests as a control tool. Insectes Sociaux, 60(4), 507-516. https://doi.org/10.1007/s00040-013-0317-3

Espinoza, C., Vega, A., Medina, C., Schlauch, K., Cramer, G., \& Arce-Johnson, P. (2007). Gene expression associated with compatible viral diseases in grapevine cultivars. Functional and Integrative Genomics, 7(2), 95-110. https://doi.org/10.1007/s10142-006-0031-6

Fagundes, R., Dáttilo, W., Ribeiro, S. P., Rico-Gray, V., \& Del-Claro, K. (2016). Food source availability and interspecific dominance as structural mechanisms of ant-plant-hemipteran multitrophic networks. Arthropod-Plant Interactions, 10(3), 207-220. https://doi.org/10.1007/s11829-016-9428-x

Fantail Viticulture Consultants. (2012). New Zealand winegrowers export wine grape spray schedule 2012/2013. New Zealand Winegrowers.

Fereres, A., \& Moreno, A. (2009). Behavioural aspects influencing plant virus transmission by homopteran insects. Virus Research, 141(2), 158-168. https://doi.org/10.1016/j.virusres.2008.10.020

Flanagan, T. P., Pinter-Wollman, N. M., Moses, M. E., \& Gordon, D. M. (2013). Fast and flexible: Argentine ants recruit from nearby trails. PLoS ONE, 8(8), 1-8. https://doi.org/10.1371/journal.pone.0070888

Furness, G. O., \& Charles, J. G. (1994). Mealybugs. In P. Nicholas, P. Magarey, \& M. Wachtel (Eds.), Grape Production Series Number 1: Diseases and Pests (1st ed., pp. 54-55). Adelaide: Winetitles.

Giraud, T., Pedersen, J. S., \& Keller, L. (2002). Evolution of supercolonies: The Argentine ants of Southern Europe. In Proceedings of the National Academy of Sciences of the United States of America (Vol. 99, pp. 6075-6079).

Green, O. R. (1990). Entomologist sets new record at Mt. Smart for Iridomyrmex humilis establishment in New Zealand. Weta, 13, 14-16.

Harris, R. J. (2002). Potential impact of the Argentine ant (Linepithema bumile) in New Zealand and options for its control. Science for Conservation, 36(196), 5-36.

Heller, N. E., Ingram, K. K., \& Gordon, D. M. (2008). Nest connectivity and colony structure in unicolonial Argentine ants. Insectes Sociaux, 55(4), 397-403. https://doi.org/10.1007/s00040008-1019-0 
Hölldobler, B., \& Wilson, E. O. (1977). The number of queens: An important trait in ant evolution. Naturvissenschaften, 64(1), 8-15. https://doi.org/10.1007/BF00439886

Holway, D. A. (1998a). Effect of Argentine ant invasion on ground dwelling arthropods in northern California riparian woodlands. Oecologia, 116, 252-258. Retrieved from http://www.invasivespecies.ucsd.edu/pubs/Holway-D.A._1998_1.pdf

Holway, D. A. (1998b). Factors governing rate of invasion : A natural experiment using Argentine ants. Oecologia, 115(1), 206-212.

Holway, D. A. (1999). Competitive mechanisms underlying the displacement of native ants by the invasive Argentine ant. Ecology, 80(1), 238-251. https://doi.org/doi:10.1890/00129658(1999)080[0238:CMUTDO]2.0.CO;2

Holway, D. A., Lach, L., Suarez, A. V, Tsutsui, N. D., \& Case, T. J. (2002). The causes and consequences of ant invasions. Annual Review of Ecology and Systematics, 33(1), 181-233. https://doi.org/10.1146/annurev.ecolsys.33.010802.150444

Holway, D. A., Suarez, A. V, \& Case, T. J. (2002). Role of abiotic factors in governing susceptibility to invasion: A test with Argentine ants. Ecological Society of America, 83(6), 1610-1619.

Human, K. G., \& Gordon, D. M. (1996). Exploitation and interference competition between the invasive Argentine ant, Linepithema humile, and native ant species. Oecologia, 105(3), 405-412. https://doi.org/10.1007/BF00328744

Human, K. G., \& Gordon, D. M. (1999). Behavioral interactions of the invasive Argentine ant with native ant species. Insectes Sociaux, 46(2), 159-163. https://doi.org/10.1007/s000400050127

Ingwell, L. L., Eigenbrode, S. D., \& Bosque-Pérez, N. A. (2012). Plant viruses alter insect behavior to enhance their spread. Scientific Reports, 578(2), 1-6. https://doi.org/10.1038/srep00578

Jahn, G. C., Beardsley, J. W., \& González-Hernández, H. (2003). A review of the association of ants with mealybug wilt disease of pineapple. Proceedings, Hawaiian Entomological Society, 36(1910), 928.

James, D. G., Stevens, M. M., \& O’Malley, K. J. (1998). Prolonged exclusion of foraging ants (Hymenoptera: Formicidae) from citrus trees using controlled-release chlorpyrifos trunk bands. International Journal of Pest Management, 44(2), 65-69. https://doi.org/10.1080/096708798228338

Johnson, M., Luukinen, B., Gervais, J., Buhl, K., \& Stone, D. (2010). Bifenthrin general fact sheet. Retrieved 15 September 2017, from http://npic.orst.edu/factsheets/bifgen.html

Kaplan, I., \& Eubanks, M. D. (2002). Disruption of cotton aphid (Homoptera: Aphididae) Natural enemy dynamics by red imported fire ants (Hymenoptera: Formicidae). Environmental Entomology, 31(6), 1175-1183. https://doi.org/10.1603/0046-225X-31.6.1175

Keller, M. (2010). Viruses. In The Science of Grapevines Anatomy and Physiology (1st ed., pp. 308-310). London: Elsevier Ltd.

Klotz, J. H., Rust, M. K., Costa, H. S., Reierson, D. A., \& Kido, K. (2002). Strategies for controlling Argentine ants (Hymenoptera: Formicidae) with sprays and baits. Journal of Agriculture and Urban Entomology, 19(2), 85-94.

Klotz, J. H., Rust, M. K., Gonzalez, D., Greenberg, L., Costa, H., Phillips, P., ... Kido, K. (2003). Directed sprays and liquid baits to manage ants in vineyards and citrus groves. Journal of 
Agriculture and Urban Entomololgy, 20(1), 31-40.

Krushelnycky, P. D., Joe, S. M., Medeiros, A. C., Daehler, C. C., \& Loope, L. L. (2005). The role of abiotic conditions in shaping the long-term patterns of a high-elevation Argentine ant invasion. Diversity and Distributions, 11(4), 319-331. https://doi.org/10.1111/j.13669516.2005.00151.x

Lester, P. J., Baring, C. W., Longson, C. G., \& Hartley, S. (2003). Argentine and other ants (Hymenoptera: Formicidae) in New Zealand horticultural ecosystems: Distribution, hemipteran hosts, and review. New Zealand Entomologist, 26(1), 79-89. https://doi.org/10.1080/00779962.2003.9722112

Lo, P. L., Bell, V. A., \& Walker, J. T. S. (2009). Maximising the effectiveness of insecticides to control mealybugs in vineyards. New Zealand Plant Protection, 62, 296-301.

Lo, P. L., \& Walker, J. T. S. (2011). Soil applications of two neonicotinoid insecticides to control mealybugs (Pseudococcidae) in vineyards. New Zealand Plant Protection, 64, 101-106.

Lough, T. J., \& Lucas, W. J. (2006). Intergrative plant biology: Role of phloem long-distance macromolecular trafficking. Annual Review of Plant Biology, 57(1), 203-232. https://doi.org/10.1146/annurev.arplant.56.032604.144145

Mansour, R., Belzunces, L. P., Suma, P., Zappalà, L., Mazzeo, G., Grissa-Lebdi, K., ... Biondi, A. (2018). Vine and citrus mealybug pest control based on synthetic chemicals: A review. Agronomy for Sustainable Development, 38(4), 36-37. https://doi.org/10.1007/s13593-018-05137

Maree, H. J., Almeida, R. P. P., Bester, R., Chooi, M. K., Cohen, D., Dolja, V. V, .. Burger, J. T. (2013). Grapevine leafroll-associated virus 3. Frontiers in Microbiology, 4, 1-21. https://doi.org/10.3389/fmicb.2013.00082

Markin, G. P. (1970). The seasonal life cycle of the Argentine ant, Iridomyrmex bumilis (Hymenoptera: Formicidae) in Southern California. Annals of the Entomological Society of America, 63(5), 1238-1242. https://doi.org/10.1093/aesa/63.5.1238

Martelli, G. P., Agranovsky, A. A., Bar-Joseph, M., Bosica, D., Candresse, T., Coutts, R. H. A., ... Yoshikawa, N. (2002). The family Closteroviridae revised. Archives of Virology, 10(147), 2039_ 2045.

Martelli, G. P., Ghanem-Sabanadzovic, N. A., Agranovsky, A. A., Al Rwahnih, M., Dolja, V. V, \& Dovas, C. I. (2012). Taxonomic revision of the family Closteroviridae with special reference to the Grapevine leafroll-associated members of the genus Ampelovirus and the putative species unassigned to the family. Journal of Plant Pathology, 94(1), 7-19. https://doi.org/10.4454/JPP.FA.2012.022

Mauck, K., Bosque-Pérez, N. A., Eigenbrode, S. D., De Moraes, C. M., \& Mescher, M. C. (2012). Transmission mechanisms shape pathogen effects on host-vector interactions: Evidence from plant viruses. Functional Ecology, 26(5), 1162-1175. https://doi.org/10.1111/j.13652435.2012.02026.x

McMaugh, J. (1985). What garden pest or diseases is that? (1st ed.). N.S.W. Australia: Lansdowne Press.

Mgocheki, N., \& Addison, P. (2009a). Incorporating sampling precision into an action threshold for monitoring ant (Hymenoptera: Formicidae) population levels in vineyards. Crop Protection, 28(3), 257-263. https://doi.org/10.1016/j.cropro.2008.10.010

Mgocheki, N., \& Addison, P. (2009b). Interference of ants (Hymenoptera: Formicidae) with 
biological control of the vine mealybug Planococcus ficus (Signoret) (Hemiptera: $\begin{array}{llll}\text { Pseudococcidae). } & \text { Biological } & \text { Control, } & \text { 49(2), }\end{array}$ https://doi.org/10.1016/j.biocontrol.2009.02.001

Moreno-Delafuente, A., Garzo, E., Moreno, A., \& Fereres, A. (2013). A plant virus manipulates the behavior of its whitefly vector to enhance its transmission efficiency and spread. PLoS ONE, 8(4), 1-10. https://doi.org/10.1371/journal.pone.0061543

Naidu, R., Rowhani, A., Fuchs, M., Golino, D., \& Martelli, G. (2014). Grapevine leafroll: A complex viral disease affecting a high-value fruit crop. Plant Disease, 98(9), 1172-1185. https://doi.org/10.1094/PDIS-08-13-0880-FE

Nault, L. R. (1997). Arthropod transmission of plant viruses: A new synthesis. Annals of the Entomological Society of America, 90(5), 521-541. https://doi.org/http://dx.doi.org.eres.library.manoa.hawaii.edu/10.1093/aesa/90.5.521

Nelson, E. H., \& Daane, K. M. (2007). Improving liquid bait programs for Argentine ant control: Bait station density. Environmental Entomology, 36(6), 1475-84. https://doi.org/http://dx.doi.org/10.1603/0046-225X(2007)36[1475:ILBPFA]2.0.CO;2

Neoh, K.-B., Yeoh, B.-H., \& Lee, C.-Y. (2014). Mortality patterns in Coptotermes gestroi (Blattodea: Rhinotermitidae) following horizontal transfer of nonrepellent and repellent insecticides: Effects of donor: Recipient ratio and exposure time. Journal of Economic Entomology, 107(4), 1563-1572. https://doi.org/10.1603/EC14080

New, T. R. (2017a). Ants and other insects - Hemiptera. In Mutualisms and insect conservation (pp. 105-118). Cham: Springer. https://doi.org/10.1007/978-3-319-58292-4

New, T. R. (2017b). Mutualisms and insect conservation. Cham: Springer. https://doi.org/10.1007/978-3-319-58292-4

New Zealand Winegrowers. (2011). Vine removal and leafroll virus. Retrieved 23 March 2013, from http: $/ /$ wineinf.nzwine.com/research_outputs.asp?id=7\&cid=2\&type $=\mathrm{r}$

New Zealand Winegrowers. (2015). What are the commercial costs associated with GLRaV-3? $\begin{array}{lllll}\text { Retrieved } & 2 & \text { October } & 2016, & \text { from }\end{array}$ http://www.nzwine.com/assets/sm/upload/eb/a5/mz/m9/NZVE-103-Revised 2015.pdf

Ng, J. C. K., \& Perry, K. L. (2004). Transmission of plant viruses by aphid vectors. Molecular Plant Pathology, 5(5), 505-511. https://doi.org/10.1111/J.1364-3703.2004.00240.X

Nimmo-Bell \& Company Ltd. (2006). Report for New Zealand Winegrowers: The economic effects and financial impact of GLRaV3. Retrieved 23 March 2013, from http://wineinf.nzwine.com/research_outputs.asp?id=7\&cid=2\&type $=\mathrm{r}$

Nyamukondiwa, C., \& Addison, P. (2011). Preference of foraging ants (Hymenoptera: Formicidae) for bait toxicants in South African vineyards. Crop Protection, 30(8), 1034-1038. https://doi.org/10.1016/j.cropro.2011.03.014

Nyamukondiwa, C., \& Addison, P. (2014). Food preference and foraging activity of ants: Recommendations for field applications of low-toxicity baits. Journal of Insect Science, 14(48), 1-13. https://doi.org/10.1093/jis/14.1.48

Petersen, C. L., \& Charles, J. G. (1997). Transmission of grapevine leafroll-associated closteroviruses by Pseudococcus longispinus and P. calceolariae. Plant Pathology, 46(4), 509-515. https://doi.org/10.1046/j.1365-3059.1997.d01-44.x 
Pranschke, A. M., Hooper-Bùi, L. M., \& Moser, B. (2003). Efficacy of bifenthrin treatment zones against red imported fire ant. Journal of Economic Entomology, 96(1), 98-105. https://doi.org/10.1603/0022-0493-96.1.98

Price, P. W., Denno, R. F., Eubanks, M. D., Finke, D. I., \& Kaplan, I. (2011). Mutualisms. In Insect ecology: Behaviour, populations and communites (1st ed., pp. 224-267). New York: Cambridge University Press.

Pringle, E. G., Novo, A., Ableson, I., Barbehenn, R. V, \& Vannette, R. L. (2014). Plant-derived differences in the composition of aphid honeydew and their effects on colonies of aphidtending ants. Ecology and Evolution, 21(4), 4065-4079. https://doi.org/10.1002/ece3.1277

Reid, D. (2010). Ant control. New Zealand Winegrowers. Retrieved from http:/ /wineinf.nzwine.com/research_outputs.asp?id=7\&cid=2\&type $=\mathrm{r}$

Reierson, D. A., Rust, M. K., \& Hampton-Beesley, J. (1998). Monitoring with sugar water to determine the efficacy of treatments to control Argentine ants, Linepithema bumile (Mayr). In Proceedings of the National Conference on Urban Entomology, San Diego, CA (pp. 78-82).

Ricketts, K. D., Gomez, M. I., Atallah, S. S., Fuchs, M. F., Martinson, T. E., Battany, M. C., ... Smith, R. J. (2015). Reducing the economic impact of grapevine leafroll disease in California: Identifying optimal disease management strategies. American Journal of Enology and Viticulture, 66(2), 138-149. https://doi.org/10.5344/ajev.2014.14106

Rotenberg, D., Jacobson, A. L., Schneweis, D. J., \& Whitfield, A. E. (2015). Thrips transmission of tospoviruses. Current Opinion in Virology, 15, 80-89. https://doi.org/10.1016/j.coviro.2015.08.003

Roura-Pascual, N., Suarez, A. V, Gómez, C., Pons, P., Touyama, Y., Wild, A. L., \& Peterson, T. A. (2004). Geographical potential of Argentine ants (Linepithema bumile Mayr) in the face of global climate change. In Proceedings. Biological sciences / The Royal Society (Vol. 271, pp. 25272535). https://doi.org/10.1098/rspb.2004.2898

Rubinstein, G., \& Czosnek, H. (1997). Long-term association of tomato yellow leaf curl virus with its whitefly vector Bemisia tabaci: Effect on the insect transmission capacity, longevity and fecundity. Journal of General Virology, 78(10), 2683-2689. https://doi.org/10.1099/0022-131778-10-2683

Rust, M. K., Reierson, D. A., \& Klotz, J. H. (2004). Delayed toxicity as a critical factor in the efficacy of aqueous baits for controlling Argentine ants (Hymenoptera: Formicidae). Journal of Economic Entomology, 97(3), 1017-1024. https://doi.org/10.1603/00220493(2004)097[1017:DTAACF]2.0.CO;2

Rust, M. K., Soeprono, A., Wright, S., Greenberg, L., Choe, D.-H., Boser, C. L., ... Hanna, C. (2015). Laboratory and field evaluations of polyacrylamide hydrogel baits against Argentine ants (Hymenoptera: Formicidae). J. Econ. Entomol, 108(3), 1228-1236. https://doi.org/10.1093/jee/tov044

Rust, M., Reierson, D., \& Klotz, J. (2003). Pest management of argentine ants (Hymenoptera : Formicidae). Journal of Entomological Science, 38(2), 159-169.

Sandler, H. A. (2010). Integrated pest management: Cranberry Station best management practices guide - 2010 revision. Notes. Amherst: University of Massachusetts. Retrieved from https: / / scholarworks.umass.edu/cgi/viewcontent.cgi?article $=1015 \&$ context $=$ cranberrybm p2010 
Sether, D. M., \& Hu, J. S. (2002). Closterovirus infection and mealybug exposure are necessary for the development of mealybug wilt of pineapple disease. Phytopathology, 92(9), 928-935. https://doi.org/10.1094/PHYTO.2002.92.9.928

Shelton, T. G., \& Grace, J. K. (2003). Effects of exposure duration on transfer of nonrepellent termiticides among workers of Coptotermes formosanus Shiraki (Isopter: Rhinotermitidae). Journal of Economic Entomology, 96(2), 456-460.

Silverman, J., \& Roulston, T. H. (2001). Acceptance and intake of gel and liquid sucrose compositions by the Argentine ant (Hymenoptera: Formicidae). Journal of Economic Entomology, 94, 511-515. https://doi.org/10.1603/0022-0493-94.2.511

Smith, E. P. (2002). BACI design. In A. H. El-Shaarawi \& W. W. Piegorsch (Eds.), Encyclopedia of Environmetrics (1st ed., Vol. 1, pp. 141-148). Chichester: John Wiley \& Sons Ltd. https://doi.org/10.1002/9780470057339.vab001

Soeprono, A. M., \& Rust, M. K. (2004). Effect of horizontal transfer of barrier insecticides to control Argentine ants (Hymenoptera: Formicidae). Journal of Economic Entomology, 97(5), 1675-1681.

Styrsky, J. D., \& Eubanks, M. D. (2007). Ecological consequences of interactions between ants and honeydew-producing insects. In Proceedings of the Royal Society B: Biological Sciences (Vol. 274, pp. 151-164). https://doi.org/10.1098/rspb.2006.3701

Suarez, A., Holway, D., \& Case, T. (2001). Patterns of spread in biological invasions dominated by long-distance jump dispersal: Insights from Argentine ants. In Proceedings of the National Academy of Sciences (Vol. 98, pp. 1095-1100). https://doi.org/10.1073/pnas.98.3.1095

Syngenta. (2016). Actara insecticide. Retrieved from https://syngentaau.my.salesforce.com/sfc/p/\#90000000atoO/a/900000008gia/PzAZprKUKZA2dFzv_q3 FYaqKe6sYqqnlr47r3OjidLw

Toft, R. (2011). Research on improving containment of Argentine ant infestations. Nelson. Retrieved from http://envirolink.govt.nz/assets/Envirolink/940-TSDC-73-Research-on-improvingcontainment-of-Argentine-ant-infestations.pdf

Tsutsui, N. D., Suarez, A. V, Holway, D. A., \& Case, T. J. (2001). Relationships among native and introduced populations of the Argentine ant (Linepithema bumile) and the source of introduced populations. Mol. Ecol., 10(9), 2151-2161. https://doi.org/doi:10.1046/j.09621083.2001.01363.x

Uzest, M., Gargani, D., Drucker, M., Hébrard, E., Garzo, E., Candresse, T., ... Blanc, S. (2007). A protein key to plant virus transmission at the tip of the insect vector stylet. Proceedings of the National Academy of Sciences of the United States of America, 104(46), 17959-17964. https://doi.org/10.1073/pnas.0706608104

Völkl, W., Woodring, J., Fischer, M., Lorenz, M. W., \& Hoffmann, K. H. (2010). Ant-aphid mutualisms: The impact of honeydew production and honeydew sugar composition on ant preferences. Ecology, 118, 483-491.

Ward, D. F., Green, C., Harris, R. J., Hartley, S., Lester, P. J., Stanley, M. C., .. Toft, R. J. (2010). Twenty years of Argentine ants in New Zealand: Past research and future priorities for applied management. New Zealand Entomologist, 33(1), 68-78. https://doi.org/10.1080/00779962.2010.9722193

Ward, D. F., Harris, R. J., \& Stanley, M. C. (2005). Human-mediated range expansion of Argentine 
ants Linepithema humile (Hymenoptera: Formicidae) in New Zealand. Sociobiology, 45(2), 401407. https://doi.org/www.csuchico.edu/biol/Sociobiology/sociobiologyindex.html

Ward, D. F., \& Toft, R. J. (2011). Argentine ants in New Zealand. Retrieved 9 November 2016, from http://argentineants.landcareresearch.co.nz/

Way, M. J. (1963). Mutualism between ants and honeydew producing- homoptera. Annual Review of Entomology, 8, 307-344. https://doi.org/10.1146/annurev.en.08.010163.001515

Westermann, F. L., Bell, V. A., Suckling, D. M., \& Lester, P. J. (2016). Synthetic pheromones as a management technique - dispensers reduce Linepithema humile activity in a commercial vineyard. Pest Management Science, 72(4), 719-724. https://doi.org/10.1002/ps.4043

Westermann, F. L., Bell, V. A., Suckling, D. M., \& Lester, P. J. (2016). The long-term effects of reduced competitive ability on foraging success of an invasive pest species. Journal of Economic Entomology, 109(4), 1628-1635. https://doi.org/10.1093/jee/tow131

Whitehorn, P. R., O’Connor, S., Wackers, F. L., \& Goulson, D. (2012). Neonicotinoid pesticide reduces bumble bee colony growth and queen production. Science, 336(April), 351-352. https://doi.org/10.1002/ps.1616

Whitfield, A. E., Falk, B. W., \& Rotenberg, D. (2015). Insect vector-mediated transmission of plant viruses. Virology, 479-480, 278-289. https://doi.org/10.1016/j.virol.2015.03.026

Wild, A. L. (2004). Taxonomy and distribution of the Argentine ant, Linepithema bumile (Hymenoptera: Formicidae). Annals of the Entomological Society of America, 97(6), 1204-1215. https://doi.org/10.1603/0013-8746(2004)097[1204:TADOTA]2.0.CO;2

Wiltz, B. A., Suiter, D. R., \& Gardner, W. A. (2010). Activity of bifenthrin, chlorfenapyr, fipronil and thiamethoxam against red imported fire ants (Hymenoptera: Formicidae). Journal of Economic Entomology, 103(3), 754-761. https://doi.org/10.1603/EC09350

Yao, I. (2014). Costs and constraints in aphid-ant mutualism. Ecological Research, 29(3), 383-391. https://doi.org/10.1007/s11284-014-1151-4 


\section{Appendices}

APPENDIX A: Google Earth Pro image showing the distribution of Linepithema bumile and other ant species throughout the Hunter vineyard on $30^{\text {th }}$ March 2017

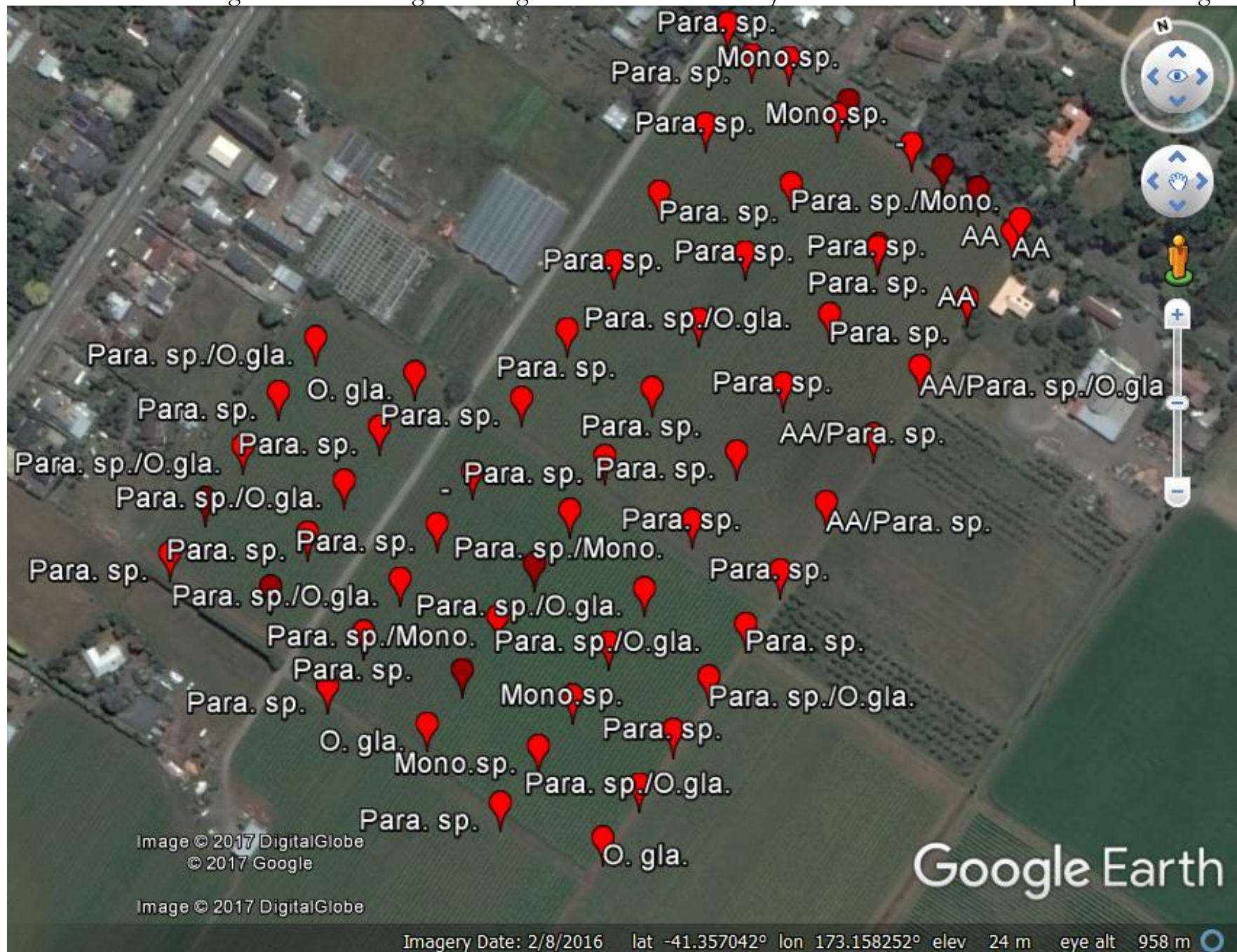

KEY

Para. sp. = Paratrechina sp.

Mono. sp. = Monomorium sp.

O. gla = Ochetellus glaber

$\mathbf{A A}=$ Argentine ant (Linepithema humile) 
APPENDIX B: Calculation of number of Argentine ants in nest boxes at Mt. Albert Plant and Food Research

\begin{tabular}{|c|c|c|c|c|c|c|c|c|c|c|c|}
\hline $\begin{array}{l}\text { Ant } \\
\text { nestbox } \\
\text { number \# }\end{array}$ & \begin{tabular}{|c|} 
1st \\
weighing \\
of \\
antless \\
nestbox \\
(g) \\
\end{tabular} & \begin{tabular}{|} 
2nd \\
weighing \\
of \\
antless \\
nestbox \\
(g)
\end{tabular} & $\begin{array}{c}\text { Mean } \\
\text { weight of } \\
\text { nestbox } \\
\text { (g) }\end{array}$ & $\begin{array}{c}\text { 1st } \\
\text { weighing } \\
\text { of ant } \\
\text { inhabited } \\
\text { nestbox } \\
\text { (g) }\end{array}$ & \begin{tabular}{|} 
2nd \\
weighing \\
of ant \\
inhabited \\
nestbox \\
(g) \\
\end{tabular} & \begin{tabular}{|c|} 
Mean \\
weight of \\
nestbox \\
(g)
\end{tabular} & $\begin{array}{l}\text { Mass of } \\
\text { ants and } \\
\text { larvae (g) }\end{array}$ & $\begin{array}{c}\text { Provisional } \\
\text { estimated } \\
\text { number of } \\
\text { Argentine } \\
\text { ants and } \\
\text { larvae }\end{array}$ & $\begin{array}{c}\text { Estimated } \\
\text { number of } \\
\text { Argentine } \\
\text { ants and } \\
\text { larvae }\end{array}$ & $\begin{array}{c}\text { Rounded } \\
\text { number of } \\
\text { Argentine } \\
\text { ants and } \\
\text { larvae }\end{array}$ & $\begin{array}{l}\text { Nestbox treatment or } \\
\text { control description }\end{array}$ \\
\hline$\# 1$ & 237.74 & 237.74 & 237.74 & 240.13 & 240.11 & 240.12 & 2.38 & 5535 & 2767 & 2760 & Control water/dye $\operatorname{rep}(2)$ \\
\hline$\# 2$ & 239.20 & 239.20 & 239.20 & 240.17 & 240.16 & 240.17 & 0.97 & 2244 & 2244 & 2240 & Bifenthrin rep (3) \\
\hline \#3 & 241.84 & 241.85 & 241.85 & 242.89 & 242.86 & 242.88 & 1.03 & 2395 & 1198 & 1200 & Bifenthrin/dye rep (2) \\
\hline$\# 4$ & 238.24 & 238.24 & 238.24 & 238.70 & 238.66 & 238.68 & 0.44 & 1023 & 1023 & 1020 & Bifenthrin/dye rep (1) \\
\hline$\# 5$ & 229.06 & 229.06 & 229.06 & 229.49 & 229.49 & 229.49 & 0.43 & 1000 & 1000 & 1000 & Bifenthrin/dye rep (3) \\
\hline$\# 6$ & 229.37 & 229.37 & 229.37 & 229.70 & 229.69 & 229.70 & 0.32 & 756 & 756 & 750 & Control water rep (1) \\
\hline \#7 & 243.34 & 243.34 & 243.34 & 243.48 & 243.46 & 243.47 & 0.13 & 302 & 302 & 300 & Bifenthrin rep (2) \\
\hline$\# 8$ & 232.83 & 232.82 & 232.83 & 233.45 & 233.44 & 233.45 & 0.62 & 1442 & 1442 & 1440 & Control water/dye rep (1) \\
\hline$\# 9$ & \multicolumn{7}{|c|}{ One test-tube taken from nestbox \#1 and put in nestbox \#9 } & 2767 & 2767 & 2760 & Bifenthrin rep (1) \\
\hline$\# 10$ & \multirow{2}{*}{\multicolumn{9}{|c|}{$\begin{array}{l}\text { One test-tube taken from nestbox } \# 3 \text { and put in nestbox } \# 10 \\
\text { number of worker ants per nest box }\end{array}$}} & 1200 & Control water rep (2) \\
\hline \multirow{2}{*}{\multicolumn{10}{|c|}{$\begin{array}{l}\text { Average number of worker ants per nest box } \\
\text { Assumptions: The mass of one Argentine worker ant is } 43 \mathrm{mg} \text { or } 0.00043 \mathrm{~g}\end{array}$}} & 1467 & \\
\hline & & & & & & & & & & & \\
\hline \multicolumn{12}{|c|}{ For each nestbox there is an equal amount of ants and larvae in each test-tube } \\
\hline
\end{tabular}

